ESCOLA POLITÉCNICA DA UNIVERSIDADE DE SÃO PAULO

EDUARDO ZIED MILIAN

MÉTODO DE ANÁLISE PARA ADOÇÃO DE COMPUTAÇÃO EM NUVEM: ESTUDO DE CASOS EM ORGANIZAÇÕES DE GRANDE PORTE

São Paulo

2014 
EDUARDO ZIED MILIAN

\section{MÉTODO DE ANÁLISE PARA ADOÇÃO DE COMPUTAÇÃO EM NUVEM: ESTUDO DE CASOS EM ORGANIZAÇÕES DE GRANDE PORTE}

Dissertação apresentada à Escola Politécnica da Universidade de São Paulo para obtenção do título de Mestre em Ciências

Área de Concentração:

Engenharia de Produção

Orientador:

Prof. Dr. Mauro de Mesquita Spínola

São Paulo 
EDUARDO ZIED MILIAN

MÉTODO DE ANÁLISE PARA ADOÇÃO DE COMPUTAÇÃO EM NUVEM: ESTUDO DE CASOS EM ORGANIZAÇÕES DE GRANDE PORTE

Dissertação apresentada à Escola Politécnica da Universidade de São Paulo para obtenção do título de Mestre em Ciências

São Paulo 
Autorizo a reprodução e divulgação total ou parcial deste trabalho, por qualquer meio convencional ou eletrônico, para fins de estudo e pesquisa, desde que citada a fonte.

Este exemplar foi revisado e corrigido em relação à versão original, sob responsabilidade única do autor e com a anuência de seu orientador.

São Paulo, 15 de dezembro de 2014.

Assinatura do autor

Assinatura do orientador

Catalogação-na-publicação

Milian, Eduardo Zied

Método de análise para adoção de computação em nuvem: estudo de casos em organizações de grande porte / E.Z. Milian. -- versão corr. -- São Paulo, 2014.

$164 \mathrm{p}$.

Dissertação (Mestrado) - Escola Politécnica da Universidade de São Paulo. Departamento de Engenharia de Produção.

1.Tecnologia da informação 2.Computação em nuvem 3.Software como serviço (SaaS) I.Universidade de São Paulo. Escola Politécnica. Departamento de Engenharia de Produção II.t. 
Para minha esposa, minha mãe e minha filha.

Em memória de meu pai, André Milian Ortega. 


\section{AGRADECIMENTOS}

Minha profunda gratidão à minha família, especialmente minha mãe dona Emília, minha esposa Gisele, minha filha Ana Luiza e meu irmão Edson. Sem o apoio incondicional, transformado em amor, compreensão, paciência, afeto, enfim, nada deste projeto e momento da minha vida teriam sido possível.

Agradeço ao meu professor Dr. Mauro de Mesquita Spinola pela orientação sábia e segura. Ao conviver com sua liderança percebi que, sabiamente, permite às pessoas realizar seu trabalho sem interferências excessivas, sem comandos constantes, sem cobranças sistemáticas, sempre acreditando no potencial e capacidade de cada um dos seus alunos. Quero acreditar que fui digno da sua confiança.

Muito obrigado ao professor Dr. Marcelo Schneck de Paula Pessôa, não somente pelo apoio efetivo e afetivo ao meu desejo de continuar estudando, mas, principalmente, pela sua dedicação e entusiasmo como um educador apaixonado e incansável que contagia a todos ao seu redor.

Meus agradecimentos aos colegas e professores do departamento de engenharia de produção, especialmente aos professores do grupo de pesquisa em Gestão de TI, Drs. Fernando José Barbin Laurindo, Renato Moraes, André Leme Fleury.

Obrigado à banca de qualificação pela contribuição decisiva e ao prof. Dr. Rodrigo Franco Gonçalves pela "força” no referencial teórico e tantas outras dicas.

Agradeço aos executivos das organizações pesquisadas pelo seu tempo, disposição em me receber, e pela precisão aos responder aos questionamentos.

Sou grato ao apoio financeiro do programa de pós-graduação da Engenharia de Produção da EPUSP, recebido através da bolsa do CNPq.

E, para finalizar, obrigado a todos os meus amigos e colegas que acompanham minha jornada. Não há meios de nominá-los todos, mas tenham certeza que recebo enorme energia de vocês, através das palavras de apoio, respeito e incentivo aos caminhos que escolhi para retribuir à sociedade tudo que tenho recebido; e acreditem, não é pouco!

Novamente, muito obrigado! 


\section{RESUMO}

A Computação em Nuvem (CN) tem potencial para transformar grande parte do setor de Tecnologia da Informação (TI). Sua evolução ao longo dos últimos anos, certamente é tida como um dos maiores avanços na história da computação. Ela vem ganhando espaço significativo como um modelo bem sucedido ao prometer economia, facilidade de uso e maior flexibilidade no controle de como os recursos são usados, a qualquer momento e em qualquer lugar, para entregar a capacidade computacional desejada. A proposta de valor capturada pelo modelo da $\mathrm{CN}$ é que os recursos não ficam mais ociosos a maior parte do tempo, sendo agora quase totalmente utilizados (com menores custos unitários). Esta pesquisa tem por objetivo compreender como são tomadas as decisões para aquisição, contratação e operação dos serviços de $\mathrm{CN}$ em organizações de grande porte atuando no Brasil. Para alcançar este objetivo foi elaborado um Método de Análise para adoção da CN a partir de elementos extraídos da literatura. Fatores associados à adoção da $\mathrm{CN}$ como vantagens, desafios, riscos e barreiras e capacidades essenciais dos gestores para atingir objetivos de negócios $(B O B)$, desempenhar a gestão da função $\mathrm{TI}$ (MNG), dispor dos atributos da qualidade dos serviços (QAS) e tomar decisões de arquitetura $(A R C)$, consideradas essenciais para a operação das áreas de $\mathrm{TI}$ das organizações, estão entre estes elementos. $O$ trabalho também investigou como a $\mathrm{CN}$ pode contribuir para o alinhamento estratégico da $\mathrm{TI}$ ao negócio destas organizações. A metodologia utilizada é o estudo de casos múltiplos, com a aplicação do Método de Análise em quatro organizações, onde foram entrevistados os principais executivos da área de TI capazes de influenciar decisões para adotar ou aprofundar a adoção da nuvem. Os resultados obtidos mostraram a viabilidade e a aplicabilidade do Método de Análise. Ao mapear os fatores associados à adoção, o processo de decisão pode ser mais bem compreendido, possibilitando às organizações melhor estruturar o processo de aprovação e de adoção propriamente dito. Também pôde ser observado nos casos estudados de que forma se deu a contribuição da adoção da nuvem para o alinhamento estratégico da $\mathrm{TI}$ ao negócio.

PALAVRAS-CHAVE: Computação em nuvem, Software como Serviço (SaaS), Gestão da Tecnologia da Informação. 


\begin{abstract}
Cloud Computing $(\mathrm{CC})$ is potentially able to change a major part of Information Technology (IT) industry. Its evolution over the past few years is certainly one of the greatest advancements in the history of computing. Cloud Computing has been gaining ground as a successful model as it promises economic savings, easiness of use and greater flexibility in the control of resource use, anytime and anywhere, while delivering the required computing power. CC model value proposition is that resources are no longer idle most of the time, as they are almost used to the fullest (with lower unit costs). The purpose of this research is to understand how the decisions are made for the purchase, hiring and operation of CC services in large organizations operating in Brazil. In order to achieve this objective, we prepared an Analysis Method to adopt CC based on elements found in literature. Such elements are those factors associated to the adoption of CC such as advantages, challenges, risks and barriers and core capabilities for managers to achieve business objectives $(B O B)$, perform management of IT function (MNG), provide quality of services ( $Q A S)$ and manage architecture decisions $(A R C)$, considered essential for operation of IT areas of organizations. The study also investigated how CC can contribute with IT strategic alignment with business of these organizations. The methodology employed is multiple cases study, applying the Analysis Method in four organizations, through interviews with main IT executives capable of influencing decisions to adopt or increase cloud adoption. The results obtained show feasibility and applicability of Analysis Method. By mapping factors associated with adoption, the decision making process may be better understood, allowing organizations to better structure approval process and the adoption itself. In cases studied it is possible to note how the adoption of cloud computing contributes with strategic alignment of IT with business. KEYWORDS: Cloud Computing, Software as a Service (SaaS), IT Management.
\end{abstract}




\section{LISTA DE FIGURAS}

Figura 1 - Hierarquia dos Modelos de Serviços ...................................................22

Figura 2 - Complexidade da Computação em Nuvem - Definição do NIST .............22

Figura 3 - Camadas da computação em nuvem .................................................25

Figura 4 - Modelo de alinhamento estratégico........................................................39

Figura 5 - Perspectivas de alinhamento estratégico............................................41

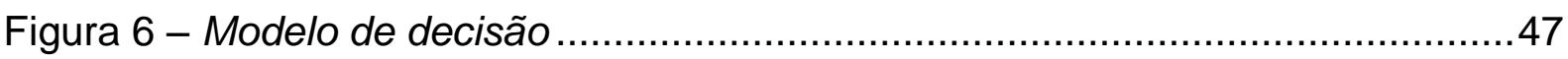

Figura 7 - Diagrama esquemático da construção dos resultados.............................64

Figura 8 - Método de Análise para computação em nuvem ....................................74 


\section{LISTA DE QUADROS}

Quadro 1 - As cinco características essenciais da computação em nuvem ..............16

Quadro 2 - Modelos de serviço da computação em nuvem ....................................18

Quadro 3 - Modelos de implantação da computação em nuvem..............................20

Quadro 4 - Tecnologias relacionadas à computação em nuvem ..............................23

Quadro 5 - Requisitos e características dos métodos de pesquisa .........................53

Quadro 6 - Modelo de registro de referências com as oportunidades para análise..70

Quadro 7 - Objetivos e proposições da pesquisa ...............................................71

Quadro 8 - Gestão da Função TI (MNG) ……………...................................75

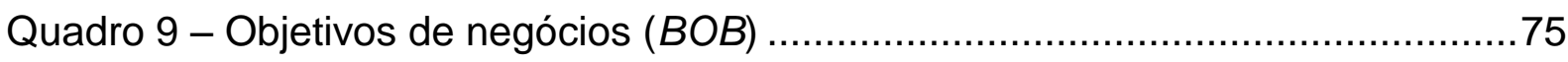

Quadro 10 - Atributos da Qualidade dos Serviços (QAS) ....................................76

Quadro 11 - Decisões de Arquitetura $(A R C)$..................................................

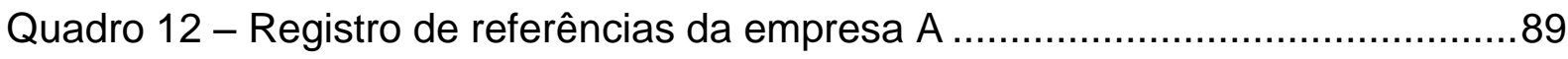

Quadro 13 - Registro de referências da empresa B .........................................98

Quadro 14 - Registro de referências da empresa C .........................................111

Quadro 15 - Registro de referências da empresa D ..........................................121

Quadro 16 - Evidências encontradas em Gestão da Função TI (MNG) ..................124

Quadro 17 - Evidências encontradas em Objetivos de Negócios $(B O B)$................125

Quadro 18 - Evidências encontradas em Qualidade dos Serviços (QAS) ..............127

Quadro 19 - Evidências encontradas nas Decisões de Arquitetura $(A R C)$.............128

Quadro 20 - Resultados sobre as proposições................................................134 


\section{LISTA DE ABREVIATURAS E SIGLAS}

API Application Program Interface - Interface para a Aplicação

ARC Área de capacidades - Decisões de Arquitetura

ASP Application Service Provider - Modelo de oferecimento de serviços de TI

AT\&T Empresa tradicional americana de comunicação de voz e dados

BOB Área de capacidades - Objetivos de Negócios

BPM Business Process Management - Gerenciamento de Processos de Negócio

CAPEX Capital Expenditure - Investimentos em bens de capital

CN Computação em Nuvem

CRM Customer Relationship Management - Gestão de Relacionamento com o Cliente

Dell Fabricante de computadores e servidores

ECM Enterprise Content Management - Gestão de conteúdo empresarial

ERP Enterprise Resource Planning - Sistemas de Gestão Empresarial

ESB Enterprise Service Bus - Integração entre sistemas baseado em padrões de mensagens

GE Empresa americana conhecida pelas suas boas práticas de gestão

HP Hewlett Packard - Fabricante de computadores e sistemas

laaS Infrastructure as a Service - Infraestrutura Como serviço

IBM International Business Machines - Fabricante de computadores e sistemas

IFS IFS Applications - Fornecedor de sistemas para gestão da manufatura

MBA Master Business Administration - Curso de pós-graduação latu sensu

MNG Área de capacidades - Gestão da Função TI

NF-e Nota fiscal eletrônica - Serviço de emissão de nota fiscal pela Internet 
NIST National Institute of Standards and Technology

OPEX Operational Expenditure - Despesas operacionais

PaaS Platform as a Service - Plataforma Como serviço

PDC Painel de Dados Coletados - planilha excel utilizada na pesquisa

QAS Área de capacidades - Atributos da Qualidade dos Serviços

RFP Request for Proposal - Proposta técnica e de preço para fornecimento

RFQ Request for Quotation - Solicitação de proposta de preço para fornecimento

SaaS Software as a Service - Software Como serviço

SAP Fornecedor de Sistema de Gestão Empresarial (ERP)

SCM Supply Chain Management - Gestão da cadeia logística

SI Sistema de Informação

Skype Aplicação para comunicação interpessoal de voz e texto via Internet

SLA Service Level Agreement - Acordo de Nível de Serviço

TCO Total cost of ownership - Custo total de propriedade

TI Tecnologia da Informação

VolP Comunicação telefônica via redes digitais de dados (protocolo da Internet)

WAN Wide Area Network - Rede de longa distancia

WEB World Wide Web - Internet ou a rede mundial de computadores 


\section{SUMÁRIO}

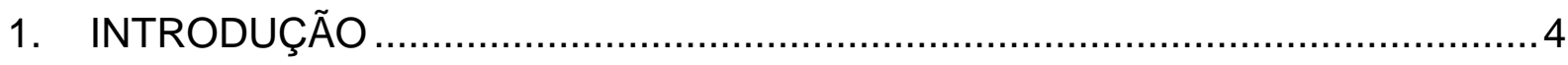

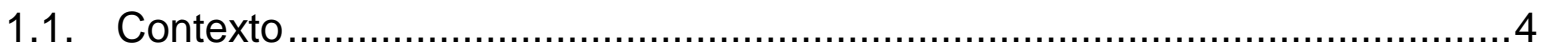

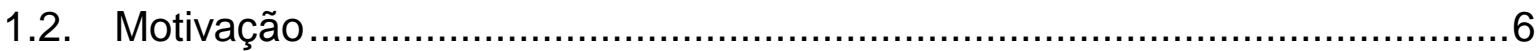

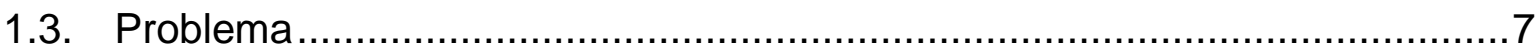

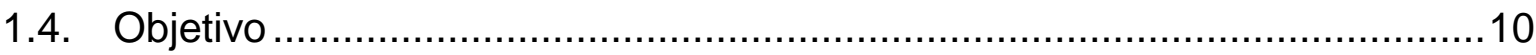

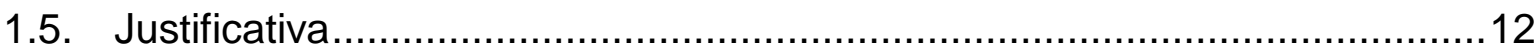

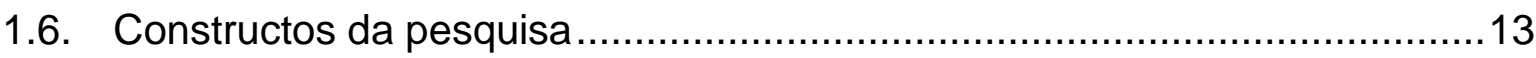

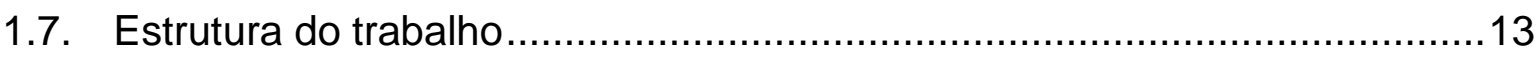

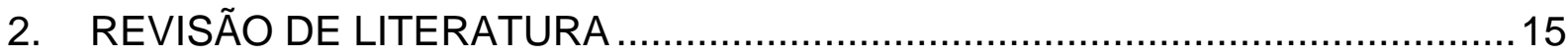

2.1. Definição de computação em nuvem ...................................................... 15

2.2. Tecnologias relacionadas à computação em nuvem .............................21

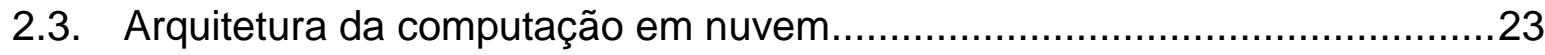

2.4. Vantagens, desafios e barreiras para a adoção da nuvem .......................26

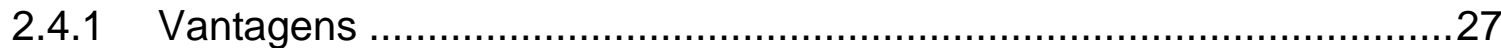

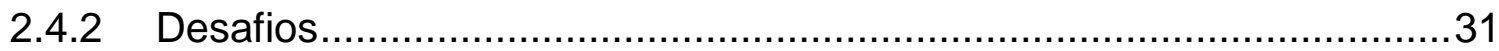

2.4.3 Riscos e barreiras ......................................................................

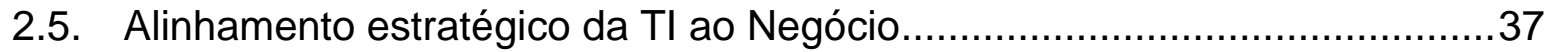

2.5.1 Modelo de Alinhamento Estratégico ...............................................38

2.5.2 Perspectivas de alinhamento impulsionado pela área de negócios.......38

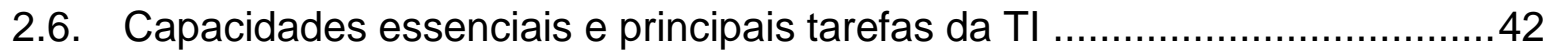

2.6.1 Principais tarefas para a entrega dos serviços da $\mathrm{TI}$..........................43

2.6.2 Capacidades essenciais para a gestão da $\mathrm{TI}$..................................44

2.7. Modelo de decisão para adoção da computação em nuvem ......................46

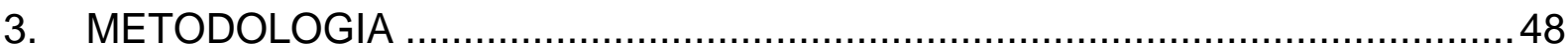

3.1. Escolha da metodologia de pesquisa ........................................... 49 
3.2. Definição da pesquisa e construção do referencial teórico .56

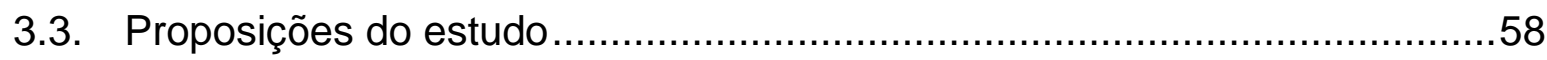

3.4. Estruturas e etapas do Estudo de Casos ................................................59

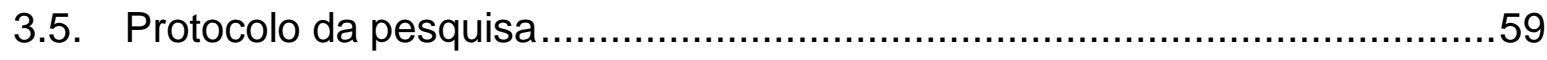

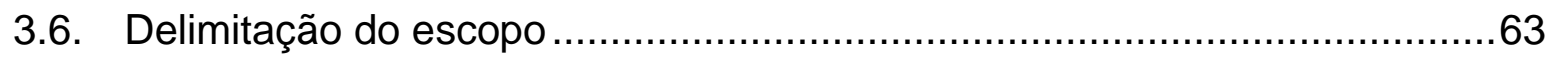

3.7. Construção do roteiro de pesquisa........................................................64

3.8. Proposta do teste piloto e os seus resultados .........................................65

3.9. Seleção das Unidades de Análise ..........................................................66

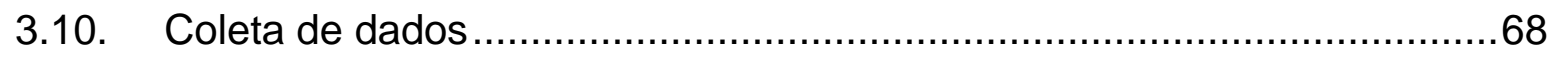

3.11. Oportunidades para análise dos dados coletados ..................................69

4. MÉTODO DE ANÁLISE PARA ADOÇÃO DA COMPUTAÇÃO EM NUVEM .....73

4.1. Método de Análise para adoção da Computação em Nuvem .......................73

4.2. Roteiro para aplicação do Método de Análise ...........................................77

5. OBSERVAÇÕES E ANÁLISES PRELIMINARES DOS CASOS .......................80

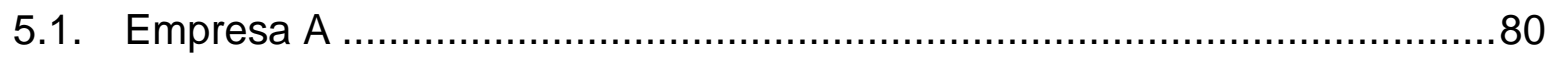

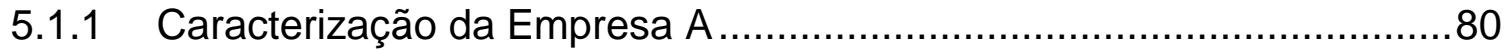

5.1.2 Adoção da computação em nuvem ........................................................ 81

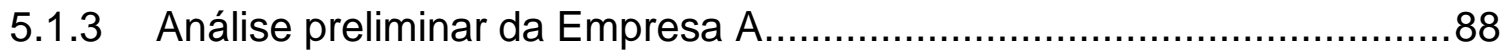

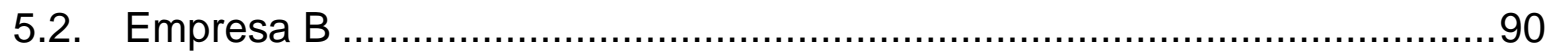

5.2.1 Caracterização da Empresa B .....................................................90

5.2.2 Adoção da computação em nuvem .....................................................90

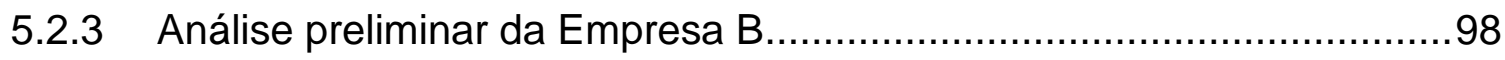

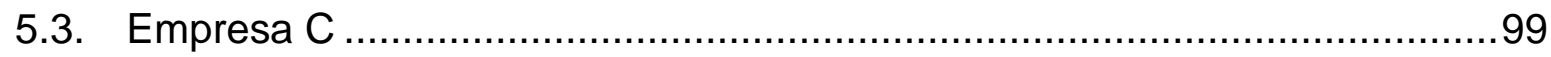

5.3.1 Caracterização da Empresa C ........................................................99

5.3.2 Adoção da computação em nuvem ..............................................101

5.3.3 Análise preliminar da Empresa C …………..............................110 


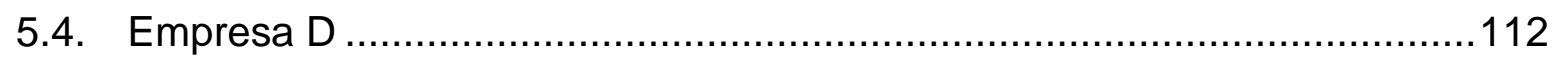

5.4.1 Caracterização da Empresa D ....................................................112

5.4.2 Adoção da computação em nuvem ...............................................114

5.4.3 Análise preliminar da Empresa D …………..............................120

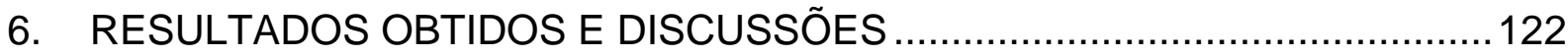

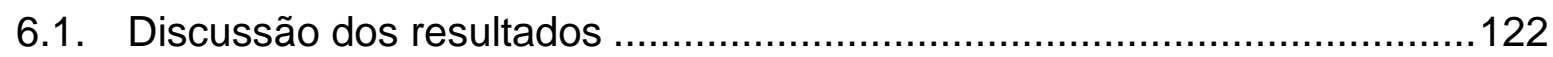

6.2. Resultados sobre a aplicação do Método de Análise ................................129

6.3. Resultados sobre os constructos do Método de Análise ...........................130

6.4. Alinhamento Estratégico da $\mathrm{Tl}$ ao negócio ..............................................133

6.5. Resultados sobre as proposições do estudo..........................................133

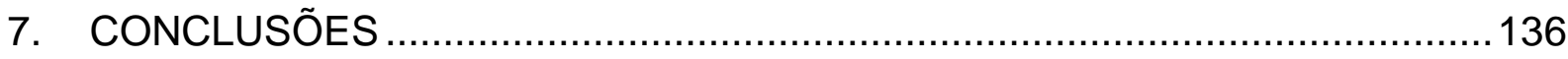

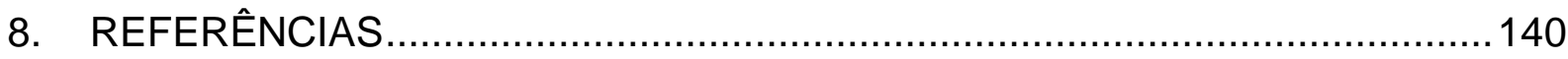

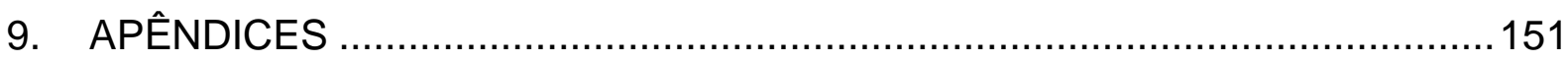

9.1. APÊNDICE I - Protocolos para caracterização das organizações e descrição dos sistemas foco da aplicação do método ..................................................151

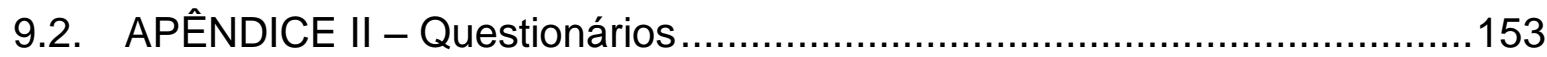

9.2.1 Questionário 1 - Vantagens da adoção da computação em nuvem....153

9.2.2 Questionário 2 - Desafios para adoção da computação em nuvem....154

9.2.3 Questionário 3 - Barreiras para utilização da nuvem .........................155

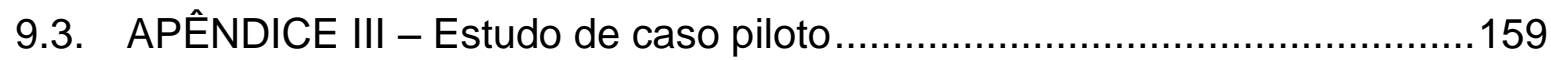

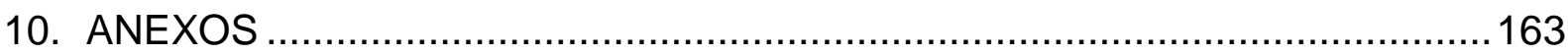

10.1. ANEXO I - Condução do estudo de caso ............................................163 


\section{INTRODUÇÃO}

A evolução da computação em nuvem $(\mathrm{CN})$, ao longo dos últimos anos, certamente é tida como um dos maiores avanços na história da computação (MARSTON et al., 2010). Ela vem ganhando espaço significativo como um modelo bem sucedido ao prometer economia, facilidade de uso e maior flexibilidade no controle de como os recursos são usados, a qualquer momento e em qualquer lugar, para entregar aos seus usuários a capacidade computacional desejada (MELL e GRANCE, 2011).

\subsection{Contexto}

A CN é considerada um novo paradigma para entrega de serviços computacionais, oferecendo diversas vantagens sobre modelos tradicionais de implantação de Sistemas de Informação (SI). Pesquisas recentes têm identificado os benefícios que a $\mathrm{CN}$ oferece para as organizações: aumento da flexibilidade e velocidade da implementação, fácil acesso, escalabilidade massiva, desempenho adequado e configurações especificáveis pelo cliente (ARMBRUST et al., 2010; KONDO et al., 2009; ZHANG et al., 2010).

Uma vez que estes benefícios frequentemente podem ser obtidos a custos relativamente baixos, comparativamente ao custo de infraestruturas dedicadas, o surgimento da $\mathrm{CN}$ vem tendo grande impacto no setor de Tecnologia da Informação (TI) (ZHANG et al., 2010). Em 2013, a computação em nuvem estava entre as 10 melhores tecnologias consideradas estratégicas para a maioria das organizações (GARTNER, 2012).

Analistas projetam que o mercado de serviços em nuvem crescerá de 25,5 bilhões de dólares americanos em 2011 para 159,3 bilhões de dólares americanos em 2020, espera-se que quase todos os recursos computacionais serão movidos para a nuvem (RIED et al., 2011). Considerando que as ofertas de nuvem, como o Amazon Elastic Compute Cloud e do Google Apps estão rapidamente ganhando uma grande base de usuários, a migração das aplicações das empresas para a nuvem está apenas começando (BOILLAT e LEGNER, 2013).Foster et al. (2008) identificam particularmente três fatores que facilitaram o desenvolvimento da $\mathrm{CN}$ : i) 
redução do custo do hardware concomitantemente com o aumento do poder computacional e da capacidade de armazenamento; ii) quantidade de dados crescendo rapidamente; iii) conexões de banda larga para acesso à Internet e iv) serviços computacionais diversos e aplicação WEB $2.0^{1}$ sendo largamente adotados.

Para Altman et al. (2013), a CN diminuiu as restrições para obtenção de capacidade de processamento e armazenamento de informações, bem como acesso aos meios de comunicação de dados, usualmente enfrentadas pelos indivíduos e organizações de pequeno porte. Com serviços oferecidos através da nuvem como HP Cloud, Google Drive, Amazon Web Services EC2, por exemplo, estes indivíduos e organizações agora dispõem dos recursos computacionais com preços significativamente menores (ou mesmo sem custo, em determinadas circunstâncias) que aqueles quando a aquisição de equipamentos era necessária. Para este autor esta redução das barreiras de acesso à tecnologia da informação, através da nuvem, possibilita que pesquisas e inovações migrem das grandes organizações para organizações de menor porte e mesmo para os indivíduos (ALTMAN et al., 2013).

Como consequência, o mundo da computação está se transformando rapidamente em direção ao desenvolvimento de software, para que este seja consumido como um serviço por milhões, ao invés de executar em seus computadores individuais (BUYYA et al., 2009), fazendo com que a computação se transforme em um modelo de serviços padronizados (também conhecido como modelo de utilidades), pois são entregues de forma semelhante àqueles das concessionárias tradicionais, como água, eletricidade, gás ou telefonia (BUYYA et al., 2009).

Desta forma, a computação em nuvem, um sonho de longa data da computação como uma utilidade, tem potencial de transformar grande parte do setor de Tecnologia da Informação, fazendo com que o software seja ainda mais atraente

\footnotetext{
${ }^{1}$ Aplicações Web 2.0 são software e serviços baseados na Internet que permitem que indivíduos criem, compartilhem, colaborem e se comuniquem via Web, independentemente de restrições geográficas, temporais ou tecnológicas (O’REILLY, 2005).
} 
como um serviço (ARMBRUST et al., 2010). Por estas razões, muitos autores consideram a CN o próximo paradigma para a computação (BUYYA et al., 2008; WEISS, 2007; PRING, 2010; ZHANG et al., 2010).

\subsection{Motivação}

A proposta de valor capturada pelo modelo da $\mathrm{CN}$ é que os recursos não ficam mais ociosos a maior parte do tempo, sendo agora quase totalmente utilizados (com menores custos unitários) (KAISLER et al., 2012). Ao reduzir os custos de propriedade e de suporte, o modelo aumenta o alcance do capital e oferece maior flexibilidade na utilização dos recursos.

Marston et al. (2010) consideram que o modelo da CN possibilita a confluência para um ambiente onde as informações possam ser acessadas, independentemente do dispositivo e da localização. Este fato representa uma grande mudança na computação que pode trazer vantagens significativas para aquelas organizações que adotarem este modelo.

No entanto, para Brynjolfsson et al. (2010), se o modelo de utilidades como proposto por Buyya et al. (2009) fosse adequado, os desafios da CN poderiam ser resolvidos com soluções similares às do fornecimento de eletricidade, por exemplo, mas não são. Para Brynjolfsson et al. (2010), a realidade é que a CN ainda não pode alcançar a simplicidade do "plug-and-play" da eletricidade, pelo menos não enquanto for mantido este ritmo de inovações, tanto em relação à própria $\mathrm{CN}$, quanto desta miríade de novas aplicações e novos modelos de negócios (BRYNJOLFSSON et al., 2010).

As incertezas sobre os benefícios da $\mathrm{CN}$, quando comparados à infraestrutura de TI tradicional, e as preocupações em relação aos seus custos, confiabilidade, segurança e regulamentação devem inibir muitas empresas e seus executivos de fazerem movimentos ousados na direção da nuvem. Quais são as implicações de negócios desta adoção relutante de CN? Para McAfee (2011) se o impacto da nuvem for apenas sobre os orçamentos das empresas de $\mathrm{TI}$, as implicações seriam menores. Mas, para este autor, não é este o caso; a $\mathrm{CN}$ oferece vantagens como 
aumento da produtividade e da colaboração, maior agilidade na análise e desenvolvimento de aplicações, entre outras.

Quão valiosas são estas vantagens? Como os executivos e responsáveis pela $\mathrm{TI}$ nas organizações se sentiriam se seus principais concorrentes em suas áreas começassem a ganhar maior espaço no mercado, simplesmente mudando sua infraestrutura de computação? E quão pior seria se essa mudança criasse outros benefícios ainda não tão óbvios? Uma característica comum de grandes mudanças tecnológicas é que os seus efeitos completos não são visíveis à primeira vista. Por exemplo, era inconcebível no alvorecer da eletrificação fabril que um dia poderia ser colocado um motor separadamente para cada máquina na fábrica, mas foi exatamente o que acabou acontecendo (McAFEE, 2011).

Portanto, para que a CN possa alcançar plenamente o seu potencial é preciso que haja uma compreensão clara das várias questões envolvidas na sua adoção, através de novos estudos, tanto do ponto de vista dos fornecedores, quanto dos clientes (KAISLER et al., 2012).

Em razão do exposto, as principais motivações para o trabalho foram, por um lado, investigar a possibilidade da elaboração de um modelo para dar subsídios para a análise da adoção da nuvem e verificar a viabilidade da aplicação do modelo proposto, e por outro contribuir efetivamente com as organizações que pretendem começar a utilizar, ou ainda, aquelas que desejam aumentar a sua utilização da CN.

Por fim, espera-se que este trabalho possa contribuir para que as organizações mantenham-se competitivas, atualizadas e eficazes, com a utilização o mais eficiente possível da sua infraestrutura de TI.

\subsection{Problema}

Computação em Nuvem de uma maneira geral e o seu modelo de oferecimento de aplicativos de negócios através da Internet, em particular, que é considerado a maior e mais maduro modelo de oferecimento de CN (VENTERS e WHITLEY, 2012; JOHA e JANSSEN, 2012), são áreas relativamente novas e que devem ser consideradas pelas organizações como potencialmente capazes de 
fornecer serviços de $\mathrm{TI}$, podendo ser vistas como uma quarta onda ${ }^{2}$ da terceirização (JOHA e JANSSEN, 2012).

Contudo, sua implementação traz riscos (PAQUETTE et al., 2010; SVANTESSON e CLARKE, 2010), que podem ser categorizados como riscos organizacionais, técnicos e legais. Subashini e Kavitha (2011) argumentam que frequentemente a $\mathrm{CN}$ traz dores de cabeça, tais como, problemas relacionados com acesso aos dados, proteção e privacidade. Chen e Zhao (2012) concordam, argumentando que a "segurança surge como a barreira mais significativamente defensável para uma adoção mais abrangente e significativa da CN" (pag. 647). Por exemplo, pesquisas realizadas têm mostrado que o medo em relação à $\mathrm{CN}$ derivam fortemente da percepção da perda de controle sobre dados sensíveis ( $\mathrm{CHOW}$ et al., 2009), Svantesson e Clarke (2010) listam uma gama de riscos relativos à privacidade dos clientes. Subashini e Kavitha (2011) identificam os problemas de segurança que precisam ser levados em conta quando da adoção da CN.

Assim, os desafios relacionados à implementação da $\mathrm{CN}$ são tanto técnicos quanto de gerenciamento e têm sido um tópico de pesquisa relevante na área dos Sistemas de Informação (ARMBRUST et al., 2010; BUYYA et al., 2009; VAQUERO et al., 2009; ZHANG et al., 2010). Contudo, a pesquisa sobre adoção da nuvem possui lacunas relacionadas a uma melhor sistematização para um conjunto fundamental de fatores e de capacidades que auxiliem os gestores das áreas de TI na tomada de decisões de quais aplicações ou Sistemas de Informações devem ou não ser colocados na nuvem.

Ainda que tenham sido encontrados na literatura trabalhos que tratam das vantagens, desafios, barreiras e riscos (definidos nesta pesquisa como sendo

\footnotetext{
${ }^{2} \mathrm{~A}$ primeira onda diz respeito à entrega de bens, recursos e/ou atividades de TI/SI baseada em uma relação um-para-um entre o prestador e o cliente (WILLCOCKS e KERN, 1998). A segunda onda com foco no negócio, resultou em uma terceirização seletiva (LACITY et al., 1996), enquanto que a terceira onda foi a ascensão do modelo ASP (CURRIE e SELTSIKAS, 2001) (JOHA e JANSSEN,2012).
} 
fatores associados) envolvidos no processo de escolha da $\mathrm{CN}$ sob a perspectiva das organizações usuárias (CHOUDHARY, 2007; MILLER, 2008; XIN e LEVINA, 2008; MATHER at al., 2009; MARSTON et al., 2010; MARKS e LOZANO, 2010; CHUDNOV, 2010; BENLIAN e HESS, 2011; MARTENS e TEUTEBERG, 2011; WILLCOCKS et al., 2012; JOHA e JANSSEN, 2012), estes não têm por objetivo fornecer um método propriamente dito para análise da sua adoção.

Adicionalmente, Kaisler et al. (2012) argumentam que muitas vezes as organizações não fazem uma análise rigorosa para decidir pelo uso da CN. Ao invés disso, decidem experimentá-la implementando uma aplicação simples e de baixo risco, com a finalidade de avaliá-la.

Baseado no modelo ("framework") para adoção da CN apresentado por Kaisler et al. (2012), no conceito de capacidades essenciais (WILLCOCKS, FEENY e OLSON, 2006) e nos fatores associados à avaliação para adoção da CN (MILLER, 2008; MARKS e LOZANO, 2010; CHAVES e SOUSA, 2012; WILLCOCKS et al., 2012) este trabalho organiza esses elementos na forma de um método, denominado Método de Análise para a adoção da computação em nuvem.

Além do Método de Análise, o trabalho procura trazer elementos que auxiliam os gestores a visualizarem possibilidades da adoção da nuvem como mais uma ferramenta para o alinhamento estratégico da $\mathrm{Tl}$ ao negócio.

Dado que a presença cada vez maior da TI nas empresas tem-se dado por razões estratégicas fundamentais: a competitividade crescente leva à necessidade de maior domínio sobre os parâmetros que estão em jogo, maior flexibilidade para adaptar-se a novas condições do mercado e maior capacidade de absorção de novas técnicas e tecnologias (SPÍNOLA e PESSÔA, 1997). 
Desta forma, a questão central da pesquisa pode ser assim formulada:

Como as organizações tomam decisões para adotar ou não a Computação em Nuvem?

Esta questão central foi desdobrada nas seguintes questões a ela relacionadas:

Q1. Como organizações que adotaram ou pretendem adotar a computação em nuvem procuram identificar os fatores associados, envolvidos na avaliação para esta adoção? (MILLER, 2008; MARKS e LOZANO, 2010; CHAVES e SOUSA, 2012; WILLCOCKS et al., 2012)

Q2. Como organizações que adotaram ou pretendem adotar a computação em nuvem identificam as vantagens desta adoção? (SOMMERVILLE, 2003; XIN e LEVINA, 2008; MARSTON et al., 2010; BENLIAN e HESS, 2011)

Q3. Como as organizações que adotaram ou pretendem adotar a computação em nuvem analisam suas capacidades essenciais (WILLCOCKS, FEENY e OLSON, 2006), relacionadas com a adoção da computação em nuvem?

Q4. A adoção da computação em nuvem pode contribuir para o alinhamento estratégico da TI com o negócio? (HENDERSON e VENKATRAMAN, 1993; LUFTMAN et al., 1993)

Como resposta, este trabalho desenvolve um Método de Análise que identifica fatores que impactam estas decisões. De acordo com Chow et al. (2009) "quando se pensa em soluções para o problema da adoção da CN, é importante perceber que muitas questões são essencialmente velhos problemas com uma nova moldura, ainda que mais críticos" (pag. 85).

\subsection{Objetivo}

O objetivo deste trabalho de pesquisa é buscar um melhor entendimento de como as organizações contratam e gerenciam serviços de $\mathrm{CN}$, ou seja, como são tomadas as decisões para aquisição, contratação e a operação dos serviços.

Portanto, a contribuição deste trabalho é no sentido de reduzir algumas lacunas relacionadas a uma melhor sistematização para um conjunto de 
capacidades essenciais e de fatores associados à adoção da $\mathrm{CN}$, que auxiliem os gestores das áreas de TI na tomada de decisões de quais aplicações ou Sistemas de Informações devem ou não ser colocados na nuvem.

Assim, uma vez a decisão tenha sido tomada, o trabalho procura mostrar quais são as capacidades essenciais necessárias para lidar com os desafios, riscos e barreiras impostos pela utilização de serviços na nuvem. Entre as capacidades essenciais estão capacidades para as seguintes áreas: objetivos de negócios $(B O B)$, gestão da função TI (MNG), atributos da qualidade dos serviços (QAS) e decisões de arquitetura $(A R C)$ essenciais na condução das suas áreas de $\mathrm{TI}$.

As capacidades relacionadas aos objetivos de negócios $(B O B)$ promovem a integração dos esforços da TI com os objetivos e atividades do negócio. Capacidade sobre a gestão da função TI (MNG) entende-se como sendo a garantia de que as habilidades e as tecnologias específicas de TI estejam previstas em cada processo de negócio. Os atributos da qualidade dos serviços (QAS) são as capacidades necessárias às compras especializadas, à gestão de contratos, ao monitoramento dos contratos e ao desenvolvimento de fornecedores.

Por último, capacidades para decisões de arquitetura $(A R C)$ compreendem o cuidado com o projeto da plataforma técnica, visando criar um modelo coerente para a arquitetura corporativa de $\mathrm{TI}$, que responda às necessidades de negócios atuais $\mathrm{e}$ futuras da organização.

Para cada uma das áreas de capacidades, acima descritas, estão associados fatores que as influenciam como: vantagens, desafios, riscos e barreiras associados à contratação, adoção e utilização da CN. Ao agrupar os fatores associados à adoção da CN nas áreas de capacidades essenciais este trabalho tem por objetivo direcionar a atenção dos gestores e decisores das empresas para as pessoas responsáveis pelo desenvolvimento e pelo desempenho destas capacidades.

O objetivo geral da pesquisa pode ser descrito como sendo:

Compreender como são tomadas as decisões para aquisição, contratação e operação dos serviços de computação em nuvem em organizações de grande porte. 
Este objetivo geral da pesquisa pode ser desdobrado nos seguintes objetivos mais específicos:

I. Propor um Método de Análise para adoção de computação em nuvem;

II. Avaliar a aplicabilidade do Método de Análise proposto;

III. Avaliar a relevância de um conjunto de fatores associados à computação em nuvem, constituintes do Método;

IV. Avaliar a aplicabilidade da abordagem por áreas de capacidades essenciais;

V. Avaliar se e como a adoção da computação em nuvem pode contribuir para o alinhamento estratégico da TI ao negócio.

\subsection{Justificativa}

As principais justificativas para o trabalho são, em primeiro lugar, dar subsídios às organizações que pretendem adotar a $\mathrm{CN}$, procurando identificar os principais benefícios e os potenciais riscos e barreiras para a sua adoção; em segundo lugar, subsidiar as organizações que já adotaram a $\mathrm{CN}$ em relação às questões operacionais envolvendo aos seus objetivos de negócios, gestão da função TI, atributos da qualidade dos serviços e decisões de arquitetura e, por último, possibilitar uma análise em retrospecto para as organizações que pretendam ampliar ou redesenhar suas necessidades de contratação de serviços da nuvem.

Fundamentalmente, o resultado do trabalho deverá subsidiar organizações que consideram a utilização, ou mesmo já estejam utilizando a CN para que o atingimento dos objetivos da TI ocorra com eficiência, buscando alcançar um melhor desempenho dos seus Sistemas de Informação (SI) e da infraestrutura de TI. Para atingir os objetivos propostos, foram consultadas, na literatura, pesquisas que tratam das questões essenciais ao tema, para fornecer subsídios para mitigação dos riscos naturais ao novo paradigma da CN (MILLER, 2008; MARKS e LOZANO, 2010; CHAVES e SOUSA, 2012; WILLCOCKS et al., 2012). Assim, as organizações serão beneficiadas com informações atualizadas em relação às possíveis vantagens, riscos e barreiras deste modelo de computação. 


\subsection{Constructos da pesquisa}

Como resultados da construção do referencial teórico, que fundamenta as questões decorrentes do problema central da pesquisa, foram estabelecidos os seguintes constructos:

- Relacionados à computação em nuvem:

- Definições, arquitetura e as tecnologias relacionadas.

- Vantagens, desafios e barreiras da computação em nuvem.

- Relacionados à gestão da Tecnologia da Informação:

- Modelo de alinhamento estratégico

- Conceito de capacidades essenciais

- Modelo de decisão hierárquico para adoção da CN

Estes constructos estão descritos em detalhes na revisão da literatura (capítulo 2) e são utilizados na construção do Método de Análise (capítulo 4).

\subsection{Estrutura do trabalho}

Este trabalho está estruturado da seguinte forma: após a Introdução é apresentada a Revisão da literatura com a fundamentação teórica, que traz os principais conceitos e definições da $\mathrm{CN}$, suas vantagens, os seus desafios, os riscos e as barreiras para a sua adoção, os conceitos de modelo de alinhamento estratégico e de capacidades essenciais (constructos).

$\mathrm{Na}$ sequência está o capítulo Metodologia da pesquisa descrevendo os seguintes pontos: escolha da metodologia de pesquisa, questão central de pesquisa, questões desdobradas da questão central (descrição de como foram identificadas as questões relevantes, que serviram de base para construção do Método de Análise para adoção da $\mathrm{CN}$ a partir da revisão da literatura), proposições do estudo, estrutura e etapas do estudo de casos, protocolo da pesquisa, delimitação do escopo, construção do roteiro de pesquisa, proposta do teste piloto e os seus resultados, seleção das unidades de análise com os critérios utilizados de análise (com a justificativa para a escolha de organizações de grande porte como unidades de análise para o trabalho), coleta dos dados e as oportunidades para análise dos dados coletados. 
No capítulo seguinte está a apresentação do Método de Análise para adoção da $\mathrm{CN}$ e a descrição do roteiro para a sua aplicação. Os resultados do trabalho de campo estão mostrados nos capítulos Resultados obtidos e discussões. Seguindo as conclusões estão listadas as Referências bibliográficas aqui utilizadas.

Ao final do trabalho estão os apêndices com os protocolos para caracterização das organizações e descrições dos serviços avaliados e/ou contratados na nuvem, com os questionários utilizados na pesquisa de campo e o enunciado para os trabalhos que serviram como estudo de casos piloto e um anexo com uma proposta de conteúdo e sequência para a condução de um estudo de caso, como foi apresentada por Miguel (2012). 


\section{REVISÃO DE LITERATURA}

Para que seja atingido o objetivo proposto para o trabalho serão buscadas na literatura pesquisas que tratam das questões essenciais ao tema da adoção da CN.

Assim, objetivando investigar como são tomadas as decisões para aquisição, contratação e a operação dos serviços da $\mathrm{CN}$ serão buscadas na literatura a definição da $\mathrm{CN}$ e demais tecnologias a ela relacionadas, procurando situá-la dentro de um contexto da evolução tecnológica. Será mostrada ainda a arquitetura da $\mathrm{CN}$ e apresentados os seus modelos de serviços e de implantação. Considerados fatores com influência nos processos de decisão para a sua adoção as vantagens, desafios, riscos e barreiras da $\mathrm{CN}$ são chamados neste trabalho de fatores associados ao processo de decisão e serão identificados nesta revisão bibliográfica.

Também serão buscados os conceitos de Alinhamento Estratégico da $\mathrm{TI}$ ao negócio, das capacidades essenciais para a gestão das áreas de TI no que diz respeito aos seus objetivos de negócios $(B O B)$, à gestão da função $\mathrm{TI}(M N G)$, aos atributos da qualidade dos serviços (QAS) e às decisões de arquitetura $(A R C)$.

Por fim, será apresentado um modelo de decisão hierárquico em três camadas para avaliar os tipos de decisões necessárias para mover os serviços para a nuvem, que servirá de base, assim como os demais conceitos aqui apresentados, para a construção do Modelo de Análise proposto no capítulo 4 deste trabalho.

\subsection{Definição de computação em nuvem}

Embora muitas definições formais tenham sido propostas pela academia e pelo setor de Tecnologia da Informação (LINTHICUM, 2009b; TAURION, 2009; VAQUERO et al., 2009; VERAS, 2009), a definição fornecida pelo NIST (National Institute of Standards and Technology) (MELL e GRANCE, 2011) inclui os principais conceitos comumente utilizados na comunidade de computação em nuvem ("Cloud Computing"). O NIST apresenta a seguinte definição: "computação em nuvem é um modelo que possibilita acesso, de modo conveniente e sob demanda, a um conjunto de recursos computacionais configuráveis (por exemplo, redes, servidores, armazenamento, aplicações e serviços) que podem ser rapidamente adquiridos e liberados com mínimo esforço gerencial ou interação com o provedor de serviços". 
O Quadro 1 apresenta os cinco elementos essenciais da computação em nuvem e como eles estão articulados.

Também de acordo com o NIST (MELL e GRANCE, 2011) a definição de CN inclui os modelos de oferecimento dos serviços, como mostrados Quadro 2.

O Quadro 3 apresenta os modelos de implantação da $\mathrm{CN}$, que são as diferentes maneiras para a implantação física da infraestrutura nuvem, comumente chamada de data centers ou centros de processamento de dados. Por simplicidade, neste trabalho esta infraestrutura será referida como sendo um data center.

QUADRO 1 - AS CINCO CARACTERÍSTICAS ESSENCIAIS DA COMPUTAÇÃO EM NUVEM

\begin{tabular}{|c|l|}
\hline Características & \multicolumn{1}{|c|}{ Descrição } \\
\hline $\begin{array}{c}\text { Contratação } \\
\text { self-service" } \\
\text { da demanda }\end{array}$ & $\begin{array}{l}\text { lonsumidor com uma necessidade imediata e para um } \\
\text { intervalo de tempo determinado pode se utilizar dos } \\
\text { recursos de computação (como o tempo de CPU, } \\
\text { armazenamento de rede, uso de software, e assim por diante) } \\
\text { automaticamente (ou seja, de forma conveniente e "self-service"), } \\
\text { sem recorrer a interações humanas com os provedores desses } \\
\text { recursos. }\end{array}$ \\
\hline $\begin{array}{l}\text { Amplo acesso } \\
\text { à rede }\end{array}$ & $\begin{array}{l}\text { Estes recursos de computação são entregues através da rede } \\
\text { (por exemplo, da Internet) e usados por vários aplicativos cliente } \\
\text { com plataformas heterogêneas (como telefones celulares, } \\
\text { laptops e PDAs) situados no local do consumidor. }\end{array}$ \\
\hline
\end{tabular}




\begin{tabular}{|c|c|}
\hline Características & Descrição \\
\hline $\begin{array}{l}\text { "Pool" de } \\
\text { recursos }\end{array}$ & $\begin{array}{l}\text { Recursos de um provedor de serviços de CN estão "agrupados" } \\
\text { conjuntamente, em um esforço para servir aos vários } \\
\text { consumidores que os utilizam (ou "multi-tenancy" - múltiplos } \\
\text { inquilinos), "com diferentes recursos físicos e virtuais atribuídos } \\
\text { dinamicamente e novamente de acordo com a demanda do } \\
\text { consumidor". Normalmente os consumidores são cobrados pelo } \\
\text { tempo de uso dos recursos (modalidades conhecidas como "pay- } \\
\text { per-use" ou "charge-per-use"). A motivação para a criação de tal } \\
\text { paradigma de computação baseada em "pool" ("pool-based } \\
\text { modef") reside em dois fatores importantes: economias de } \\
\text { escala e especialização. O resultado de um modelo baseado } \\
\text { em "pool" ("pool-based model") é que os recursos físicos de } \\
\text { computação se tornam "invisíveis" para os consumidores, que } \\
\text { em geral não têm controle ou conhecimento sobre a sua } \\
\text { localização, formação e origem destes recursos (banco de } \\
\text { dados, CPU, etc.) Por exemplo, os consumidores não são } \\
\text { capazes de dizer onde seus dados serão armazenados na } \\
\text { nuvem. }\end{array}$ \\
\hline $\begin{array}{c}\text { Rápida } \\
\text { elasticidade }\end{array}$ & $\begin{array}{l}\text { Capacidades podem ser elasticamente provisionadas e } \\
\text { liberadas, em alguns casos automaticamente, podendo ser } \\
\text { aumentas ou diminuídas rapidamente de acordo com a procura. } \\
\text { Para o consumidor, as capacidades disponíveis para utilização } \\
\text { frequentemente parecem ser ilimitadas e podem ser apropriadas, } \\
\text { em qualquer quantidade a qualquer momento, a fim de cumprir } \\
\text { suas exigências de picos de demanda. Não há compromisso } \\
\text { contratual inicial de utilização, de forma que o consumidor pode } \\
\text { alocar e liberar os recursos de acordo com suas necessidades. }\end{array}$ \\
\hline
\end{tabular}




\begin{tabular}{|c|l|}
\hline Características & \multicolumn{1}{|c|}{ Descrição } \\
\hline $\begin{array}{c}\text { Medição do } \\
\text { Serviço }\end{array}$ & $\begin{array}{l}\text { Embora os recursos computacionais estejam reunidos e } \\
\text { compartilhados por vários consumidores (ou seja, "multi-tenancy" } \\
\text { - com múltiplos inquilinos), a infraestrutura de nuvem é capaz de } \\
\text { usar os mecanismos adequados para medir o uso desses } \\
\text { recursos para cada um dos consumidores através de suas } \\
\text { ferramentas de medição. }\end{array}$ \\
\hline
\end{tabular}

FONTE: DEFINIÇÃO DO NIST (MELL E GRANCE, 2011)

QUADRO 2 - MODELOS DE SERVIÇO DA COMPUTAÇÃO EM NUVEM

\begin{tabular}{|c|l|}
\hline $\begin{array}{c}\text { Modelo de Serviço } \\
\text { Infraestrutura } \\
\text { como Serviço } \\
\text { (laaS) }\end{array}$ & $\begin{array}{l}\text { Descrição } \\
\text { armazenamento, redes e outros recursos básicos de } \\
\text { computação, onde o consumidor é capaz de implantar e } \\
\text { executar os softwares de sua escolha, que podem incluir } \\
\text { sistemas operacionais e aplicativos. O consumidor não } \\
\text { gerencia ou controla a infraestrutura subjacente da nuvem, } \\
\text { mas tem controle sobre sistemas operacionais, } \\
\text { armazenamento e aplicativos implementados e, } \\
\text { possivelmente, controle limitado sobre determinados } \\
\text { componentes de rede (por exemplo, "firewalls" do provedor). }\end{array}$ \\
\hline
\end{tabular}




\begin{tabular}{|c|l|}
\hline Modelo de Serviço & Descrição \\
\hline Serviço (PaaS) & $\begin{array}{l}\text { Capacidade fornecida ao consumidor para implantar sobre a } \\
\text { infraestrutura da nuvem aplicações por ele adquiridas ou } \\
\text { criadas, tendo sido desenvolvidas utilizando linguagens de } \\
\text { programação, bibliotecas, serviços e ferramentas suportadas } \\
\text { pelo provedor (vale destacar que esta capacidade não } \\
\text { necessariamente impede o uso de linguagens de programação, } \\
\text { bibliotecas, serviços e ferramentas de outras fontes } \\
\text { compatíveis). o consumidor não gerencia ou controla a } \\
\text { infraestrutura subjacente da nuvem, incluindo rede, } \\
\text { servidores, sistemas operacionais ou armazenamento, mas } \\
\text { tem controle sobre os aplicativos implementados e, } \\
\text { possivelmente, definições de configuração para o ambiente de } \\
\text { hospedagem dos aplicativos. }\end{array}$ \\
\hline Software como & $\begin{array}{l}\text { Capacidade fornecida ao consumidor para utilização de } \\
\text { aplicativos do provedor rodando em uma infraestrutura de } \\
\text { nuvem (conforme definida no parágrafo abaixo). As aplicações } \\
\text { são acessíveis a partir de dispositivos clientes, através das mais } \\
\text { variadas interfaces, quer sejam "thin client", como um } \\
\text { navegador web (por exemplo, "e-mail web-based") ou de um } \\
\text { programa específico. O consumidor não gerencia ou controla } \\
\text { a infraestrutura subjacente da nuvem, incluindo rede, } \\
\text { servidores, sistemas operacionais, armazenamento ou } \\
\text { mesmo capacidades de aplicativos individuais, com a } \\
\text { possível exceção de configurações específicas e limitadas } \\
\text { do usuário para utilização do aplicativo. }\end{array}$ \\
\hline Sas)
\end{tabular}

FONTE: DEFINIÇÃO DO NIST (MELL E GRANCE, 2011)

Para o NIST (MELL e GRANCE, 2011), a infraestrutura de nuvem é a coleção de hardware e software que viabiliza as cinco características essenciais da $\mathrm{CN}$. A infraestrutura de nuvem pode ser vista como contendo tanto uma camada física, como uma camada de abstração. A camada física consiste em recursos de hardware que são necessários para apoiar os serviços de nuvem que estão sendo oferecidos; normalmente inclui servidor, armazenamento e componentes de rede. 
Conceitualmente a camada de abstração fica acima da camada física, consistindo do software sobre ela implantado e que implementa suas características essenciais.

\section{QUADRO 3 - MODELOS DE IMPLANTAÇÃO DA COMPUTAÇÃO EM NUVEM}

\begin{tabular}{|c|c|}
\hline $\begin{array}{c}\text { Modelo de } \\
\text { Implantação }\end{array}$ & Descrição \\
\hline $\begin{array}{l}\text { Nuvem } \\
\text { privada }\end{array}$ & $\begin{array}{l}\text { A infraestrutura de nuvem é de utilização exclusiva de uma } \\
\text { organização, que pode compreender vários consumidores (por } \\
\text { exemplo, unidades de negócio). Pode ser de propriedade, } \\
\text { gerenciada e operada pela própria organização, por um terceiro, ou por } \\
\text { alguma combinação deles. Esta infraestrutura pode estar dentro (local) } \\
\text { ou fora das instalações da organização (remota). }\end{array}$ \\
\hline $\begin{array}{c}\text { Nuvem } \\
\text { comunitária }\end{array}$ & $\begin{array}{l}\text { A infraestrutura de nuvem é oferecida para uso exclusivo por uma } \\
\text { comunidade específica de consumidores de organizações que } \\
\text { têm preocupações comuns (por exemplo, a missão, requisitos de } \\
\text { segurança, política e considerações de "compliance"). Pode ser de } \\
\text { propriedade, gerenciadas e operadas por uma ou mais das } \\
\text { organizações da comunidade, por um terceiro, ou alguma combinação } \\
\text { deles. Esta infraestrutura pode estar dentro ou fora das instalações das } \\
\text { organizações. }\end{array}$ \\
\hline $\begin{array}{l}\text { Nuvem } \\
\text { pública }\end{array}$ & $\begin{array}{l}\text { A infraestrutura de nuvem é oferecida para uso aberto ao público } \\
\text { em geral. Pode ser de propriedade, gerenciada e operada por uma } \\
\text { empresa, por uma organização acadêmica ou governamental, ou } \\
\text { alguma combinação deles. Esta infraestrutura está nas instalações do } \\
\text { provedor de nuvem. }\end{array}$ \\
\hline $\begin{array}{l}\text { Nuvem } \\
\text { híbrida }\end{array}$ & $\begin{array}{l}\text { A infraestrutura de nuvem é uma composição de duas ou mais } \\
\text { infraestruturas de nuvem distintas (privada, comunitária ou } \\
\text { pública) que permanecem entidades únicas, mas são unidas por } \\
\text { tecnologia padronizada ou proprietária que permite a portabilidade de } \\
\text { dados e aplicações (por exemplo, balanceamento de carga entre } \\
\text { nuvens). }\end{array}$ \\
\hline
\end{tabular}

FONTE: DEFINIÇÃO DO NIST (MELL E GRANCE, 2011) 
Para Linthicum (2009a) muitas empresas descobrirão que o modelo de implantação como nuvem privada poderá ser a melhor solução para sua situação, ao aproveitar os benefícios da $\mathrm{CN}$, porém dentro de seu próprio modelo de segurança. Essa questão é pertinente ao estudo e será objeto de análise e aprofundamento ao longo do trabalho.

A Figura 1 mostra hierarquia dos Modelos de Serviços da $C N$, associando a cada um deles alguns dos fornecedores globais mais conhecidos. A Figura 2 mostra uma visão conceitual da $\mathrm{CN}$, exibindo sua potencialidade representada por suas características essenciais e modelos de serviço e de implantação.

Neste trabalho os problemas e as oportunidades relacionados exclusivamente à oferta de infraestrutura de hardware não serão abordados diretamente, uma vez que o seu foco é o impacto da computação em nuvem nas aplicações, soluções, produtos ou sistemas de informação. A análise sobre a infraestrutura de hardware somente será tratada quando imprescindível para compreensão dos fatores que possam impacta a adoção de aplicações, soluções ou sistemas de informação.

\subsection{Tecnologias relacionadas à computação em nuvem}

O objetivo da apresentação das tecnologias relacionadas é situar a $\mathrm{CN}$ dentro de um contexto da evolução tecnológica, procurando mostrar que, ao mesmo tempo em que não se trata de um assunto novo, a abordagem atual difere substancialmente daquelas do passado. Para Buyya et al. (2008), a CN é muitas vezes comparada com as tecnologias do Quadro 4, com as quais compartilha algumas características.

Em resumo, a CN utiliza tecnologia de virtualização para alcançar o objetivo de fornecer recursos de computação como uma utilidade, chamada de quinta utilidade (BUYYA et al., 2009) em referência a água, energia elétrica, gás e telefone. Ainda mais, compartilha certas características com a computação em grade e computação autonômica, mas difere delas em outras tantas. Por isso, a CN oferece benefícios exclusivos e impõe desafios distintos para atender às suas peculiaridades. 


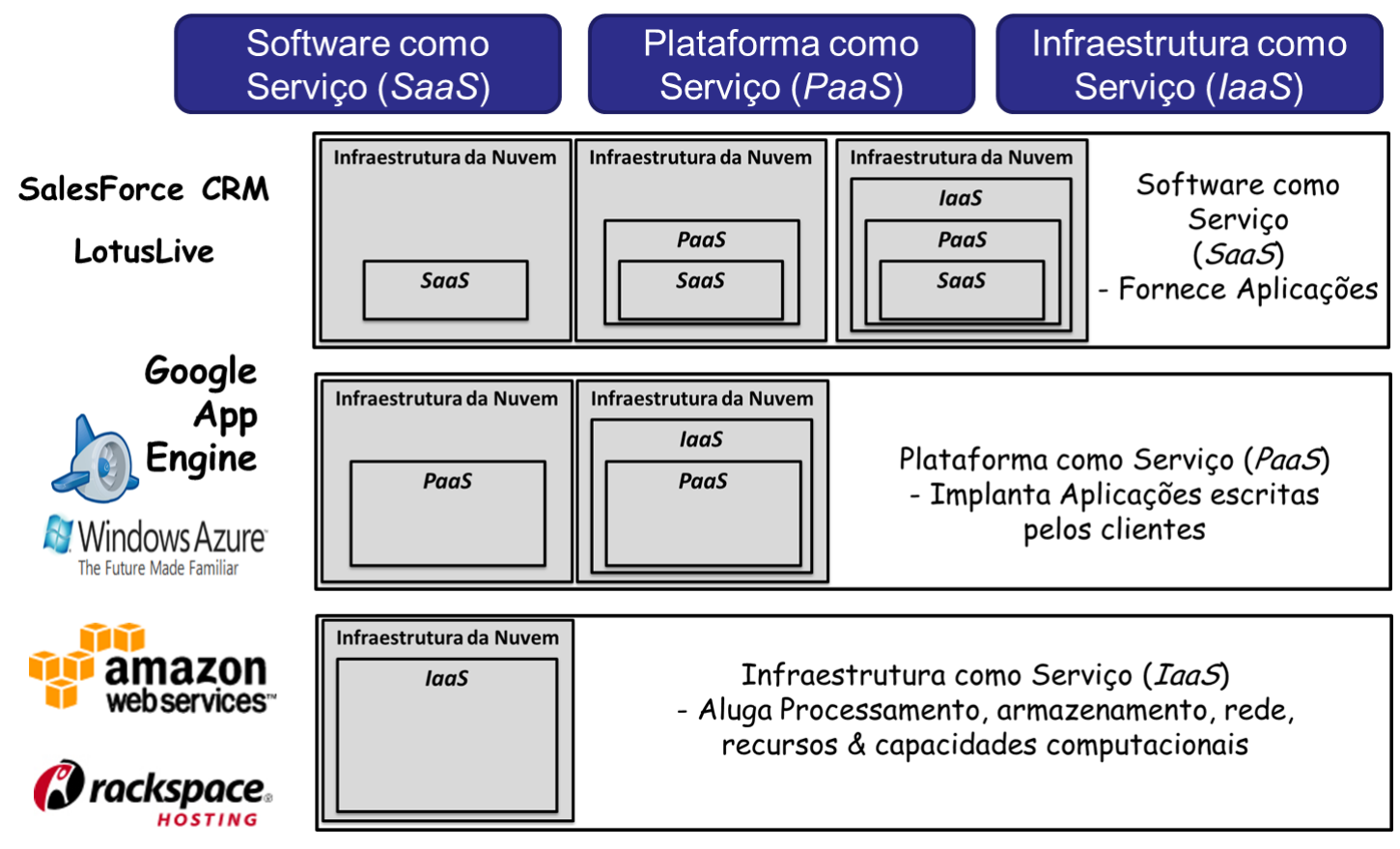

Figura 1 - Hierarquia dos Modelos de SERVIÇOS

FONTE: ADAPTADO DE (SUBASHINI E KAVITHA, 2011)

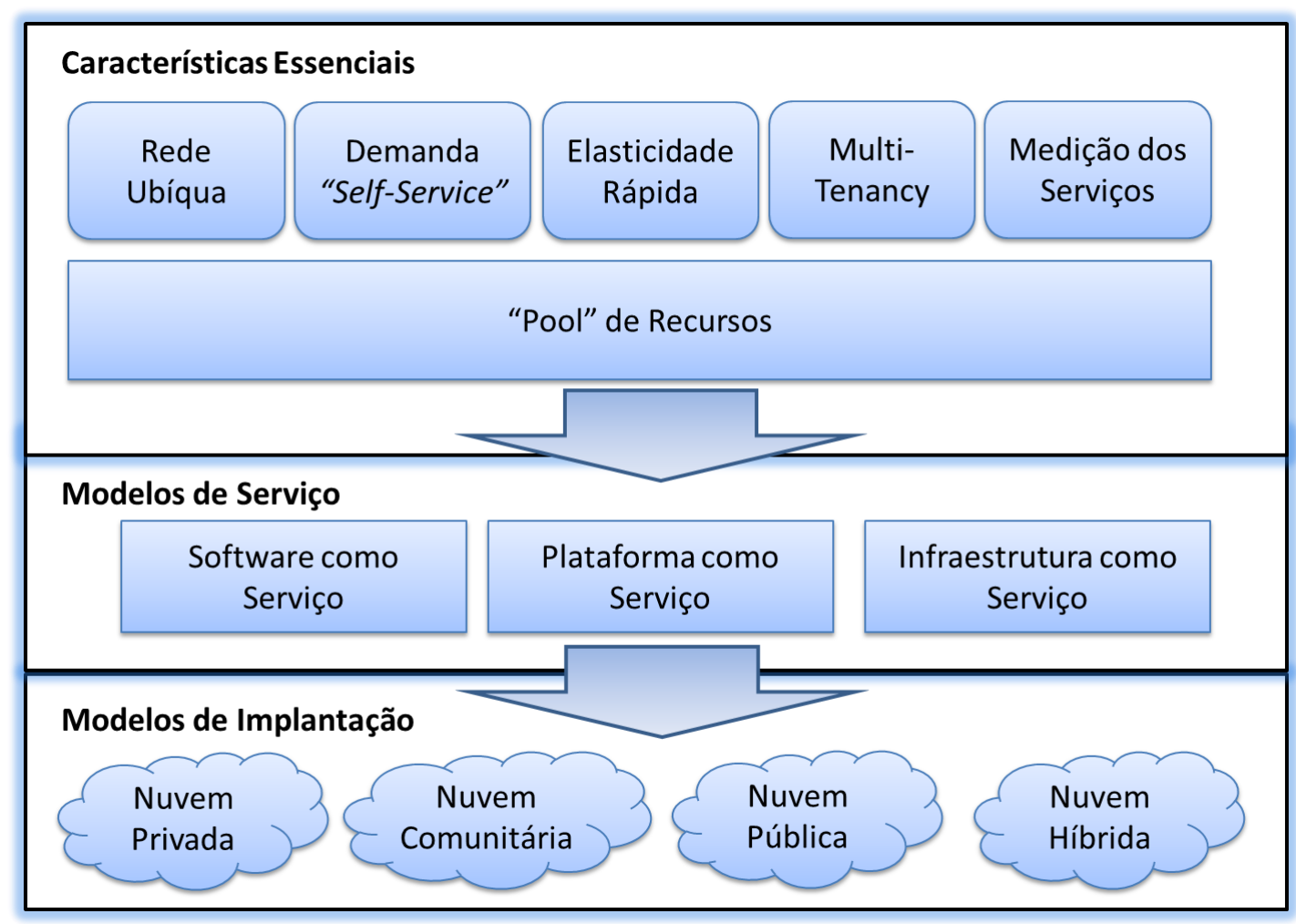

Figura 2 - CoMpleXIDADE dA COMPUTAÇÃo EM NUVEM - DEFINIÇÃO DO NIST

(NATIONAL INSTITUTE OF STANDARDS AND TECHNOLOGY)

FONTE: Adaptado de (SUBASHINI e KAVITHA, 2011) 


\subsection{Arquitetura da computação em nuvem}

A arquitetura de CN é baseada em camadas, sendo que cada uma destas trata de uma particularidade na disponibilização de recursos para as aplicações (BUYYA et al., 2009). Uma camada é uma divisão lógica de componentes de hardware e software. Alguns destes recursos computacionais podem ser agrupados e organizados para realizar uma determinada tarefa do sistema como um todo. Cada camada pode ter seu gerenciamento ou monitoramento de forma independente das outras camadas, melhorando a flexibilidade, reuso e escalabilidade no que diz respeito à substituição ou adição de recursos computacionais sem afetar as outras camadas. A Figura 3 exibe essas camadas e suas respectivas associações.

\section{QUADRO 4 - TECNOLOGIAS RELACIONADAS À COMPUTAÇÃO EM NUVEM}

\begin{tabular}{|c|c|}
\hline Tecnologia & Descrição \\
\hline $\begin{array}{c}\text { “Grid Computing” } \\
\text { ou Computação } \\
\text { em Grade }\end{array}$ & $\begin{array}{l}\text { É um paradigma de computação distribuída que coordena } \\
\text { recursos em rede para alcançar um objetivo computacional } \\
\text { comum. O desenvolvimento da computação em grade foi } \\
\text { originalmente dirigido para aplicações científicas, que são } \\
\text { geralmente de computação intensiva. } \\
\text { A CN é similar à computação em grade na medida em que } \\
\text { também emprega recursos distribuídos para alcançar } \\
\text { objetivos no nível das aplicações. No entanto, a CN } \\
\text { representa um passo adiante ao usar as tecnologias de } \\
\text { virtualização em vários níveis (hardware e plataforma de } \\
\text { aplicativos) para realizar o compartilhamento e } \\
\text { provisionamento dinâmicos de recursos. }\end{array}$ \\
\hline $\begin{array}{c}\text { - “Utility } \\
\text { Computing" ou } \\
\text { Computação como } \\
\text { Utilidade } \\
\text { (como o são água, } \\
\text { energia elétrica, } \\
\text { gás ou telefone) }\end{array}$ & $\begin{array}{l}\text { Representa o modelo de fornecer recursos sob demanda e } \\
\text { cobrar de seus clientes com base no uso em vez de uma } \\
\text { taxa fixa. A CN pode ser vista como uma materialização da } \\
\text { "utility computing", pois adota um regime de preços baseado na } \\
\text { utilização inteiramente por razões econômicas. Isto é, com o } \\
\text { provisionamento sob demanda de recursos e preços baseados } \\
\text { no volume de utilização, os provedores de serviços podem } \\
\text { realmente maximizar utilização destes recursos, minimizando } \\
\text { seus custos operacionais. }\end{array}$ \\
\hline
\end{tabular}




\begin{tabular}{|c|l|}
\hline Tecnologia & Descrição \\
\hline Virtualização & $\begin{array}{l}\text { É uma tecnologia que abstrai os detalhes do hardware } \\
\text { físico e fornece recursos virtualizados de alto nível para } \\
\text { aplicações. Um servidor virtualizado é comumente chamado } \\
\text { de máquina virtual (VM). Virtualização é a base da CN, uma vez } \\
\text { que fornece a capacidade de reunir recursos de computação } \\
\text { em "clusters" (ou grupos) de servidores, dinamicamente } \\
\text { atribuindo ou retirando recursos virtuais para as aplicações, } \\
\text { conforme a demanda. }\end{array}$ \\
\hline "Autonomic & $\begin{array}{l}\text { Expressão originalmente cunhada pela IBM em 2001, } \\
\text { computação autonômica visa à construção de sistemas de } \\
\text { computação capazes de autogestão, ou seja, reagir a } \\
\text { determinadas condições ou situações internas e externas } \\
\text { ao sistema, sem intervenção humana. O objetivo da } \\
\text { computação autonômica é superar a complexidade de } \\
\text { gerenciamento dos sistemas de computadores atuais. Embora } \\
\text { a CN apresente certas características autônomas, tais como } \\
\text { provisionamento automático de recursos, seu objetivo } \\
\text { primordial não é reduzir a complexidade do sistema, mas sim o } \\
\text { custo destes recursos. }\end{array}$ \\
\hline
\end{tabular}

FONTE: ADAPTADO DE (BUYYA ET AL., 2008)

A camada de mais baixo nível é a de infraestrutura física, que contém os dispositivos para armazenamento de dados, servidores e clusters, desktops e outros recursos de hardware, podendo ter recursos heterogêneos. Com isso, fornece certa flexibilidade e facilidade de agregação de novos recursos à medida que se tornem necessários.

Uma camada de "middleware" é responsável por gerenciar a infraestrutura física e tem por objetivo fornecer o núcleo lógico de uma nuvem, fundamentalmente representada por máquinas virtuais (virtualização de servidores físicos).

A camada de nível mais alto atende às solicitações de serviços de usuários ou de seus representantes ("brokers") enviadas de qualquer lugar do mundo para serem processadas em um determinado provedor. Fornece também os mecanismos 
para as negociações acerca da qualidade do serviço (QoS), gerenciamento dos acordos de nível de serviços (SLAs), serviços de cobrança, serviços para verificar aceitação de requisições baseadas na qualidade do serviço (QoS) e o seus preços, serviços para cálculo da utilização específica dos recursos da nuvem para cada usuário, serviços de gerenciamento de virtualização, entre outros (BUYYA et al., 2009).

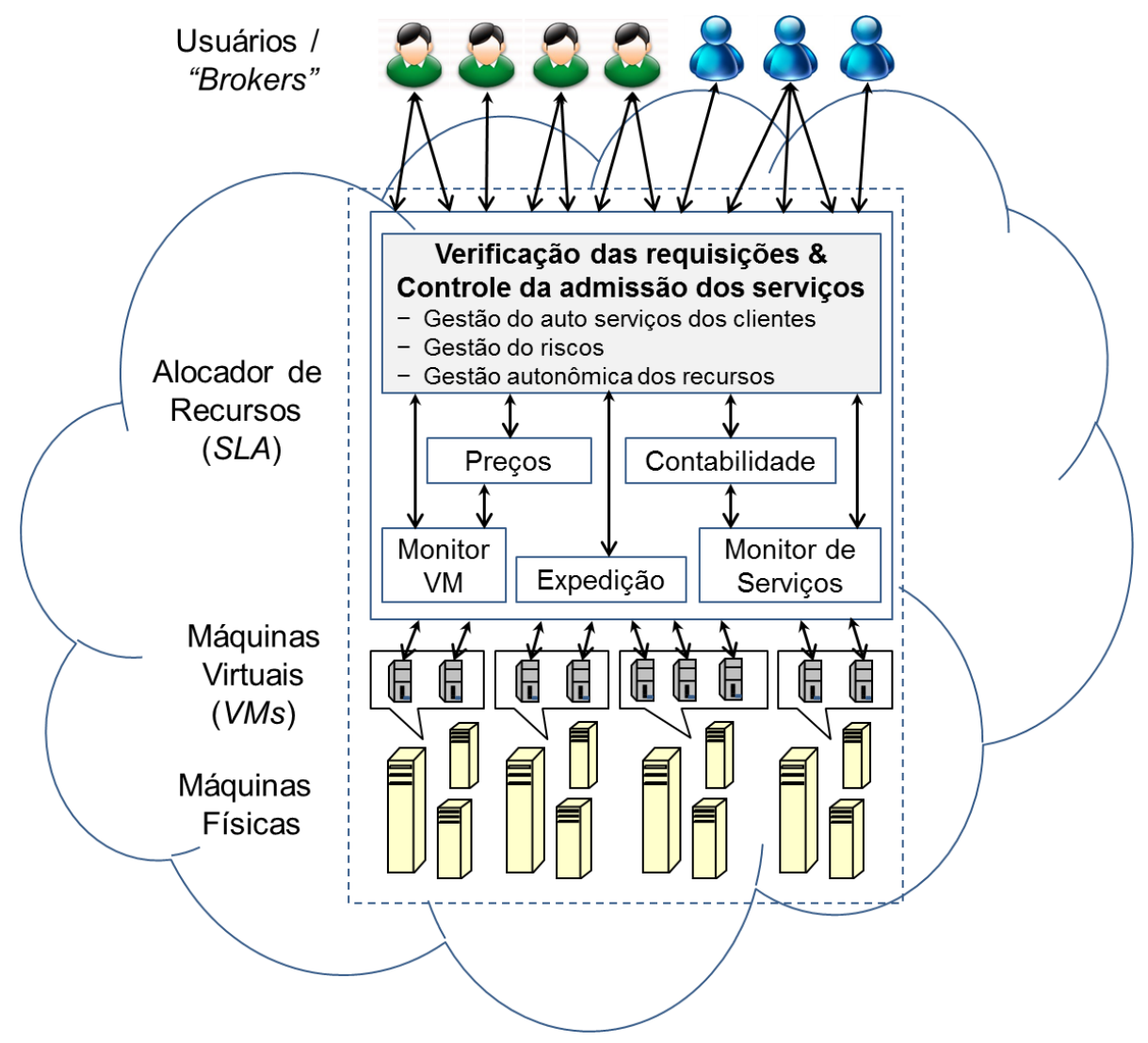

FIGURA 3 - CAMADAS DA COMPUTAÇÃo EM NUVEM

FONTE: (BUYYA ET AL., P.604, 2008)

Desta forma, a compreensão desta construção em camadas é importante para o presente trabalho ao mostrar que os softwares ou aplicações oferecidas com um serviço (SaaS), na maior parte das vezes também são usuários de infraestrutura da nuvem. Portanto, é necessário conhecer quais serão as camadas, tecnologias selecionadas e/ou compatíveis, provedores de infraestrutura e outras informações necessárias à tomada de decisões para a contratação deste tipo de serviço.

Até o momento, as conversas sobre a $\mathrm{CN}$ têm sido dominadas por fornecedores que se concentram mais em tecnologia e menos no valor do negócio. 
Enquanto ainda não se está plenamente de acordo quanto aos componentes que constituem a tecnologia de $\mathrm{CN}$, vão surgindo diversos exemplos de seus usos potenciais (IYER e HENDERSON 2010).

\subsection{Vantagens, desafios e barreiras para a adoção da nuvem}

Aqui são introduzidas as vantagens, desafios e barreiras para a adoção da nuvem, que servem de base para elaboração do Método de Análise para adoção da $\mathrm{CN}$, proposto no trabalho (capítulo 4). São diversos os trabalhos que tratam das vantagens (BENLIAN e HESS, 2011; MARSTON et al., 2010; SOMMERVILLE, 2003; XIN e LEVINA, 2008), desafios (WILLCOCKS et al., 2012), riscos e barreiras (CHAVES E SOUSA, 2012; MARKS e LOZANO, 2010; MILLER, 2008; SOMMERVILLE, 2003), que serão apresentados de acordo com as necessidades desta pesquisa.

Como um ponto de partida, vale dizer que uma medida comumente utilizada para avaliar a eficácia de despesas de TI uma organização é o Custo total de propriedade (TCO - Total Cost of Onwership). Como definido por Bill Kirwin do Gartner Group, TCO é "uma visão holística dos custos relacionados com aquisição e utilização de TI em um nível empresarial" (CAPPUCIO et al., 1996), tendo por objetivo entender os custos reais da infraestrutura de TI.

Sem diminuir sua importância, este tema não é tratado de forma direta no contexto deste trabalho, pois é controverso quando da utilização de software como serviço (SaaS) ou em outras modalidade de CN. Para Linthicum (2009), na CN o custo total de propriedade deveria ser menor que os da computação tradicional. Em um artigo mais recente o autor diz que, no passado, promoveu a $\mathrm{CN}$ como capaz de reduzir os custos da TI (LINTHICUM, 2011).

Contudo, ao invés de redução de custos de hardware e de software, as organizações estão comprando serviços da nuvem, serviços de consultoria de alto nível e contratando especialista na área. Portanto, ao invés de redução dos custos há aumento nos investimentos. Para Linthicum (2011), "o pequeno segredo sujo" no mundo da $\mathrm{CN}$ é que as reduções de custos de operação não entregam valor para as organizações. Ao invés disso, o valor decorre da agilidade operacional das 
aplicações baseadas na nuvem, quando consideradas a sua elasticidade e agilidade. Desta forma, este autor defende que projetos de $\mathrm{CN}$, vendidos como redução de custos, devem ser vistos como investimentos estratégicos (LINTHICUM, 2011).

Tais projetos permitiram uma redução do "backlog" de aplicações de negócios, não entregues objetivando racionalização dos custos e para, este que talvez seja o fator mais importante, disponibilizar as aplicações para dispositivos móveis como "tablets" e "smartphones". Assim, no contexto deste trabalho, TCO apesar da sua importância não é tratado diretamente, devendo ser sempre considerado nas situações objetivas das organizações, quando na elaboração dos orçamentos de $\mathrm{TI}$.

\subsubsection{Vantagens}

De acordo com Benlian e Hess (2011), revisões mais recentes da literatura têm deslocado a atenção para avaliar a importância em relação às oportunidades decorrentes da contratação de serviços ou terceirização. Gonzalez et al. (2009), por exemplo, identificaram um foco maior nas questões estratégicas, considerando a flexibilidade e qualidade como as principais razões para as empresas clientes envolvidas em contratação de serviços e terceirização.

Da mesma forma, em um estudo empírico de empresas bancárias, Gewald e Dibbern (2009) encontraram que o foco nas competências essenciais para o negócio e melhorias de qualidade são os fatores mais significativos de oportunidades.

Marston et al. (2010) consideram que a possibilidade da confluência para um ambiente onde as informações possam ser acessadas, independentemente do dispositivo e da localização, representa uma grande mudança na computação como a conhecemos. Assim, o autor defende que esta mudança pode significar uma série de vantagens para os utilizadores da $\mathrm{CN}$.

Especificamente para estes autores (BENLIAN e HESS, 2011; MARSTON et al., 2010; SOMMERVILLE, 2003; XIN e LEVINA, 2008), as principais vantagens da CN são as seguintes: 
Custo de capital do cliente: no modelo SaaS, aplicações de software são implantados nas instalações dos fornecedores, antes da sua adoção pelos clientes. Os clientes não compram software ou infraestrutura (hardware e sistema operacional, por exemplo) "in advance", mas pagam pelo acesso aos serviços ao longo do tempo (MARSTON et al., 2010). Ou seja, não se trata das modalidades tradicionais de remuneração de software, como pagamento mensal por quantidade de licenças utilizadas ou pagamento a vista no ato da compra mais pagamentos anuais, a título de manutenção. Deste fato decorre a ideia de um modelo de computação oferecido como utilidade, chamada de quinta utilidade por Buyya, et al., (2009). (V1)

Custo de capital do fornecedor: a $\mathrm{CN}$ pode oferecer um acesso quase imediato aos recursos de hardware, sem investimentos iniciais para os seus usuários, melhorando o "time to market" para produtos de muitas empresas. Como se trata de uma despesa operacional (recursos empregados como um "OPEX" em oposição ao modelo de "CAPEX"), também ajuda a reduzir drasticamente os custos iniciais na computação corporativa. (MARSTON et al., 2010). Isto decorre da própria definição da $\mathrm{CN}$, como apresentada neste capítulo, pelas características da contratação "self-service" da demanda e pela rápida elasticidade. Assim, as empresas contratam somente a capacidade computacional estritamente necessária para começar sua operação, sabendo que poderão aumentar (ou diminuir) sua carga computacional.

Para Marston et al. (2010), a flexibilidade da infraestrutura permite que as cargas de computação permaneçam equilibradas, ainda que mais usuários venham a aderir ao sistema, isto é possível, pois o processo de criação de infraestrutura tornou-se tão padronizado que a adição de capacidade de computação tornou-se quase tão simples como adicionar novos servidores e outros equipamentos de comunicação em uma rede já existente. (V2)

Ciclo de implementação é reduzido: uma vez que as aplicações já estão implantados em sites de fornecedores de SaaS. O modelo SaaS também permite economia de custos na operação em larga escala de componentes de negócios padronizados. Assim, as empresas com alto custo de capital podem encontrar mais 
benefícios no modelo SaaS, pois Ihes permite economizar no custo de capital fixo, diluindo o custo do serviço ao longo do tempo, permitindo um menor prazo para o retorno do investimento, e, potencialmente, trazendo significativa economia de custos (XIN e LEVINA, 2008). (V3)

Custo de entrada em novos negócios: reduz significativamente o custo de entrada para as pequenas empresas que podem se beneficiar de aplicativos de negócios, que até então eram disponíveis apenas para as grandes corporações (MARSTON et al., 2010). (V4)

Custo de ampliação do negócio ou de entrada em novos mercados: a CN torna mais fácil para as empresas a expansão de seus serviços - que são cada vez mais dependentes de informações precisas - de acordo com a demanda do cliente. Uma vez que os recursos computacionais são gerenciados através de software, que podem ser implantados muito rapidamente e de acordo com novas necessidades. $\mathrm{Na}$ verdade, o objetivo da $\mathrm{CN}$ é dimensionar recursos para cima ou para baixo dinamicamente através de APIs de software, dependendo da carga do cliente com o mínimo de interação do prestador de serviços (MARSTON et al., 2010). (V5)

Facilidade de manutenção: o fornecedor do sistema de informação tem maior facilidade para corrigir, melhorar ou mesmo incluir novas funcionalidades, dado que possui um maior controle na distribuição e na gestão das configurações das suas aplicações (MARSTON et al., 2010; SOMMERVILLE, 2003). (V6)

Flexibilidade estratégica: pressupõe que os clientes de SaaS são mais flexíveis em relação a troca de provedores comparados àqueles de instalações tradicionais "on-premise". Esta flexibilidade é devida a entrega sob demanda de aplicativos, de capital e investimentos operacionais que estão sendo deslocados do cliente para o provedor de SaaS. Desta forma, este modelo pode reduzir consideravelmente os efeitos de "vendor lock-in", devido aos elevados custos de troca de fornecedor, típicos do fornecimento de softwares instalados localmente ("onpremise"). Além disso, a adoção de SaaS proporciona um elevado grau de flexibilidade em relação à utilização de recursos de TI facilmente escaláveis (BENLIAN e HESS, 2011). (V7) 
Foco nos negócios da organização: na literatura sobre terceirização de $\mathrm{Tl}$, estudos empíricos que basearam seus argumentos teóricos sobre a visão baseada em recursos descobriram que a terceirização permite às empresas concentrar-se em seus negócios principais ("core business"), pois permite liberar recursos que podem ser usados de forma mais produtiva em áreas que criam valor (LEVINA e ROSS, 2003). Benlian e Hess (2011), argumentam que, da mesma forma como ocorreu com - Application Service Provider (ASP), a adoção de SaaS também facilitará uma reorientação das empresas para as suas competências essenciais para o negócio (BENLIAN e HESS, 2011). (V8)

Acesso aos recursos de ponta de tecnologia de Tl: tem se mostrado um dos principais indicadores de sucesso do $\mathrm{ClO}$ e um importante motor de decisões de terceirização. Uma vez que o modelo de negócios SaaS é baseado em uma arquitetura de plataforma "multi-tenant" ("múltiplos inquilinos"), os fornecedores se beneficiam das economias de escala através da consolidação e virtualização de seus centros de dados. Além disso, o fornecedor também se beneficia dos efeitos da curva de aprendizagem quando profissionaliza a prestação de serviços de software através da Internet. Como resultado da terceirização de software, a partir de um prestador de serviços externo, os clientes de SaaS se beneficiam de economias e de habilidades, aproveitando os recursos, competências e capacidades que o prestador de serviços oferece (BENLIAN e HESS, 2011). (V9)

Melhoria da qualidade: também é uma razão citada pelas empresas que optam por terceirizar suas aplicações (LACITY et al., 2009). Acredita-se que possa haver um aumento na eficiência e eficácia dos processos que se apoiam nos serviços de aplicação (LACITY e WILLCOCKS, 1998). Os estudos empíricos que investigaram a adoção do modelo ASP descobriram que melhorar a excelência operacional é o principal motivador para a sua adoção. Esta constatação é baseada na capacidade de um ASP em focar suas capacidades exclusivamente no fornecimento de serviços de aplicações de acordo com um nível de serviço preestabelecido.

As empresas também podem esperar que um provedor de SaaS incorporasse as melhores práticas do setor de Tecnologia da Informação e procedimentos de 
gerenciamento total da qualidade, tais como conceitos de "Lean Management" para centros de dados, pois os fornecedores de SaaS devem ser mais sensível às necessidades dos clientes (WHITTEN et al., 2010). Caso contrário, correm o risco de perder receitas de assinaturas devido aos menores custos de mudança dos clientes. Além disso, relações comerciais em SaaS entre fornecedores e clientes, que são comumente baseadas em indicadores chave de desempenho (como o tempo de resposta do usuário final ou tempo de atividade ininterrupta), permitem um aumento da mensurabilidade (resultados) da qualidade do serviço e as especificações contratuais claras em relação níveis de serviços adequados (por ex., com disposições explícitas, que incluem multas, penalidades e até mesmo de rescisão do contrato). (BENLIAN e HESS, 2011). (V10)

As vantagens que podem ser obtidas com a adoção da $\mathrm{CN}$ acima descritas estão identificadas como V1 até V10, ao final do parágrafo correspondente, com o propósito de facilitar o entendimento da construção do método proposto neste trabalho e que será mostrado no capítulo 4.

\subsubsection{Desafios}

Segundo Willcocks et al., (2012), são cinco os grandes desafios que precisam ser enfrentados por aqueles que hoje se utilizam do modelo tradicional de infraestrutura de TI e que pretendem mudar para a CN. Estes desafios resultam da complexidade da CN, conforme exposto nos itens 2.1, 2.2 e 2.3 deste capítulo e foram identificados como D1 até D5, ao final do parágrafo correspondente, com o propósito de facilitar o entendimento da construção do método que este trabalho propõe, que será mostrado no capítulo 4. Estes desafios são os seguintes:

Recursos Humanos: na prática o recrutamento e retenção de um time, ainda que pequeno, mas de alta qualidade, é um dos maiores desafios da gestão de $\mathrm{RH}$. Em geral os recursos capacitados para trabalhar com CN são disputados no mercado, exigindo das organizações que os remunere ligeiramente acima da concorrência, dentro de com um plano de carreira, mantendo-os sempre desafiados e estimulados (adaptado de WILLCOCKS et al., 2012). (D1) 
Mudança no “ethos": "ethos" é o núcleo de uma organização. Ele descreve sua cultura e valores, seus princípios orientadores e crenças (em oposição à "ética", que se refere à distinção entre o bem e o mal) e as informações básicas, segundo a qual o sistema evolui (o seu "DNA"). Como tal, ela fornece significado para as tarefas em uma organização. "... Os empregados que executam uma função sem ver o seu valor não podem executá-la de acordo com a sua melhor capacidade, nem usar sua criatividade para melhorar o desempenho da tarefa. Eles podem simplesmente seguir as instruções" (DOSTAL, 2005, p.60). Mudanças na cultura das organizações não podem ocorrer se não houver mudança na sua visão do mundo, nos seus valores e crenças. Mudanças na cultura das organizações não podem ocorrer se não houver mudança no "ethos". (DOSTAL, 2005). Especificamente, a CN possibilita uma mudança na visão da função da TI. Tradicionalmente as áreas de $\mathrm{TI}$ gastam de $60 \%$ a $80 \%$ dos seus esforços para manter sua infraestrutura funcionando, resultando em pouco tempo para focar nas necessidades de negócio. Com a CN a atuação da TI pode ser mais rápida para responder às necessidades de mudanças nos requisitos de negócios. Este desafio representa possibilitar a mudança da situação atual das organizações, representada pelas capacidades existentes para o desenvolvimento tradicional dos Sistemas de Informação (SI), pelas capacidades necessárias para atender aos negócios e às funções de arquitetos e especialistas em CN (adaptado de WILLCOCKS et al., 2012). (D2)

Gestão de Projetos: deve ser uma capacidade "core" da organização e não apenas a manutenção de um recurso da área de negócios. É mais provável que os candidatos para a função de gerente de projeto sejam encontrados entre os construtores de relacionamento e evangelizadores de tecnologia. Os idealizadores dos sistemas de negócios, líderes, arquitetos e compradores especializados devem ter um papel muito ativo em projetos com um forte componente ou tecnologia da $\mathrm{CN}$ (adaptado de WILLCOCKS et al., 2012). (D3)

Inovação: as áreas de TI devem ser projetadas para lidar com contextos de negócios dinâmicos; que entre outras tarefas são concebidas para inovar. As organizações ainda precisam fazer grandes mudanças, se quiserem aproveitar grandes inovações da tecnologia / fornecedores de serviços em nuvem. Práticas fundamentais como apoiar a inovação colaborativa eficaz e aprofundar a 
colaboração entre áreas da organização podem oferecer não apenas uma TI operacional, mas também de processos de negócios e inovações estratégicas (adaptado de WILLCOCKS et al., 2012). (D4)

Evolução com a Nuvem: os executivos de TI precisam focar na realidade das capacidades técnicas e dos serviços, enquanto se asseguram de que os gerentes de negócios possuem a percepção correta das melhorias necessárias ao desempenho da TI. São particularmente importantes as capacidades de planejar a arquitetura, corrigir erros técnicos e facilitar a gestão dos contratos. Exige ainda maior pro-atividade na entrega de tecnologias estratégicas para o negócio e maior foco nas suas necessidades (adaptado de WILLCOCKS et al., 2012). (D5)

\subsubsection{Riscos e barreiras}

Risco percebido foi formalmente definido como "a expectativa de perdas associadas com a compra e age como um inibidor do comportamento de compra." (PETER e RYAN, 1976). É relevante na tomada de decisões quando as circunstâncias da decisão criam insegurança, desconforto, ansiedade ou conflitos no tomador de decisão (BETTMAN, 1973). Com base nessas definições, podemos definir o risco percebido como "o potencial de perda na busca de um resultado desejado quando adquirem software como um serviço" (BENLIAN e HESS, 2011).

A literatura sobre a CN traz alguns estudos (MILLER, 2008; MARKS e LOZANO, 2010; CHAVES e SOUSA, 2012) mencionado as dificuldades para sua adoção representada pelas barreiras inerentes ao modelo de computação e que estão relacionadas com governança de $\mathrm{TI}$, segurança, capacidades técnicas e requisitos não funcionais, como disponibilidade e desempenho. A seguir estão listadas as 10 barreiras identificadas na literatura, tendo sido adaptadas de (SOMMERVILLE, 2003; MILLER, 2008; MARKS e LOZANO, 2010; CHAVES e SOUSA, 2012). Foram identificadas de B1 até B10, ao final de cada parágrafo. As principais barreiras para utilização da $\mathrm{CN}$ são as seguintes:

Viabilidade estratégica da contratação externa ou oferecimento de determinados serviços: também chamados de riscos estratégicos, significa a possibilidade de uma companhia vir a perder recursos e capacidades críticas quando 
adquirem aplicativos via SaaS. Isso vale especialmente se as aplicações críticas de negócios e aquelas que suportam um amplo espectro de áreas funcionais dentro de uma organização, incluindo ERP (Enterprise Resource Planning), SCM (Supply Chain Management) ou sistemas de CRM (Customer Relationship Management), são terceirizadas. $O$ fornecimento externo desses recursos essenciais pode resultar em um alto nível de interdependência entre o cliente e a empresa fornecedora. No mesmo sentido, a adoção de SaaS pode reduzir a capacidade da empresa para reagir rapidamente as novas forças internas (por ex., alinhando-se com as novas estratégias de negócios) e forças externas (por ex., aproveitando novas oportunidades de mercado). A redução da capacidade pode ser motivada pelo fato do provedor de SaaS ter controle total sobre o desenvolvimento e manutenção de aplicativos. (BENLIAN e HESS, 2011). Desta forma, as organizações podem entender que determinados sistemas de informação, em função da sua criticidade para o negócio e da necessidade da manutenção sob seu controle, em especial dos dados, não podem ser contratados ou oferecidos na nuvem. Isto ainda pode ocorrer quando as regras de negócio do sistema podem representar uma vantagem competitiva para aquela organização, dentro do segmento em que opera. (CHAVES e SOUSA, 2012). (B1)

Falta de capacidade técnica: projetar e implantar um ambiente de $\mathrm{CN}$ é um grande desafio técnico; centenas ou milhares de computadores e servidores devem ser adquiridos, instalados com algum grau de interação e ter sua utilização gerenciada. Soluções complexas de software têm que ser desenvolvidas e disponibilizadas em regime 24x7 (MILLER, 2008). (B2)

Deficiências do modelo de negócio: são aquelas relacionadas à viabilidade econômico-financeira do fornecedor. A capacidade do fornecedor de prosperar e prosseguir na atividade podem ser fatores inibidores da disposição dos clientes em aderir aos serviços da nuvem. Nos modelos de serviços da CN, em geral, a remuneração é feita pelos serviços consumidos pelos clientes, ao invés de pagamentos à vista no momento da aquisição das licenças ou da renovação do contrato de manutenção das aplicações. Mudanças na forma da remuneração tradicional de produtos pela remuneração dos serviços, típicas do modelo SaaS, 
podem gerar problemas no fluxo de receitas do fornecedor, que podem comprometer sua viabilidade econômico-financeira (MILLER, 2008). (B3)

Maturidade do fornecedor: os consumidores receiam que os fornecedores, como resultado da complexidade técnica e contratual e o ineditismo para as organizações e consequente pouco tempo de maturação destes temas, não estejam preparados para tratá-los de forma satisfatória, ocasionando eventualmente dificuldades no relacionamento, especialmente em médio e longo prazos (MARKS e LOZANO, 2010). (B4)

Falhas de segurança: quando um cliente utiliza SaaS, alguns, ou até mesmo todos, os dados serão armazenados no data center do provedor do serviço. Estes clientes permitem um acesso direto do fornecedor sobre aos seus dados (e, portanto, sobre ativos valiosos), sem saber exatamente como este provedor vai protegê-los e quais são os procedimentos de backup e recuperação de desastres disponíveis no site. (BENLIAN e HESS, 2011). Acordos de Nível de Serviço (SLAs) podem ser usados para indicar os níveis exatos de segurança de dados que devem ser mantidos. No entanto, a experiência do cliente na aquisição de software através de um provedor de serviços é muitas vezes pequena, dificultando a indicação destes níveis exatos nos acordos. Ambiguidades e/ou lacunas no contrato poderá gerar comportamento oportunista por parte do fornecedor (WILLCOCKS e FITZGERALD, 1993). Além disso, a natureza das tecnologias baseadas na Internet e incertezas ambientais ainda são imprevisíveis. A perspectiva de falhas de segurança, como roubo ou corrupção de dados, podem, portanto, causar ansiedade e desconforto em reais e potenciais clientes de SaaS (KERN et al., 2002).

Além destas questões ligadas diretamente ao cliente do serviço, seu fornecedor pode tê-lo implantado no modelo de Infraestrutura como Serviço (laaS). Neste modelo, são alocados recursos de computação, representados pelas máquinas virtuais, que consistem de sistemas operacionais e aplicativos (CHUDNOV, 2010). Migrar para este modelo apresenta diversos riscos de segurança. Além da segurança física e dos dados da organização, existem as questões técnicas, legais e políticas (MATHER at al., 2009). Possíveis vulnerabilidades internas e externas podem fazer com que os dados dos clientes dos 
serviços na nuvem possam ser acessados indevidamente ou mesmo violados (MILLER, 2008; MARKS e LOZANO, 2010).

Portanto, o modelo de riscos deve cobrir todos os aspectos dos requisitos de segurança, incluindo segurança física, segurança dos dados, questões políticas, técnicas e legais (MATHER at al., 2009) (B5)

Tradição comportamental: segurança, latência, níveis de serviço e disponibilidade são problemas que, com razão, preocupam os executivos de TI quando da adoção da CN. No entanto, há uma barreira mais importante de natureza cultural, que pode gerar desconfianças e incertezas. Esta barreira pode ser representada pela necessidade do cliente abandonar o modelo tradicional da $\mathrm{TI}$, no qual os recursos físicos e lógicos de TI para suportar os negócios das organizações são mais tangíveis (MILLER, 2008).

Outro aspecto é que, além de influenciar a percepção de risco no nível da empresa, o "outsourcing" também pode afetar a vida pessoal dos gerentes responsáveis pela terceirização do aplicativo. Riscos empresariais, que estudos anteriores também chamados riscos psicossociais (GEWALD e DIBBERN, 2009), é a possibilidade de que a reputação pessoal e profissional do gestor responsável pela aplicação venha a ser prejudicada se o software é proveniente de um prestador de serviços externo. Os meios de comunicação muitas vezes associam empreendimentos de terceirização com eventos negativos, tais como perda de emprego e nos acordos de outsourcing malsucedidos. Isso pode afetar a forma como os gestores são percebidos por seus pares, clientes e funcionários (BENLIAN e HESS, 2011). (B6)

Disponibilidade: os serviços requerem uma conexão de internet constantemente disponível. Se isto não ocorrer, estas quedas das conexões podem resultar em indisponibilidade da aplicação, resultando em prejuízos ou perdas de receitas para a organização (SOMMERVILLE, 2003; MILLER, 2008). (B7)

Desempenho: são as possibilidades do SaaS não poder entregar o nível esperado de serviço. Ou seja, não oferecer a disponibilidade de aplicativos e/ou largura de banda de rede como o provedor, inicialmente prevista (GEWALD e DIBBERN, 2009). Interrupções do sistema e problemas de conectividade podem 
afetar todos os clientes de uma só vez, o que implica um alto potencial em risco (KAUFFMAN e SOUGSTAD, 2008). Além disso, os riscos de desempenho incluem a ocorrência de problemas relacionados com a interoperabilidade do aplicativo SaaS com aplicativos caseiros localizados no lado do cliente. Perdas potenciais devido a riscos de desempenho podem ser significativas porque as operações do dia-a-dia não vão ser perfeitamente suportadas. Essa falta de suporte leva a ineficiência organizacional, ou até mesmo danos graves à reputação da organização, quando processos orientados para o cliente são afetados (BENLIAN e HESS, 2011). As fontes potenciais de falha são: incapacidade de fornecer recursos acordados, falta de recursos dos fornecedores e gestão pobre do Service Level Agreement (SLA) (GEWALD e DIBBERN, 2009). (B8)

Confiabilidade: os consumidores esperam que os ambientes de $\mathrm{CN}$ sejam confiáveis e que a disponibilidade dos serviços e recursos oferecidos atenda integralmente às suas necessidades, em especial àquelas relacionadas aos aspectos críticos dos negócios. Assim, a CN depende, fundamentalmente, de confiabilidade; se os consumidores sentem que não podem tê-la na plenitude, relutam em aderir a este modelo de serviços. (MARKS e LOZANO, 2010). (B9)

Acordos de nível de serviço (SLAs) e qualidade: dizem respeito à capacidade do fornecedor em garantir disponibilidade e dispor de recursos para atender a contingências. Estão expressos nas cláusulas do contrato de serviço, onde os seus parâmetros de atendimento estão formalmente definidos, bem como as sanções quando do seu não cumprimento (MARKS e LOZANO, 2010). (B10)

\subsection{Alinhamento estratégico da Tl ao Negócio}

As vantagens e os desafios da $\mathrm{CN}$, como foram apresentados em 2.4, tornam-se particularmente importantes se efetivamente puderem contribuir com 0 alinhamento estratégico da TI ao negócio. Em um ambiente de negócios sujeito a rápidas mudanças, a $\mathrm{CN}$ pode contribuir na elaboração ou no apoio de estratégias que acompanhem essas mudanças. A CN pode contribuir com uma área de TI, cuja capacitação e infraestrutura possam prover os recursos para que as organizações consigam operar neste novo ambiente. 


\subsubsection{Modelo de Alinhamento Estratégico}

O Modelo de Alinhamento Estratégico de Henderson e Venkatraman (1993) identifica dois tipos de integração entre os domínios do negócio e TI. O primeiro, chamado de integração estratégica, faz a ligação entre a estratégia de negócios e a estratégia de $\mathrm{Tl}$, refletindo os componentes externos. Mais especificamente, lida com a da função TI tanto apoiando, quando dando forma a estratégia de negócio. Esta capacidade é particularmente importante uma vez que a TI tem sido uma fonte de vantagens estratégica para as organizações.

Henderson e Venkatraman (1993) destacam em seu modelo a existência de múltiplas relações entre os domínios, que devem ser analisadas para que se obtenham resultados satisfatórios, indicando a necessidade de serem especificados dois tipos de integração entre os domínios do negócio e de TI:

- Ajuste estratégico: que é a ligação entre a estratégia de negócio e a Tl; é a capacidade da TI tanto de suportar como modelar estratégias de negócio.

- Integração operacional: que é a ligação entre a infraestrutura e processos de negócio e a infraestrutura e processos de TI.

\subsubsection{Perspectivas de alinhamento impulsionado pela área de negócios}

O modelo de direcionadores do alinhamento estratégico apoia-se no modelo de Henderson e Venkatraman (1993) que, em função dos conceitos apresentados, torna-se importante para a compreensão do papel estratégico da adoção da CN, que é um dos elementos essenciais do objeto de estudo deste trabalho desta pesquisa.

O modelo de Luftman, Lewis e Oldach (1993), apresentado na Figura 5, incorpora quatro perspectivas estratégicas dominantes de direcionamento da promoção do alinhamento estratégico ao modelo original (Figura 4), sendo cada uma delas composta pelos seguintes elementos: uma "âncora" que significa a área que dirige as forças de mudança sobre um domínio, um "domínio pivô" que se refere à área-problema atacada e um "domínio de impacto" que representa a área afetada pela mudança no domínio pivô. 


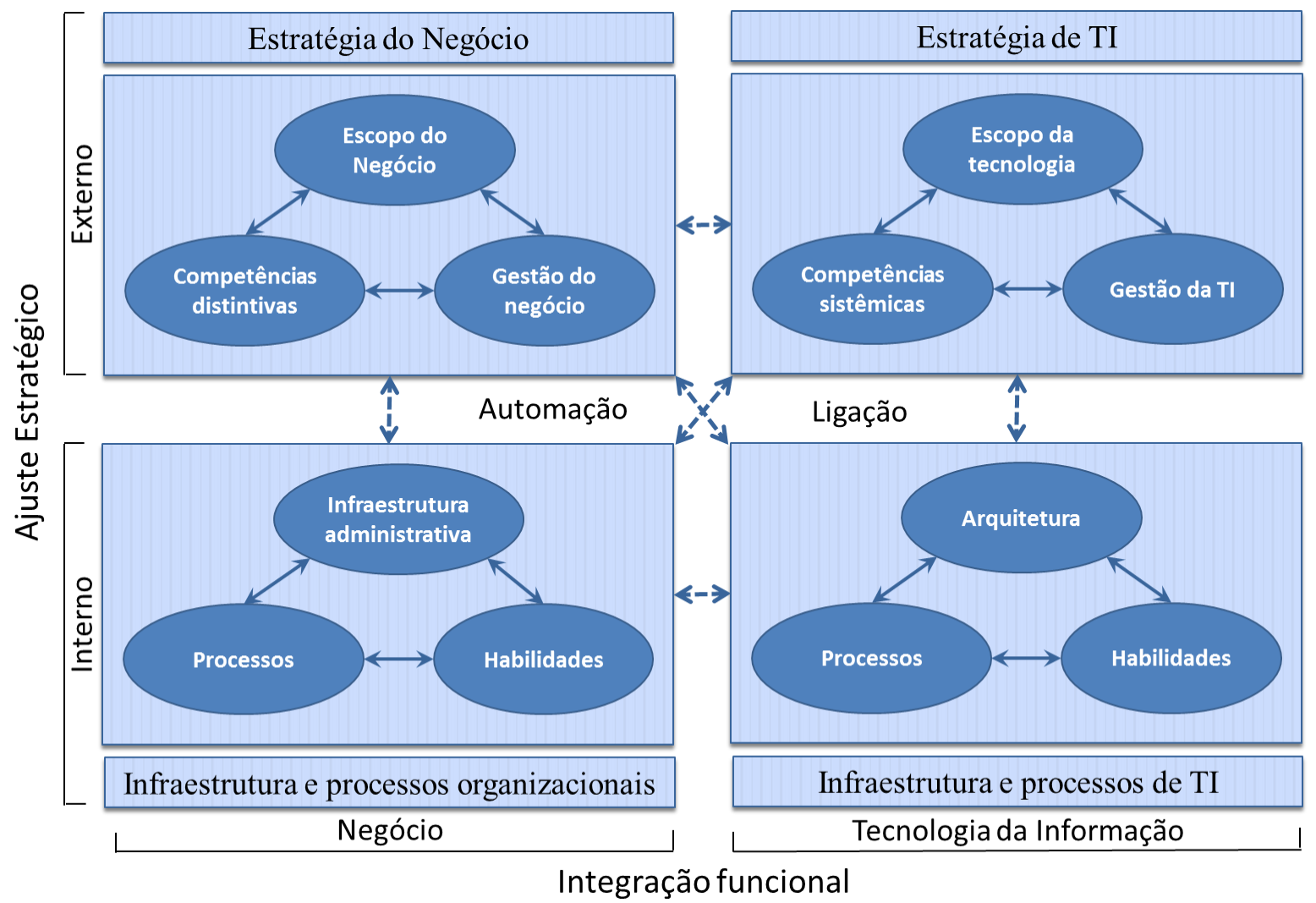

FiguRA 4 - MODELO DE ALINHAMENTO ESTRATÉGICO

FonTE: Adaptada de Henderson e Venkatraman (1993)

Execução da estratégia $\rightarrow$ as estratégias de negócio (domínio âncora) fluem pela infraestrutura organizacional (domínio pivô) até a infraestrutura de TI (domínio impactado). Nessa perspectiva, entende-se que as estratégias de negócio são suportadas pela infraestrutura da organização e da TI. A TI, nesse caso, é representada pelo portfólio de $\mathrm{TI}$, ou seja, o conjunto de equipamentos (hardware), programas (software) e sistemas de rede e comunicação disponíveis para suportar o negócio e as novas estratégias estabelecidas.

Transformação tecnologia $\rightarrow$ mantém o foco no estabelecimento do ajuste estratégico para a TI, ou seja, a TI é usada para habilitar novas estratégias de negócio. Os relacionamentos fluem no sentido das estratégias de negócio (domínio âncora) para as estratégias de TI (domínio pivô), as quais articulam ou sustentam as estratégias de negócio por meio de uma adequada infraestrutura de TI (domínio impactado). Para Laurindo (2008), a estrutura de TI não é restringida pela estrutura de organização de negócio, que permanece inalterada no ciclo de alinhamento. $O$ 
critério de desempenho baseia-se em liderança tecnológica, buscando o uso inovador da TI para implementar uma nova estratégia de negócio.

Potencial competitivo $\rightarrow$ reflete como a tecnologia emergente poderia influenciar ou habilitar novas estratégias de negócio, como novas oportunidades de mercado. A perspectiva mostra a interação entre a estratégia de TI (domínio âncora), estratégia de negócio (domínio pivô) e infraestrutura organizacional e processos (domínio impactado). Essa situação mostra como a perspectiva de $\mathrm{TI}$ pode ser aplicada para implementar as estratégias de negócio de forma mais intensa.

Nível de serviço $\rightarrow$ a situação da primeira perspectiva é retomada, porém o pivô é a infraestrutura de TI, e não a estratégia de negócio. A compreensão dessa perspectiva passa pela análise de qual seria o impacto se a TI falhasse, ou seja, se ocorre uma falha na TI, então ela impacta na infraestrutura do negócio não lhe dando suporte. Como consequência, a infraestrutura do negócio pode causar uma falha à estratégia do negócio enquanto está sendo executada. Para Laurindo (2008), esta perspectiva visa à construção de uma organização "classe mundial" em se tratando de serviços de TI. Empresas em que a TI não representa um papel estratégico relevante são candidatas a adotarem esta perspectiva, na qual a TI aparece como um "negócio dentro de um negócio" podendo levar à terceirização dos serviços de TI. Assim, a terceirização pode ser explicada pela aplicação desta perspectiva (LAURINDO, 2008).

Essas perspectivas variam de acordo com o foco e as práticas gerenciais da organização. Para esta pesquisa, esse modelo pode contribuir para uma melhor compreensão do papel da CN, observando a sua adoção como ferramenta capaz de favorecer ou inibir o alinhamento. Luftman (1996) e Luftman et al. (1999), discutindo - Modelo de Alinhamento Estratégico apresentaram uma lista de fatores que favorecem (ou viabilizam) o alinhamento e fatores que o inibem. No presente trabalho, tais fatores são considerados como sendo as vantagens, desafios, riscos e barreiras, como apresentados em 2.4. 

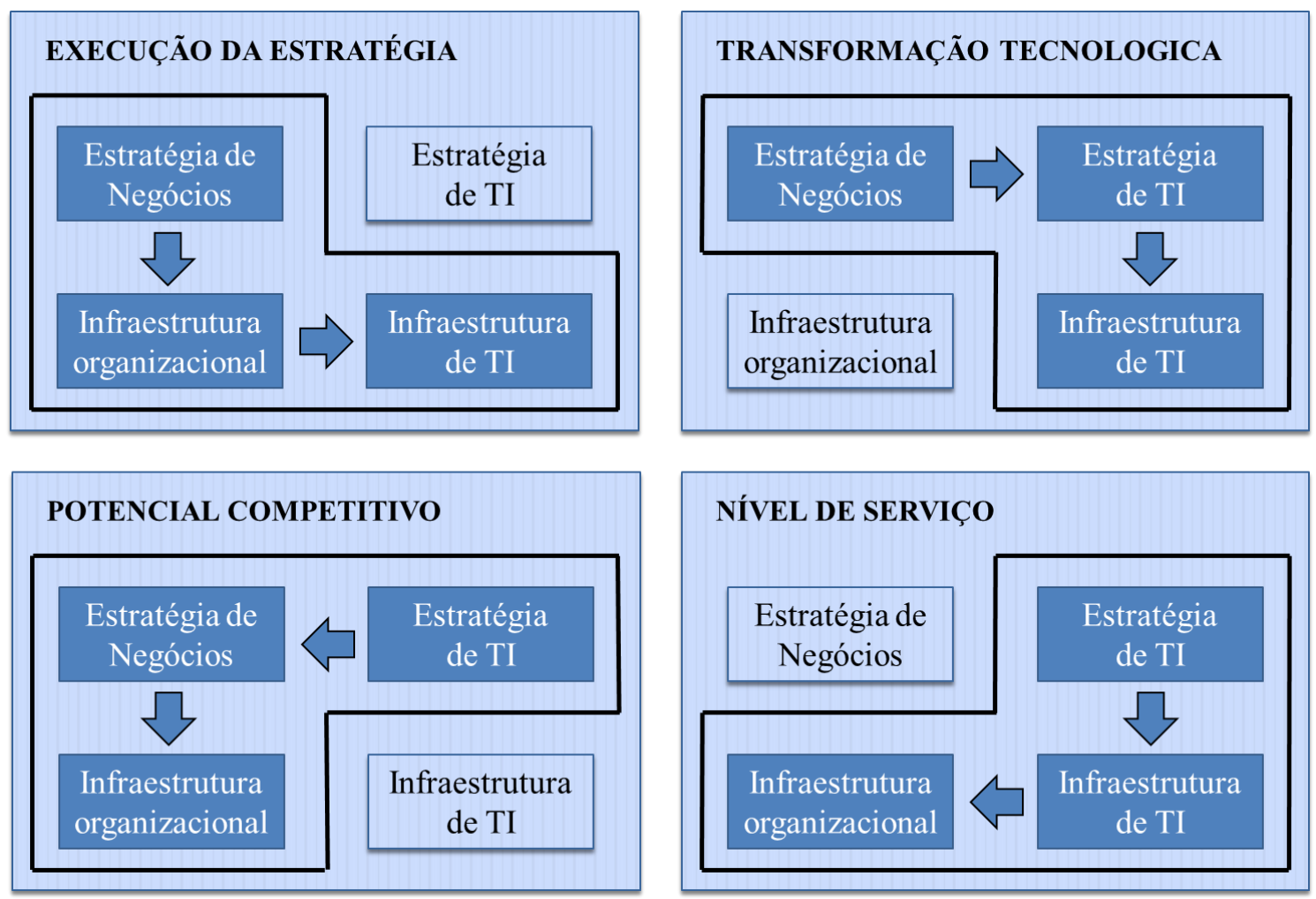

FIGURA 5 - PERSPECTIVAS DE ALINHAMENTO ESTRATÉGICO

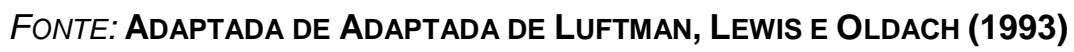

Uma das críticas mais ferrenhas ao modelo de Henderson e Venkatraman (1993) foi apresentada por Ciborra (1997), ao interpretar os modelos de alinhamento estratégico através de uma visão subjetiva, argumentando que ele não pode ser tratado tão objetivamente como vem sendo feito pelos estudos anteriores (McFARLAN, 1984; HENDERSON e VENKATRAMAN, 1993; LUFTMAN et al. 1993). Ciborra (1997) contempla que o alinhamento estratégico não é uma simples atividade de gestão; para este autor, dado que o alvo está em constante movimento, incorporando mais do que simples avaliação de elementos e estruturas organizacionais prontas e fechadas. Desta forma, para Ciborra (1997), o alinhamento estratégico pode requerer improvisação e oportunismo, sendo este o maior desafio dos que buscam por ele. Essa visão crítica é compartilhada por Chan (2002) quando revisita os estudos de alinhamento estratégico.

Para Laurindo (2008), é premissa do modelo de alinhamento estratégico a administração eficaz da $\mathrm{TI}$, que deve ser um processo contínuo, uma vez que os fatores externos estão em constante mutação. Se a empresa não estiver 
acompanhando estas mudanças, pode ser seriamente prejudicada na acirrada competição pelo mercado (LAURINDO, 2008). Isto é particularmente verdadeiro quando uma nova tecnologia é adota pela maioria das empresas de um ramo de atividade, deixando de ser um fator de vantagem competitiva para aqueles que a detém, para ser um fator de desvantagem para quem não a utiliza (LUFTMAN, 1996).

McAfee (2011) questiona quais seriam as implicações de negócios da adoção relutante de $\mathrm{CN}$. Pondera que, se o impacto da nuvem for apenas sobre os orçamentos das empresas de $\mathrm{TI}$, as implicações seriam menores. Mas, para o autor, este não é este o caso; a CN oferece vantagens como aumento da produtividade, colaboração, análise e desenvolvimento de aplicações, entre outros, que podem com o decorrer das mudanças, representar desvantagem para as empresas que não utilizam a CN, produzindo o resultado descrito por Luftman (1996).

\subsection{Capacidades essenciais e principais tarefas da TI}

Fenny e Willcocks (1998) publicaram em seu trabalho original um modelo ("framework") com as tarefas principais e as "core capabilities", sempre referidas neste trabalho como capacidades essenciais, para a entrega dos serviços e para a gestão da área de TI das organizações. No trabalho focando o alto desempenho da TI nas organizações e questões trazidas pela necessidade de terceirização, os autores sintetizaram os resultados em um quadro de gestão e de governança de $\mathrm{TI}$, sugerindo quatro tarefas da função que precisam ser desempenhadas para a construção do futuro da Tl e as nove capacidades essenciais necessárias dentro da organização ("in-house”) para gerenciar qualquer contrato ou acordo de terceirização de TI (FEENY E WILLCOCKS, 1998).

Quando revisitado em 2006 (WILLCOCKS et al., 2006), através de um estudo de casos longitudinal, o trabalho revelou uma série de omissões e problemas resultantes quando não é dada a devida importância para a manutenção da capacidade de planejamento da arquitetura técnica; para os recursos necessários para as tarefas de liderança orientadas ao negócio, juntamente com o planejamento para assegurar seu futuro; para a garantia da compra informada e para a construção das capacidades para gerir o fornecimento externo e 0 aprimoramento do 
desempenho dos fornecedores e para garantir que as tarefas operacionais, tais como a construção de relacionamento (para as unidades de negócios) e da elaboração de contrato, estão disponíveis e podem ser desempenhadas (WILLCOCKS, FEENY e OLSON, 2006).

Finalmente, os autores Willcocks et al. (2012) novamente resgatam o "framework" com as tarefes e as capacidades essenciais considerando os desafios encontrados para a gestão da área de $\mathrm{TI}$ das organizações, incluindo os da computação em nuvem. Destes trabalhos é extraído o constructo "capacidades essenciais" que será utilizado na construção do Método de Análise.

\subsubsection{Principais tarefas para a entrega dos serviços da $\mathrm{TI}$}

Willcocks et al., (2012) apresentam o que chamam de tarefas principais para gestão da Tecnologia da Informação. Estas tarefas são fundamentais para o entrega dos serviços da TI necessários aos negócios. Para estes autores, elas representam a base sobre as quais emergem os cincos desafios (D1 até D5), que precisam ser enfrentados por aqueles que hoje se utilizam do modelo tradicional de infraestrutura de TI. Para Willcocks et al. (2012), o grupo interno responsável pela plataforma de tecnologia e aplicações, incluindo a nuvem, tem de cumprir as quatro tarefas principais (estão identificadas como T1 até T4):

Governança, incluindo organização, liderança e coordenação: refere-se aos "padrões de autoridade para as principais atividades de TI" (SAMBAMURTHY e ZMUD, p. 261, 1999) e os mecanismos de governança de TI que determinam como comunicação, responsabilidades e estruturas de tomada de decisão são formalizadas (WEILL e ROSS, 2005). Envolve o alinhamento de forma dinâmica das atividades da função da TI internamente e com as demais áreas da organização (WILLCOCKS et al., 2012). (T1)

Elicitação e cumprimento dos requisitos de negócios: é uma tarefa orientada pela demanda, preocupada com a definição de sistemas, informações e processos a serem prestados e como eles podem ser aproveitados para fins comerciais. (WILLCOCKS et al., 2012). (T2) 
Gestão da oferta externa: diz respeito à gestão da estratégia de "sourcing". Exige entendimento do mercado de serviços externos e a capacidade de selecionar, contratar e gerenciar recursos e serviços internos e externos de tecnologia e da nuvem, ao longo do tempo (envolve a prestação de serviços - são as tarefas necessárias para gerenciar e garantir o abastecimento externo) (WILLCOCKS et al., 2012). (T3)

Assegurar capacidade técnica: trata-se da tarefa de fornecimento focada na definição do projeto ou arquitetura da plataforma técnica utilizada ao longo do tempo para apoiar os sistemas fim e processos e lidar com os riscos inerentes às questões técnicas não rotineiras (WILLCOCKS et al., 2012). (T4).

As capacidades essenciais dizem respeito as habilidades, as técnicas e aos meios necessários para a execução destas tarefas.

\subsubsection{Capacidades essenciais para a gestão da TI}

O objetivo da Gestão da Função TI (MNG) é possibilitar a integração dos fatores (vantagens, desafios, riscos e barreiras), mostrando que a adoção (e a posterior gestão e novas decisões de aquisição) permeia as diversas áreas de capacidades. Por exemplo, Objetivos de Negócios (BOB) e Gestão da Função TI (MNG) estão diretamente relacionados ao alinhamento estratégico da $\mathrm{TI}$ com os objetivos estratégicos da organização. Para Laurindo (2008), as aplicações da TI possibilitam novas estratégias de negócio e novas possibilidades para as organizações. No entanto, como há grande questionamento sobre os reais ganhos dos investimentos em TI, é necessário ter uma visão clara da estratégia de TI, que dever estar em alinhamento com a estratégia de negócios (LAURINDO, 2008).

Tendo por objetivo identificar eventuais contribuições da CN para o alinhamento estratégico da $\mathrm{TI}$ aos negócios da organização adotou-se como referência o Modelo Henderson e Venkatraman (1993).

1. Gestão da Função TI (MNG) - área de capacidades que tem como responsabilidade a "integração dos esforços da $\mathrm{TI}$ com os objetivos e atividades do negócio". São as práticas associadas à tecnologia da informação que consistem a capacidade de uma empresa gerenciar suas 
aplicações de tecnologia de informação e infraestrutura para sustentar suas operações, processos empresariais, tomada de decisão gerencial e inovação (MARCHAND et al., 2001). Responsável por (T1), tem como principal tarefa criar os arranjos organizacionais - estruturas, processos e recursos humanos - para gerir com sucesso as interdependências e garantir que a função de $\mathrm{TI}$ agregue valor ao capital investido (WILLCOCKS et al., 2006).

2. Objetivos de Negócios (BOB) - Responsável por (T2), tem por objetivo "garantir que as capacidades e as tecnologias específicas de TI estejam previstas em cada processo de negócio". Nas organizações com as melhores práticas, os estrategistas de negócios, a partir da função da TI, são importantes contribuintes para as equipes encarregadas de desenvolver oportunidades de novos negócios, reengenharia de processos, desenvolvimento de estratégicas de marketing e entrega dos serviços (WILLCOCKS et al., 2006).

3. Atributos da Qualidade dos Serviços (QAS) - Responsável por (T3), necessita das seguintes capacidades: a) compra especializada - implica na análise do mercado dos fornecedores de TI e de serviços especializados, na seleção de uma estratégia de "sourcing" para atender às necessidades de negócios e questões de tecnologia, elaboração das propostas, contratação e processos de gerenciamento de serviços. Em organizações que decidiram terceirizar seus serviços de $\mathrm{TI}$, o comprador especializado tem um dos papéis mais importante dentro da estrutura da área de $\mathrm{Tl}$; b) gestor dos contratos - tem por atribuição "garantir o sucesso dos contratos existentes para a execução dos serviços de TI". O gestor dos contratos busca assegurar que os problemas e os conflitos sejam resolvidos satisfatoriamente, procurando ao mesmo tempo a manutenção de relacionamentos de longo prazo com os fornecedores/parceiros; c) monitoramento de contratos - desempenha um papel de interface com os fornecedores, buscando assegurar 0 desempenho dos serviços conforme estabelecidos nos contratos e de acordo com os padrões de fornecimento existentes no mercado; e 
finalmente, d) desenvolvimento de fornecedores - "procura identificar o potencial valor acrescentado da TI e dos prestadores de serviços especializados". O trabalho de desenvolvimento dos fornecedores preocupa-se com o potencial de longo prazo para agregação de valor, criando as situações onde há vantagens para ambos ("ganha-ganha"), em que os fornecedores aumentam suas receitas pela prestação de serviços, que por sua vez, aumentam benefícios para o negócio (WILLCOCKS et al., 2006).

4. Decisões de Arquitetura (ARC) - Responsável por (T4), são as capacidades necessárias para: a) o projeto da plataforma técnica - "criar um modelo coerente de uma arquitetura corporativa de $\mathrm{TI}$ que responda às necessidades de negócios atuais e futuras". O principal desafio para o arquiteto corporativo é antecipar tendências de tecnologia, de forma que a organização seja consistentemente capaz de operar a partir de uma plataforma eficaz e eficiente; b) tornar da tecnologia disponível - "resolver rapidamente problemas que não foram solucionados por outros indivíduos em toda a cadeia de abastecimento técnico e identificar como lidar com as necessidades de negócios que não podem ser adequadamente satisfeitas por abordagens técnicas padrão" (WILLCOCKS et al., 2006).

\subsection{Modelo de decisão para adoção da computação em}

\section{nuvem}

Em seu trabalho sobre a sistematização do processo de decisão sobre adoção da CN, Kaisler et al. (2012) propuseram a utilização de um modelo ("framework") para apoiar a tomada de decisões relacionadas à nuvem. Estes autores formularam um modelo de decisão hierárquico em três camadas para avaliar os tipos de decisões necessárias para mover os serviços para a nuvem, total ou parcialmente, ou ainda, talvez alguns serviços, mas não todos. O modelo é resultado de uma análise da literatura feita pelos autores (KAISLER et al., 2012), que revelaram Objetivos de Negócios, Atributos da Qualidade dos Serviços e Decisões de Arquitetura (curto e longo prazo) como áreas para avaliação (Figura 
6). Em ordem decrescente, a organização deve decidir a importância de vários fatores e de como eles contribuem para a decisão de adoção (ou não) da nuvem.
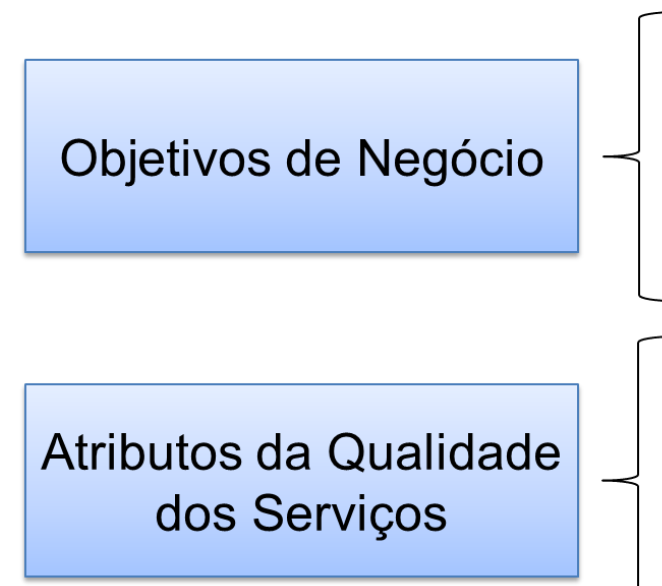

Decisões de Arquitetura
Custo total de operação (TCO); agilidade; participação de mercado/potencial de crescimento; "compliance"; serviços aos clientes; qualidade dos produtos/serviços; margens de lucro; etc.

Disponibilidade dos serviços; desempenho; custo; interoperabilidade interna e externa; adaptabilidade; segurança; mitigação de riscos; etc.

Escalabilidade dos serviços e do armazenamento; particionamento centralizado $x$ distribuído; comunicações assíncronas; baixo acoplamento; "map reduce"; componentes "stateless"; etc.

FIGURA 6 - MODELO DE DECISÃO

FONTE: (KAISLER ET AL., P. 1557, 2012)

Este modelo de decisão é um dos elementos que serão utilizados por este autor para a construção do Método de Análise para a adoção da $\mathrm{CN}$, proposto no escopo deste trabalho. 


\section{METODOLOGIA}

Para Miguel (2007), a escolha de uma abordagem metodológica adequada para um trabalho de pesquisa envolve diferentes níveis de abrangência e profundidade. Assim, para o autor, algumas decisões metodológicas são de ordem estratégica (escolha da metodologia de pesquisa mais adequada para o tratamento da questão de pesquisa), enquanto que outras são de nível mais tático ou operacional (decisões relativas aos procedimentos para condução da pesquisa) (MIGUEL, 2007). Neste trabalho esses dois níveis, propostos por Miguel (2007), são discutidos em 3.1, onde é tratada a escolha da metodologia de pesquisa e em 3.5 onde é apresentado o protocolo da pesquisa.

Esta é uma pesquisa de natureza exploratória, objetivando fornecer uma melhor compreensão da $\mathrm{CN}$, do contexto e do problema apresentados, quando propõe um Método de Análise para adoção da $\mathrm{CN}$ e quando examina a viabilidade da sua aplicação. Também tem natureza prescritiva na medida em que os resultados das aplicações do Método de Análise trazem evidências da sua relevância nos processos de contratação e gerenciamento dos serviços de $\mathrm{CN}$. $\mathrm{Ou}$ seja, pode subsidiar tomada de decisão para aquisição, contratação e a operação dos serviços e para a escolha e contratação de serviço em nuvens nas organizações de grande porte.

Neste capítulo é apresentada a metodologia da pesquisa utilizada e o planejamento para o seu desenvolvimento, descrevendo os seguintes pontos: escolha da metodologia de pesquisa, onde aparece a questão central de pesquisa e as questões desdobradas da questão central (com a descrição de como foram identificadas as questões relevantes, que serviram de base para construção do Método de Análise para adoção da CN a partir da revisão da literatura). Seguem a definição da pesquisa e construção do referencial teórico, as proposições do estudo, estruturas e etapas do estudo de casos, protocolo da pesquisa, delimitação do escopo, construção do roteiro de pesquisa, proposta do teste piloto e seus resultados. Na sequência aparecem os critérios utilizados na seleção das empresas, com a justificativa para a escolha de organizações de grande porte como unidades 
de análise para o trabalho de campo e a coleta dos dados, e encerrando o capítulo, as oportunidades para análises dos dados coletados.

\subsection{Escolha da metodologia de pesquisa}

Uma vez tendo sido determinado o problema, é preciso escolher a metodologia de pesquisa através do qual o pesquisador procurará responder os questionamentos que dele se originam. Foram identificados diversos trabalhos relacionados ao tema com o objetivo de sistematizar e subsidiar o processo de escolha (FILIPPINI, 1997; FILIPPINI e VOSS, 1997; BERTO e NAKANO, 2000; MIGUEL, 2007; MIGUEL, 2010).

Filippini (1997) sintetiza as abordagens metodológicas de pesquisa tipicamente utilizadas na engenharia de produção da seguinte forma:

- Experimento: estudo da relação causal entre duas variáveis de um sistema submetido às condições controladas pelo pesquisador;

- Modelagem: uso de técnicas matemáticas para descrever o funcionamento de um sistema ou de parte de um sistema produtivo;

- Simulação: utilização de técnicas computacionais para simular o funcionamento de sistemas produtivos a partir de modelos matemáticos;

- Survey: uso de instrumento de coleta de dados único (geralmente um questionário), aplicado a uma amostra de tamanho adequado, com o uso de técnicas de amostragem e análise e inferência estatística;

- Estudo de Caso: análise aprofundada de um ou mais objetos (casos), com o uso de múltiplos instrumentos de coleta de dados e presença da interação entre pesquisador e objeto de pesquisa;

- Pesquisa-ação: abordagem na qual o pesquisador intervém no contexto investigado e é desenvolvido com coparticipação dos envolvidos;

- Estudo de Campo: outros métodos empíricos de pesquisa (principalmente de abordagem qualitativa), geralmente com a presença de dados de campo, sem estruturação formal do método de pesquisa;

- Teórico/conceitual: discussões conceituais a partir da literatura, revisões bibliográficas e modelagens conceituais. 
Mais recentemente, Miguel (2007) resume as pesquisas mais comuns em engenharia de produção e gestão de operações, como sendo principalmente as dos tipos:

- Desenvolvimento teórico-conceitual: Ainda que desenvolvimentos teóricos possam advir de discussões conceituais da literatura ou de revisões bibliográficas (BERTO e NAKANO, 2000), seu escopo principal envolve modelagens conceituais que resultam em novas teorias.

- Estudo de caso: investiga empiricamente um determinado fenômeno, geralmente contemporâneo, dentro de um contexto real de vida, quando as fronteiras entre o fenômeno e o contexto em que ele se insere não são claramente definidas. Trata-se de uma análise aprofundada de um ou mais objetos (casos), permitindo o seu amplo e detalhado conhecimento (GIL, 1996; BERTO e NAKANO, 2000). Seu objetivo é aprofundar o conhecimento de um problema não suficientemente definido (MATTAR, 1996), visando estimular a compreensão, sugerir hipóteses e questões ou desenvolver a teoria.

- Levantamentos tipo survey: compreende um levantamento de dados em uma amostra significativa relacionada ao problema a ser estudado para, em seguida, mediante análise quantitativa, obterem-se as conclusões correspondentes aos dados coletados (GIL, 1996). Têm como objetivos contribuir para o conhecimento em uma área particular de interesse por meio da coleta de informações sobre indivíduos ou sobre os ambientes desses indivíduos (FORZA, 2002).

- Modelamento e Simulação: compreende o uso de técnicas matemáticas para descrever o funcionamento de um sistema ou parte de um sistema produtivo (BERTO e NAKANO, 2000). O uso de técnicas computacionais permite a simulação da operação de sistemas produtivos, que baseados em um conjunto de variáveis de um determinado domínio da aplicação, possibilitando a investigação de relações causais entre essas variáveis (BERTRAND e FRANSOO, 2002).

- Pesquisa-ação: com base empírica que é concebida e realizada em estreita associação com uma ação ou com a resolução de um problema 
coletivo e na qual os pesquisadores e participantes representativos da situação ou do problema estão envolvidos de modo cooperativo ou participativo (THIOLLENT, 1997).

- Pesquisa bibliográfica/revisão da literatura: apresentam-se como uma atividade importante para identificar, conhecer e acompanhar o desenvolvimento da pesquisa em determinada área do conhecimento (NORONHA e FERREIRA, 2000). As revisões, além de possibilitar a cobertura de uma gama de fenômenos geralmente mais ampla do que aquela que poderia ser pesquisada diretamente (GIL, 1996), permitem a identificação de perspectivas para pesquisas futuras, contribuindo com sugestões de ideias para o desenvolvimento de novos projetos de pesquisa (NORONHA e FERREIRA, 2000).

- Pesquisas experimentais: tratam de um estudo sobre a relação causal entre duas ou mais variáveis de um sistema sob condições controladas pelo pesquisador, geralmente conduzidas em laboratórios.

Embora usualmente apenas um método de pesquisa venha a ser escolhido, importante destacar que esta não é necessariamente uma regra, podendo ser escolhidos mais que um método de pesquisa em um mesmo trabalho (MIGUEL, 2007; MIGUEL, 2010).

O desenvolvimento do Método de Análise para a adoção da CN tem natureza de pesquisa exploratória (ou seja, uma investigação de pesquisa empírica, cujo objetivo é a formulação de questões ou de um problema, com finalidade de desenvolver hipóteses, aumentar a familiaridade do pesquisador com um ambiente, fato ou fenômeno, para a realização de uma pesquisa futura mais precisa). Senão vejamos, o método foi elaborado como consequência dos primeiros passos deste trabalho científico, onde se verificou a possibilidade da sua construção apoiado na bibliografia sobre a $\mathrm{CN}$, também motivado pela identificação e consolidação da questão de pesquisa. Assim, como um desenvolvimento inicial do esforço de pesquisa, este trabalho exploratório visou oferecer informações sobre o assunto, definir os objetivos da pesquisa e orientar a formulação da hipótese. 
Além disto, a partir da viabilidade da aplicação do Método como observado nos estudos de caso, este trabalho têm como resultado potencial recomendar (ou prescrever) a sua aplicação, como uma ferramenta de análise para a adoção da CN. Pode também ensejar outros trabalhos, apoiados no Método de Análise aqui descrito, que possibilitem a eliminação de eventuais lacunas nele existente, bem como uma melhor sistematização para a sua aplicação.

Portanto, é da natureza deste trabalho de pesquisa promover, não apenas a descrição do que foi objetivo da pesquisa científica, mas também estabelecer em um plano ideal a prescrição da aplicação do Método de Análise, buscando uma melhor solução para os casos estudados.

Como inserida no contexto deste trabalho, a $\mathrm{CN}$ é uma modalidade de oferecimento de serviços que vem ganhando espaço significativo no atual cenário de oferecimento dos serviços de $\mathrm{Tl}$. Como consequência, vem transformando rapidamente o mundo da Tecnologia da Informação na direção do desenvolvimento de software, para que este seja consumido como um serviço por milhões, ao invés de executar em seus computadores individuais (BUYYA et al., 2009), isto possibilita que a computação se transforme em um modelo de serviços padronizados, entregues de forma semelhante àqueles das concessionárias tradicionais, como água, eletricidade, gás ou telefonia (BUYYA et al., 2009).

Esta transformação promete a realização de um sonho de longa data, a computação como uma utilidade, com potencial de transformar grande parte do setor de Tecnologia da Informação, fazendo com que o software seja ainda mais atraente como um serviço (ARMBRUST et al., 2010).

Assim, considerada como sendo um novo paradigma de computação, a CN apresenta-se com um fenômeno contemporâneo, dentro de um contexto de gestão das operações da TI, que é uma área de reconhecida importância para os negócios e para a sociedade como um todo.

A partir da análise dos métodos de pesquisa para o presente trabalho, decidiu-se pelo aprofundamento do processo de escolha nas seguintes abordagens, usualmente utilizadas em gestão de operações: Survey, Estudo de Caso e Pesquisa- 
ação. Os requisitos e características destes três métodos estão apresentados no Quadro 5, que é uma adaptação de (CORRÊA, 1992 apud MIGUEL, 2010, p.139).

QUADRO 5 - REQUISITOS E CARACTERÍSTICAS DOS MÉTODOS DE PESQUISA

\begin{tabular}{|c|c|c|c|}
\hline Requisitos/Características & Survey & Estudo de Caso & Pesquisa-ação \\
\hline Presença do pesquisador & Não Usual / Difícil & Usual & Usual \\
\hline $\begin{array}{l}\text { Tamanho pequeno da } \\
\text { amostra }\end{array}$ & Não usual & Usual & Usual \\
\hline $\begin{array}{l}\text { Variáveis difíceis de } \\
\text { identificar }\end{array}$ & Possível & Possível & Possível \\
\hline Mensurações perceptivas & Possível & Possível & Possível \\
\hline $\begin{array}{l}\text { Os constructos não são } \\
\text { predefinidos }\end{array}$ & Difícil & Adequado & Possível \\
\hline $\begin{array}{l}\text { A casualidade é central na } \\
\text { análise }\end{array}$ & Possível & Adequado & Possível \\
\hline $\begin{array}{l}\text { Necessita construir teoria - } \\
\text { responder a questões do tipo } \\
\text { "como" }\end{array}$ & Difícil & Adequado & Possível \\
\hline $\begin{array}{l}\text { Necessita de entendimento } \\
\text { do processo de decisão }\end{array}$ & Difícil & Adequado & Possível \\
\hline $\begin{array}{l}\text { Participação não ativa do } \\
\text { pesquisador }\end{array}$ & Possível & Possível & Impossível \\
\hline $\begin{array}{l}\text { Falta de controle sobre as } \\
\text { variáveis }\end{array}$ & Possível & Possível & Possível \\
\hline
\end{tabular}

FONTE: ADAPTAÇÃO DE (CORRÊA, 1992 APUD MIGUEL, 2010, P.139)

Tendo como ponto de partida o problema identificado, várias são as maneiras, ou como no caso de uma pesquisa, os métodos que podem ser adotados com o objetivo de tentar responder aos questionamentos, que são gerados para resolver o problema em pauta. Os métodos de pesquisa usualmente reconhecidos no campo da Gestão de Operação e Produção são quatro: "Survey", Estudo de Caso, Pesquisa-ação e Modelagem/Simulação. A escolha do método de pesquisa depende 
da natureza do fenômeno a ser analisado e das características nele presentes. Embora usualmente apenas um método de pesquisa seja escolhido para trabalhar uma pesquisa, não necessariamente esta é uma regra, podendo ser escolhidos múltiplos métodos em um mesmo trabalho (MIGUEL, 2007; MIGUEL, 2010).

Quadro 5 mostra os métodos e as principais características/requisitos de cada um deles.

\section{O estudo de caso como estratégia de pesquisa}

Segundo Yin (2005), os estudos de caso representam a estratégia preferida quando:

- Colocam-se questões do tipo "como" e "por que";

- O pesquisador tem pouco controle sobre os eventos; e

- O foco se encontra em fenômenos contemporâneos inseridos em algum contexto da vida real.

A necessidade pelos estudos de caso surge do desejo de se compreender fenômenos sociais complexos. Ou seja, o estudo de caso permite uma investigação para se preservar as características holísticas e significativas dos eventos da vida real.

Segundo Miguel (2007), os estudos de casos podem ser classificados de acordo com seu conteúdo e objetivo final (exploratórios, explanatórios, ou descritivos) ou quantidade de casos (caso único - holístico ou incorporado ou casos múltiplos - também categorizados em holísticos ou incorporados). Normalmente estudos de caso únicos são utilizados quando se pretende realizar estudos longitudinais. Como regra geral, a principal tendência em todos os tipos de estudo de caso é que estes tentam esclarecer o motivo pelo qual uma decisão ou um conjunto delas foi tomada, como foram implementadas e quais os resultados alcançados (YIN, 2001).

Além do método de pesquisa propriamente dito, outra questão que deve ser avaliada é a abordagem de pesquisa, que pode ser quantitativa ou qualitativa. A abordagem quantitativa é indicada para as pesquisas em que variáveis podem ser medidas, enquanto que na abordagem qualitativa a ênfase é obter informações 
sobre a perspectiva do indivíduo e observar o ambiente onde o problema ocorre. Semelhante ao método pode haver uma combinação de duas abordagens em uma mesma pesquisa (MIGUEL, 2010).

De acordo com Lacerda et. al (2013), em extensiva pesquisa sobre métodos de pesquisa adotados no âmbito dos principais periódicos internacionais da área de gestão de operações, Craighead e Meredith (2008) apontam como resultado: i) a predominância do paradigma positivista/empiricista; ii) a estabilização da pesquisa envolvendo modelagem/simulação; iii) crescimento das pesquisas de cunho interpretativista. No Brasil, em análise nos anais do ENEGEP (Encontro Nacional de Engenharia de Produção), pôde-se verificar: i) predominância dos estudos de caso; ii) predominância dos estudos empíricos; iii) reduzida participação relativa das surveys; e iv) pouca aplicação da modelagem e da simulação computacional (NAKANO, 2010).

Os tipos de pesquisa mostrados no Quadro 5 são utilizados, em maior ou menor grau, na engenharia de produção (MIGUEL, 2007), sendo o estudo de caso um dos mais adotados. Também é uma metodologia de pesquisa válida quando se deseja realizar um exame em profundidade de um fenômeno atual onde o contexto em que está inserido é importante, no qual o pesquisador não possui nenhum controle sobre os eventos (SOUZA e VOSS, 2001; VOSS et al., 2002; YIN, 2005).

Levando-se em conta o que foi anteriormente exposto e baseado na revisão bibliográfica, com propósito exploratório para o estabelecimento do problema, da questão de pesquisa e do próprio Método de Análise, esse estudo pretende utilizarse da metodologia de estudos de caso, de natureza qualitativa (ou seja, basicamente buscar entender o fenômeno da adoção da $\mathrm{CN}$ em profundidade, utilizando múltiplos casos). Ao invés de estatísticas, regras e outras generalizações, esta pesquisa qualitativa trabalha com descrições, comparações e interpretações. Utilizando-se desta abordagem o autor pretende investigar e responder a seguinte questão central da pesquisa:

QC. Como as organizações tomam decisões para adotar ou não a Computação em Nuvem? 
Para responder a esta questão, foi proposto um Método de Análise para Adoção da Computação em Nuvem, que apoiado em capacidades essenciais, conforme propostas por Willcocks et al. (2012), procura sistematizar e compreender fatores como vantagens, desafios e barreiras típicos do paradigma da computação em nuvem.

$\mathrm{Na}$ revisão da bibliografia sobre o tema foram levantados os fatores envolvidos no processo de decisão e que podem ser expressos nos questões abaixo, que são desdobradas da questão central da pesquisa:

Q1. Como organizações que adotaram ou pretender adotar a computação em nuvem procuram identificar os fatores associados, envolvidos na avaliação para esta adoção? (MILLER, 2008; MARKS e LOZANO, 2010; CHAVES e SOUSA, 2012; WILLCOCKS et al., 2012)

Q2. Como organizações que adotaram ou pretender adotar a computação em nuvem identificam as vantagens desta adoção? (SOMMERVILLE, 2003; XIN e LEVINA, 2008; MARSTON et al., 2010; BENLIAN e HESS, 2011)

Q3. Como as organizações que adotaram ou pretender adotar a computação em nuvem analisam suas capacidades essenciais (WILLCOCKS, FEENY e OLSON, 2006), relacionadas com a adoção da computação em nuvem?

Q4. A adoção da computação em nuvem pode contribuir para o alinhamento estratégico da TI com o negócio? (HENDERSON e VENKATRAMAN, 1993)

De acordo com Schramm (1971), "a essência de um estudo de caso é tentar esclarecer uma decisão ou um conjunto de decisões: o motivo pelo qual foram tomadas, como foram implementadas e com quais resultados" (SCHRAMM, 1971).

\subsection{Definição da pesquisa e construção do referencial teórico}

De acordo com Croom (2005), primeiramente é necessário definir um referencial conceitual teórico para o trabalho, de forma a resultar em um mapeamento da literatura sobre o assunto. Esse mapeamento localiza o tópico de pesquisa no contexto da literatura disponível sobre o tema (CROOM, 2005). O autor 
complementa que esse mapa indica a abrangência da literatura demonstrando como o tópico em estudo é influenciado pelas fontes bibliográficas existentes. Outra função importante nesse mapa é a identificação de trabalhos de cunho teórico ou de caráter empírico. Além disso, a partir da busca bibliográfica e revisão da literatura é possível identificar lacunas onde a pesquisa pode ser justificada (em termos de relevância), bem como possibilita extrair os constructos ${ }^{3}$. A partir desses constructos, as proposições podem ser então estabelecidas (uma ou mais proposições correspondem ao que realmente será verificado, ou seja, é a representação do constructo para fins de mensuração) (MIGUEL, 2007).

Como resultado da construção do referencial teórico, que fundamenta as questões decorrentes do problema central da pesquisa, foram estabelecidos os seguintes constructos:

- Relacionados à computação em nuvem:

- Definições, arquitetura e as tecnologias relacionadas.

- Vantagens, desafios e barreiras da computação em nuvem.

- Relacionados à gestão da Tecnologia da Informação:

- Modelo de alinhamento estratégico

- Conceito de capacidades essenciais da área de TI

- Modelo de decisão hierárquico para adoção da CN

Os constructos estão descritos em detalhes na revisão da literatura (capítulo 2) e são utilizados na elaboração do Método de Análise (capítulo 4).

Uma vez que a natureza da pesquisa é exploratória quanto ao Modelo de Análise proposto e também procura explicar a relação entre os seus constructos, ela requer obrigatoriamente uma formulação e uma demonstração das proposições que evidenciem a clareza e a precisão do modelo formulado e dos constructos utilizados (RICHARDSON, 1999; VOSS et al., 2002). Com este objetivo, a verificação da

\footnotetext{
${ }^{3}$ Elementos extraídos da literatura que representam um conceito a ser verificado empiricamente, no caso do presente trabalho. (Nota do autor)
} 
abrangência do conteúdo e a sua validação em relação ao atendimento às expectativas são feitas por meio de uma estrutura, como apresentado na definição da pesquisa e na construção do referencial teórico.

\subsection{Proposições do estudo}

A questão central de pesquisa (e as questões dela derivadas) indica o seu objeto de estudo, enquanto que as proposições servem para direcionar a atenção do pesquisador para aspectos que devem ser analisados dentro do escopo do estudo (YIN, 2001).

Desta forma, quando retomada a questão central de pesquisa: "Como as organizações tomam decisões para adotar ou não a Computação em Nuvem?", bem como os desdobramentos anteriormente apresentados, torna-se pertinente a este estudo a investigação das seguintes proposições:

- Proposição 1 - A adoção da computação em nuvem decorre de necessidades específicas das organizações de grande porte, sendo um processo muito mais "ad hoc" que resultado de um desdobramento da estratégia.

- Proposição 2 - As organizações levam em conta os desafios impostos pela adoção de computação em nuvem.

- Proposição 3 - As organizações se preparam para transpor as barreiras impostas pela adoção da computação em nuvem.

- Proposição 4 - As organizações investigam previamente fatores associados (desafios, riscos e barreiras) à adoção da nuvem sob a ótica das suas capacidades essenciais.

- Proposição 5 - A adoção da computação em nuvem em organizações de grande porte contribui para o alinhamento estratégico da $\mathrm{TI}$ ao negócio - isto é, possibilita a ocorrência de "ajustes estratégicos" ou integração operacional, conforme definido por Henderson e Venkatraman (1993). 
Estas proposições têm como finalidade dar respostas ao problema central da pesquisa e a cada uma das questões dele derivadas, podendo assim, tornarem-se elementos verificáveis no estudo de casos múltiplos.

\subsection{Estruturas e etapas do Estudo de Casos}

Uma vez identificada a metodologia do estudo de caso como a mais adequada para o atingimento do objetivo da pesquisa, foi elaborada uma proposta de conteúdo e sequência para a condução deste estudo de casos. Esta proposta de conteúdo e sequência tem por base o trabalho Miguel (2012), trabalho este transcrito no ANEXO I - Condução do estudo de caso.

Como resultado desta adaptação, a condução deste estudo de caso será feita conforme está detalhadamente descrito nas seções 3.5 até 3.11 deste capítulo. Em especial, a seção 3.5 deste capítulo traz cada uma das seções do protocolo de pesquisa utilizado. A seção 3.7 mostra as principais etapas para que os resultados desta pesquisa pudessem ser construídos.

\subsection{Protocolo da pesquisa}

Como resultado do trabalho inicial exploratório da pesquisa e uma vez definida a $\mathrm{CN}$ como área de interesse para o trabalho, procurou-se identificar, dentro do contexto da gestão das operações da TI, qual seria o problema de pesquisa, as motivações e os principais objetivos do trabalho (Quadro 7).

De acordo com Yin (2004), a metodologia do estudo de caso deve ser seguida de forma disciplinada, a fim de diferenciar as pesquisas acadêmicas das estruturas elaboradas com outras finalidades. Ainda segundo o mesmo autor, para que um estudo de caso seja bem orientado e, por consequência, bem sucedido, deve-se optar por diferentes fontes de evidências, visto que uma complementará as evidências da outra.

Para Miguel (2007), o planejamento do estudo de caso deve ser delineado com cuidado, considerando os aspectos operacionais e os diversos tipos de validade que podem comprometer a caracterização do trabalho de uma pesquisa, como sendo de cunho científico. Além de prever quais os tipos de validade a que o estudo 
de caso está sujeito, a descrição do caso deve conter uma análise crítica da qualidade da pesquisa, em termos desses diferentes tipos (MIGUEL, 2007).

O protocolo de pesquisa deve ser desenvolvido para cada estudo de caso, mesmo que ela faça parte de estudos de múltiplos casos. Além de conter o roteiro de entrevistas, devem fazer parte dele os procedimentos de campo, as regras gerais que norteiam o uso do instrumento, definição clara das unidades de análise, como os dados serão coletados e com quem (MIGUEL, 2010; YIN, 2005). Através do uso do protocolo, a confiabilidade da pesquisa pode ser aumentada. Também fornece uma visão geral com a descrição do tópico que está sendo estudado, antecipar problemas, incluindo a forma como os relatórios do estudo de caso devem ser completados.

De um modo geral, um protocolo deve conter as seguintes seções (YIN, 2005):

- Uma visão geral do projeto do estudo de caso

○ Objetivo geral

- Objetivos específicos

- Definição dos constructos baseados no referencial teórico

- Procedimentos de campo

- Questões do estudo de caso

- Questão central da pesquisa

- Questões derivadas da questão central de pesquisa

- Guia para o relatório do estudo de caso

Para que a condução do trabalho acontecesse de forma estruturada e transparente, entre as evidências selecionadas por Yin (2005), o autor da pesquisa usou análise documental, análises de registros em sites e arquivos, entrevistas em profundidade, comunicações telefônicas e por e-mails e observações "in loco".

Apresentada de forma sistematiza, foram as seguintes as principais tarefas definidas para a consecução das etapas do trabalho, considerando os cuidados e a 
disciplina sugeridos anteriormente pelos autores Yin (2004) e Miguel (2007). Assim, o procedimento de campo pode ser detalhado:

- Elaboração das questões norteadoras para a condução das entrevistas semiestruturadas

- Protocolo para contato e condução das entrevistas com as unidades de análise

- Levantamento de dados secundários de cada unidade de análise

- Levantamento de dados dos entrevistados de cada unidade de análise

- Entrevistas com os responsáveis pelo fornecimento das informações, de acordo com o estabelecido no protocolo para condução das entrevistas

- Registro das entrevistas

- Transcrição das anotações e gravações

- Identificação das lacunas e das necessidades de informações complementares ou adicionais às obtidas na conversa inicial

- Envio do material gerado durante a entrevista para registro e conhecimento dos entrevistados, bem como a notificação sobre as necessidades de informações complementares ou adicionais

- Elaboração do painel dos dados da pesquisa

- Tabulação das observações para cada unidade de análise

- Análise preliminar dos dados de cada UA

- Tabulação das análises preliminares para cada UA

- Elaboração e tabulação de um resumo e dos principais pontos resultante das análises preliminares do painel dos dados para cada unidade de análise.

- Análise e discussão dos resultados obtidos na aplicação do método 
- Geração do relatório da pesquisa / Elaboração das conclusões

- Revisão e Redação finais do texto da dissertação

- Agradecimento formal aos entrevistados pelo pesquisador, orientador e em nome da universidade e do programa de pós-graduação.

Também foi considerado de antemão e vivenciado do ponto de vista prático, que o processo para projetar um estudo não acontece linearmente no tempo. Existe uma interação nesse processo que é cíclico. Dessa forma, entende-se que o projeto de pesquisa qualitativa / quantitativa seja um constructo teórico e prático dinâmico, um mapa de navegação com uma estrutura orientadora de um processo continuamente aberto ao questionamento acerca dos pontos chave do problema levantado e possível de ser avaliado através de critérios de validade cientifica (VIANNA e ENSSLIN, 2008).

Como parte do ferramental utilizado no trabalho está o Painel de Dados Coletados (PDC). Este painel foi montado utilizando-se de uma planilha Excel, com a seguinte estrutura:

- Aba "Plano Geral do Trabalho" - contem informações "Plano Geral do Trabalho de Pesquisa":

- Questão central da pesquisa

- Desdobramento da Questão central da pesquisa (que irão atender aos objetivos central e específicos)

- Objetivo geral da pesquisa

- Objetivos específicos

- Proposições da Pesquisa

- Anotações sobre o andamento do trabalho de pesquisa

- Registro das observações e recomendações do orientador

- Propostas para organização do trabalho de pesquisa

- Propostas para a redação da dissertação 
- Evolução dos registros dos casos

- Evolução das analises preliminares dos casos

- Evolução dos resumos dos casos

- Aba "Painel de Dados"

- Para cada uma das Unidades de Análise

- Narrativa dos Casos

- Análise Preliminar / Redução da descrição

- Observações Gerais / Informações de maior relevância

- Aba "Rascunho"

- Esquematização do método

- Capacidades essenciais (siglas / mnemônicos)

- Vantagens / Desafios / Barreiras (identificadores)

Ao final da revisão da literatura, da pesquisa documental e de campo, da interpretação e análise dos dados, é esperado que um conhecimento suficiente sobre o ambiente em estudo tenha sido adquirido, de forma a descrevê-lo em suas características atuais e, ao mesmo tempo, ter subsídios suficientes para responder o problema da pesquisa, refutando, aceitando total ou parcialmente as proposições do trabalho. O Quadro 7 exibe os objetivos e proposições da pesquisa.

\subsection{Delimitação do escopo}

O objetivo da delimitação do escopo, dentro da metodologia, é adequar o método proposto ao que efetivamente poderá ser observado no campo. Desta forma, este trabalho considera os seguintes delimitadores para o tema da pesquisa:

(1) O universo de empresas - são consideradas para a finalidade do estudo empresas de grande porte públicas ou privadas de capital nacional ou transnacional.

(2) A organização da área de $\mathrm{TI}$ - subordinação e a estrutura organizacional da área fornecedora dos serviços de TI para os clientes da organização 
estudada, que podem ser internos ou contratantes externos dos serviços, aplicações, sistemas de informação ou infraestruturas da TI.

(3) Os Sistemas de Informações - são as aplicações, sistemas de informação ou infraestruturas da $\mathrm{TI}$ que podem ser movidas ou adquiridas em algum dos modelos de serviço da $\mathrm{CN}$.

(4) A natureza das informações - são informações relacionadas à gestão da $\mathrm{TI}$ e as tecnologias envolvidas nos serviços da $\mathrm{TI}$.

O foco principal da pesquisa é buscar um melhor entendimento de como as organizações contratam e gerenciam serviços de $\mathrm{CN}$, ou seja, como são tomadas as decisões para aquisição, contratação e a operação destes serviços.

\subsection{Construção do roteiro de pesquisa}

A Figura 7 mostra a sequência das etapas desenvolvidas nesta pesquisa para que os seus resultados viessem a ser alcançados. Vale mencionar que o Modelo de Análise, resultado da revisão da literatura e da proposição do autor, uma vez desenhado, recebeu pouca ou nenhuma realimentação do teste piloto.

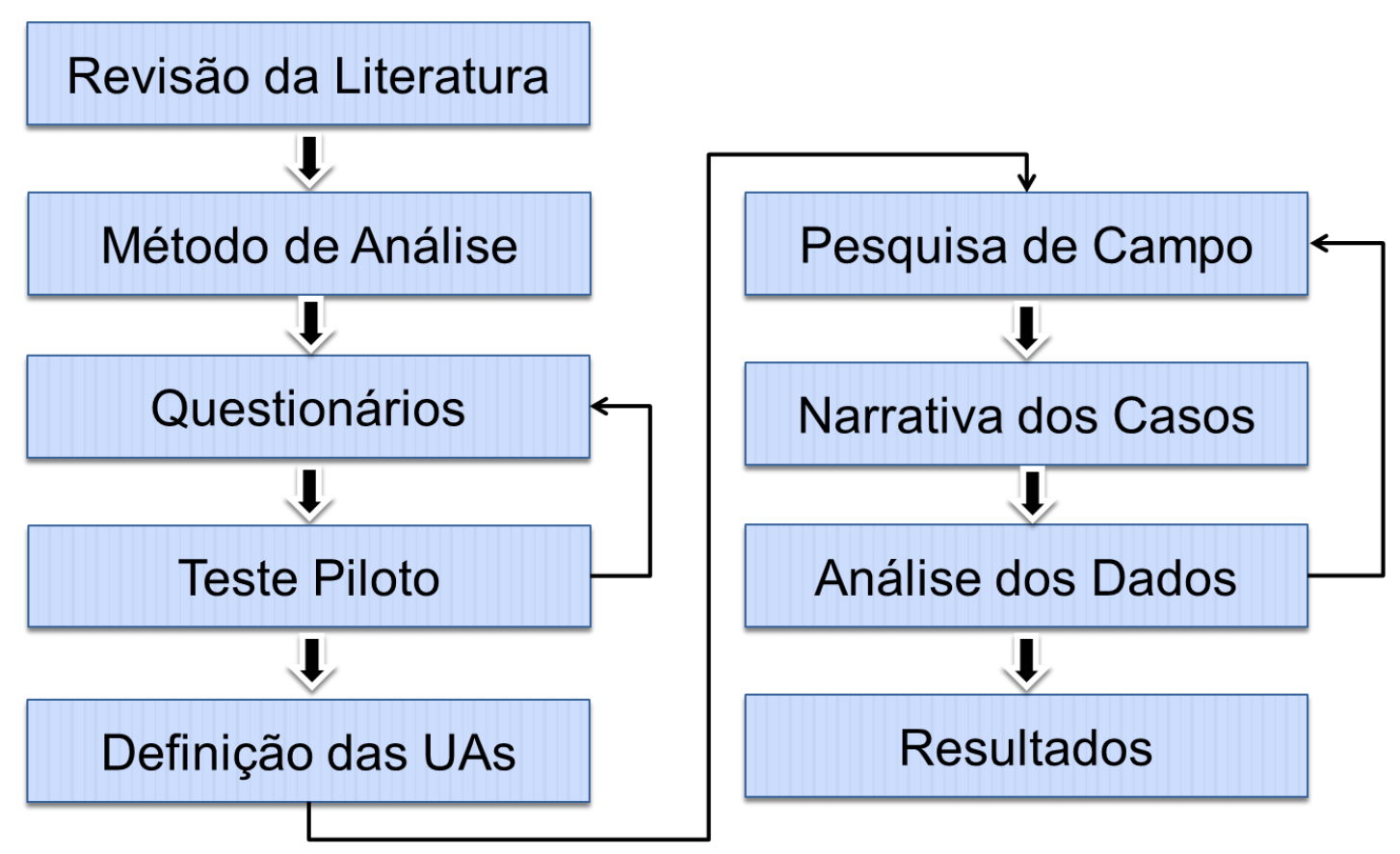

FiguRA 7 - DIAGRAMA ESQUEMÁtICO DA CONSTRUÇÃO dOS RESULTADOS 


\subsection{Proposta do teste piloto e os seus resultados}

O teste piloto foi elaborado assim que o contexto, problema, objetivos da pesquisa e o referencial teórico foram concluídos, tendo por objetivo verificar a aplicabilidade do Método de Análise para adoção da CN.

O piloto foi conduzido da seguinte forma:

- Exposição do referencial teórico, dentro do contexto das disciplinas, para duas turmas de cursos de pós-graduação (lato sensu) e $\mathrm{MBA}^{4}$, com carga horária aproximada de 6 horas/aula;

- Apresentação do enunciado de um trabalho, com finalidade de avaliação parcial das disciplinas, que deveria ser executado por um grupo de, no máximo, cinco alunos em uma situação real em uma empresa a ser escolhida pelo grupo (APÊNDICE III - Estudo de caso piloto);

- Após o trabalho de campo e análise corresponde, conforme solicitado no enunciado, cada um dos grupos deveria apresentar o resultado da pesquisa em sala. As apresentações deveriam durar aproximadamente 15 minutos. Deveriam também apresentar um relatório em documento do Microsoft Word, como os resultados obtidos (APÊNDICE III Estudo de caso piloto).

As duas turmas desenvolveram 10 trabalhos práticos em organizações das mais diversas áreas de atuação, como empresas do sistema financeiro (bancos e seguradoras), serviços (centrais de atendimento a consumidores, televisão por assinatura, universidade), telecomunicações e manufatura.

As principais contribuições do estudo piloto para o trabalho de pesquisa foram as seguintes:

\footnotetext{
${ }^{4}$ Oferecidos pela Universidade de São Paulo (USP) e operacionalizados pela Fundação Vanzolini.
} 
- Os alunos, em seus trabalhos, enfatizaram os fatores mais importantes para a pesquisa, como por exemplos, as vantagens que podem ser obtidas pela adoção da nuvem. Como resultado foi feita uma revisão dos questionários, para assegurar uma observação mais detalhada deste aspecto nas unidades de análise.

- Constatar a viabilidade da aplicação do Método de Análise, como resultado da discussão entre os componentes dos grupos na investigação de uma situação real, pelas conclusões a que chegou a maior parte dos trabalhos.

- O esclarecimento de dúvidas e observações ocorridas durante as aulas expositivas possibilitaram melhorias na redação de questões, como por exemplo, relativas à disponibilidade e confiabilidade, tornando-as mais compreensíveis para os entrevistados no trabalho de campo.

- Reiterou, de forma decisiva, a escolha das organizações de grande porte como adequadas para a aplicação do Método de Análise.

\subsection{Seleção das Unidades de Análise}

Para o atingimento dos objetivos da pesquisa, os critérios utilizados na seleção dos casos foram:

1) De acordo com DiRomauldo e Gurbaxani (1998), as motivações para a terceirização evoluíram a partir de um foco principal na redução de custos para uma ênfase crescente na melhoria do desempenho do negócio. A lógica tradicional de fornecedores com economias de escala e especialização está se tornando menos convincente. Empresas como a Dupont, a British Petroleum Exploration, Lufthansa, Swiss Bank Corporation e JP Morgan, contam com departamentos bem azeitados e inovadores, grandes o suficiente para acumular a mesma escala e benefícios de especialização como os de um fornecedor, estão, no entanto, envolvidas em processos significativos de terceirização (CROSS, 1995; LUFTMAN, 1996). Além disso, como o papel e a importância da TI tornou-se amplamente reconhecido, as empresas muitas vezes enfrentam uma grande disparidade entre as capacidades e as habilidades necessárias para realizar o potencial dessas tecnologias e da realidade de suas próprias capacidades e habilidades internas. 
Para esses autores, a terceirização da TI está desempenhando um papel cada vez mais proeminente em estratégias para preencher essa lacuna. (DiROMAULDO e GURBAXANI, 1998).

Para Dahr (2012), é fato que muitas organizações estão terceirizando seus serviços de TI já há algum tempo. No entanto, o setor de serviços de TI, incluindo a terceirização está passando por rápidas mudanças, com a crescente adoção da $\mathrm{CN}$. O impacto da CN em outsourcing de TI é, sem dúvida, significativo.

Empresas de grande porte possuem ambientes complexos de TI, que "contam com departamentos bem azeitados e inovadores, grandes o suficiente para acumular a mesma escala e benefícios de especialização como os de um fornecedor" (DiROMAULDO e GURBAXANI, 1998), apresentando os diversos fatores envolvidos na adoção da $\mathrm{CN}$, que serão objetos das análises. Usualmente nestas empresas também estão presentes (são necessárias ou desejáveis) as capacidades essenciais conforme definidas por Willcocks (2006) e Willcocks et al. (2012), ou ainda, como ponderado nas palavras de DiRomauldo e Gurbaxani (1998), "as empresas muitas vezes enfrentam uma grande disparidade entre as capacidades e as habilidades necessárias para realizar o potencial dessas tecnologias e da realidade de suas próprias capacidades e habilidades internas".

O critério para porte das empresas amplamente utilizado é o do número de empregados. É um critério quantitativo, portanto, fácil de manipular e de coletar. $\mathrm{O}$ Instituto de Geografia e Estatísticas (IBGE) adota esse critério, em suas estatísticas censitárias, que são consultadas amplamente. Por este critério grandes empresas são aquelas que possuem 250 ou mais pessoas ocupadas.

A classificação do SEBRAE, segundo o número de funcionários, onde médias empresas são as que possuem entre 100 e 499 funcionários e grandes empresas são as que possuem 500 ou mais funcionários (SEBRAE-SP, 2013) é outro critério frequentemente utilizado.

No presente trabalho as empresas selecionadas atendem a ambos os critérios apresentados anteriormente. 
2) Empresas de segmentos diversos - de preferência pelo menos uma delas pertencente ao setor público. Este critério é consequência da natureza generalista do Método de Análise proposto. Na sua formulação não há restrições em relação à origem do capital, se nacional ou transnacional, ou se a organização que será objeto da aplicação do Método pertence ao setor público ou privado da economia.

3) Empresas contratantes ou fornecedoras de serviços de TI. Neste ponto cabe uma observação: o fato de utilizarem ou não $\mathrm{CN}$ não foi considerado de antemão, dado que o Método de Análise proposto considera organização que tenha eventualmente optado pela não adoção da CN.

\subsection{Coleta de dados}

Para a coleta de dados foram utilizadas fontes primárias, contendo os dados resultantes das entrevistas em profundidade e fontes secundárias, compostas por documentos das empresas, obtidos diretamente com os entrevistados ou através dos sites das organizações. O objetivo da utilização destas duas fontes foi complementar as informações e uma triangulação entre os dados.

Os dados secundários foram obtidos por meio da leitura e análise dos seguintes documentos: plano de colocação de produtos no mercado ("road map" de produtos), apresentações sobre metodologias de gestão projetos e planos para inovações, processos formais de desenvolvimento de projetos, apresentações formais das empresas, atas de reuniões, e-mails trocados entre o pesquisador e representantes das unidades de análise.

As entrevistas realizadas com gestores das unidades de análise tiveram por objetivo a observação direta e intensiva (LAKATOS e MARCONI, 2009, p.176) dos fatos relacionados às práticas da gestão da TI de uma maneira geral e ao fenômeno da adoção da $\mathrm{CN}$ em particular, tendo como finalidade o exame da realidade encontrada em campo a procura das respostas para as questões de pesquisa. As entrevistas de deram mediante uma conversa natural e programada de forma profissional (semiestruturada, intercalando perguntas do roteiro e outras que surgem com o desenvolver da entrevista). As conversas ocorreram, na maior parte das vezes, frente a frente com entrevistado e entrevistador, de forma sistemática e 
metódica, possibilitando assim, a obtenção das informações necessárias dos entrevistados para realização do trabalho. Foi utilizado um roteiro de perguntas (sistematizado através dos questionários do APÊNDICE II - Questionários), com o conhecimento prévio dos entrevistados sobre o tema e sobre o foco de interesse. As entrevistas foram sempre agendadas previamente (com dia, hora e locais previamente determinados), proporcionando confiança aos entrevistados e garantindo a eles o sigilo em relação às suas respostas.

Sempre que possível, as entrevistas foram gravadas com uso de dois dispositivos simultaneamente (notebook e tabletes) e apagadas por completo depois de transcritas. Também foram feitas anotações e registros que deram origem a um relatório para cada uma das entrevistas, elaborado no mesmo dia da sua ocorrência, objetivando diminuir ao máximo as imprecisões naturais da comunicação. Durante a transcrição destas anotações e registros, foram contatados por e-mail alguns dos respondentes para complementação ou confirmação de algumas das informações prestadas.

Ficaram registrados quantos e quais profissionais foram entrevistados em cada unidade de análise. No caso da unidade de análise $\boldsymbol{A}$ foram entrevistados apenas dois representantes da organização. As informações obtidas com aqueles representantes foram suficientes para a obtenção das respostas aos pontos exigidos pelo trabalho. Em todas as demais unidades de análise foram entrevistados pelo menos três representantes originários de diferentes áreas e níveis gerenciais.

\subsection{Oportunidades para análise dos dados coletados}

O objetivo principal destas oportunidades para a análise dos dados coletados em campo é a revisão crítica do Modelo de Análise para adoção da CN. Com os dados colhidos nas entrevistas semiestruturadas, na análise dos documentos e nas observações, pretende-se organizar o registro da sua existência (em alguns casos os próprios dados) em quadros que têm por objetivo avaliar a capacidade do Método de Análise capturar as informações em campo necessárias à sua aplicação.

O modelo de registro de referências (Quadro 6) foi elaborado com o objetivo de agrupar, nos constructos correspondentes, as observações ou contexto onde foram obtidas as informações referentes àquele constructo. 
QUADRO 6 - MODELO DE REGISTRO DE REFERÊNCIAS COM AS OPORTUNIDADES PARA ANÁLISE

\begin{tabular}{|c|c|}
\hline Constructos do Método & Contexto / Observações \\
\hline Modelo de Serviço & $\ll<<$ Registrar para Análise $\gg>>$. \\
\hline Modelo de Implantação & e<< Registrar para Análise $>>>$. \\
\hline Alinhamento Estratégico & e<< Registrar para Análise $>>>$. \\
\hline $\begin{array}{l}\text { Perspectiva de Alinhamento } \\
\text { Estratégico }\end{array}$ & <<< Registrar para Análise $>>>$. \\
\hline Vantagens & $\begin{array}{l}\text { Registrar se foram identificadas considerações ou } \\
\text { observações em relação aos fatores: } \boldsymbol{V 1} \text { até } \mathbf{V 1 0 .}\end{array}$ \\
\hline Desafios & $\begin{array}{l}\text { Registrar se foram identificadas considerações ou } \\
\text { observações em relação a: } \boldsymbol{D} 1 \text { até } \boldsymbol{D} 5 \text {. }\end{array}$ \\
\hline Riscos e Barreiras & $\begin{array}{l}\text { Registrar se foram identificadas considerações ou } \\
\text { observações em relação a: } \mathbf{B 1} \text { até } \mathbf{B 1 0} \text {. }\end{array}$ \\
\hline Capacidades essenciais & $<<<$ Registrar observações gerais para análise $>>>$. \\
\hline
\end{tabular}

FONTE: Elaborado pelo autor

São dois os objetivos do preenchimento do registro de referências com as oportunidades para análise, o que deve ser feito para uma das unidades de análise:

1) Identificar para uma determinada organização se houve informações coletadas relativas a um determinado fator associado (V1 até V10, D1 até D5 e B1 até B10) de um determinado constructo, para posterior análise pelo Método. Da mesma forma, registrar informações a respeito dos Modelos de Serviço e de Implantação, do Alinhamento Estratégico e suas Perspectivas e, se possível, observações relevantes em nível mais geral obtidas naquela determina empresa sobre suas capacidades essenciais.

2) Verificar a aplicabilidade e abrangência dos aspectos associados aos constructos do Método de Análise. Um fator associado ou outro constructo que não possibilitou a coleta de informação em campo está desnecessariamente incorporado ao Método de Análise. Este elemento poderá ser eliminado do Método em revisões futuras. Por outro lado, 
informações relevantes para algum dos constructos não mapeados pelo Método, a ele devem ser incorporadas buscando sua completude.

\section{QUADRO 7 - OBJETIVOS E PROPOSIÇÕES DA PESQUISA}

\begin{tabular}{|c|c|c|}
\hline Objetivo Geral & Objetivos Específicos & Proposições \\
\hline \multirow{5}{*}{$\begin{array}{l}\text { "Compreender como são } \\
\text { tomadas as decisões para } \\
\text { aquisição, contratação e } \\
\text { operação dos serviços de } \\
\text { computação em nuvem em } \\
\text { organizações de grande } \\
\text { porte." }\end{array}$} & $\begin{array}{l}\text { I. Propor um Método de } \\
\text { Análise para adoção de } \\
\text { computação em nuvem. }\end{array}$ & \\
\hline & $\begin{array}{l}\text { II. Avaliar a aplicabilidade do } \\
\text { Método de Análise proposto. }\end{array}$ & \\
\hline & $\begin{array}{l}\text { III. Identificar a avaliar a } \\
\text { relevância de um conjunto de } \\
\text { fatores associados à }\end{array}$ & $\begin{array}{l}\text { P2: As organizações levam } \\
\text { em conta os desafios } \\
\text { impostos pela nuvem. }\end{array}$ \\
\hline & $\begin{array}{l}\text { computaçao em nuvem, } \\
\text { constituintes do método. }\end{array}$ & $\begin{array}{l}\text { P3: As organizações se } \\
\text { preparam para transpor as } \\
\text { barreiras impostas pela } \\
\text { adoção da computação em } \\
\text { nuvem. }\end{array}$ \\
\hline & $\begin{array}{l}\text { IV. Avaliar a aplicabilidade } \\
\text { da abordagem por áreas de } \\
\text { capacidades essenciais. }\end{array}$ & $\begin{array}{l}\text { P4: As organizações } \\
\text { investigam previamente } \\
\text { fatores associados (desafios, } \\
\text { riscos e barreiras) à adoção } \\
\text { da nuvem sob a ótica das } \\
\text { suas capacidades } \\
\text { essenciais. }\end{array}$ \\
\hline
\end{tabular}




\begin{tabular}{|c|c|c|}
\hline Objetivo Geral & Objetivos Específicos & Proposições \\
\hline & $\begin{array}{l}\text { V. Avaliar se a adoção da } \\
\text { computação em nuvem pode } \\
\text { contribuir para o alinhamento } \\
\text { estratégico da TI ao negócio. }\end{array}$ & $\begin{array}{l}\text { P1: A adoção da } \\
\text { computação em nuvem } \\
\text { decorre de necessidades } \\
\text { específicas das } \\
\text { organizações, sendo um } \\
\text { processo muito mais "ad } \\
\text { hoc" que resultado de um } \\
\text { desdobramento da } \\
\text { estratégia. }\end{array}$ \\
\hline & & $\begin{array}{l}\text { P5: A adoção da } \\
\text { computação em nuvem em } \\
\text { organizações de grande } \\
\text { porte contribui para o } \\
\text { alinhamento estratégico da } \\
\text { TI ao negócio. }\end{array}$ \\
\hline
\end{tabular}

FONTE: ELABORADO PELO AUTOR 


\section{MÉTODO DE ANÁLISE PARA ADOÇÃO DA COMPUTAÇÃO EM NUVEM}

Em seu trabalho Kaisler et al., (2012) argumentam que muitas vezes não é feita uma análise rigorosa ao decidir pelo uso da CN. Em vez disso, muitas organizações decidem experimentar a CN implementando uma aplicação simples e de baixo risco, com a finalidade de avaliá-la. Para resolver esta fragilidade, propõe como solução uma abordagem formal que requer a avaliação e combinação de vários critérios em uma eventual decisão.

\subsection{Método de Análise para adoção da Computação em}

\section{Nuvem}

O Método de Análise proposto no presente trabalho, conforme mostrado na Figura 8, é uma adaptação do modelo apresentado por Kaisler et al. (2012). Em relação ao modelo de decisão original (Figura 6) (Objetivos de Negócios, Atributos da Qualidade dos Serviços e Decisões de Arquitetura) foi feita uma modificação na nomenclatura originalmente utilizada, de áreas chave (ou simplesmente áreas de decisão), para áreas de capacidades (WILLCOCKS et al., 2006). Além disto, foi acrescentada a área de capacidades Gestão da Função TI. Ambas as adaptação estão apoiadas no "framework" das capacidades essenciais da TI, do trabalho original de Feeny e Willcocks (1998) e da sua revisão posterior (WILLCOCKS et al., 2006).

Outra motivação para a introdução da área de capacidades Gestão da Função TI (MNG) no Método foi demonstrar a dinâmica da Função TI ao longo do tempo, desta forma, considerar decisões de curto, médio e longo prazo para a implantação da nuvem. Ou seja, além de dar subsídios às organizações que pretendem adotar a $\mathrm{CN}$, procurando identificar os principais benefícios e os potenciais riscos e barreiras para a sua adoção, subsidiar as organizações que já adotaram a $\mathrm{CN}$ em relação às questões operacionais envolvendo aos seus objetivos de negócios, atributos da qualidade dos serviços e decisões de arquitetura ao longo do tempo. 
O objetivo de agrupar os fatores associados à adoção da $\mathrm{CN}$ nas áreas de capacidades essenciais é direcionar a atenção dos gestores e decisores das empresas para as pessoas responsáveis pelo desempenho destas capacidades.

Vale destacar que se trata de um método de análise qualitativo, que também tem por finalidade possibilitar uma análise em retrospecto para aquelas organizações que pretender ampliar ou redesenhar suas necessidades de contratação de serviços da $\mathrm{CN}$.

Para a construção do método foram levantados na literatura (BENLIAN e HESS, 2011; CHOUDHARY, 2007; CHUDNOV, 2010; MARKS e LOZANO, 2010; MARSTON et al., 2010; MATHER et al., 2009; MILLER, 2008; JOHA e JANSSEN, 2012; SOMMERVILLE, 2003; WILLCOCKS et al., 2012; XIN e LEVINA, 2008) vantagens (V1 até V10), desafios (D1 até D5), riscos e barreiras (B1 até B10) relacionadas às características dos serviços, aos benefícios esperados, ao atendimento aos requisitos de negócios, à configuração da arquitetura e do modelo de dados e à gestão do fornecedor.

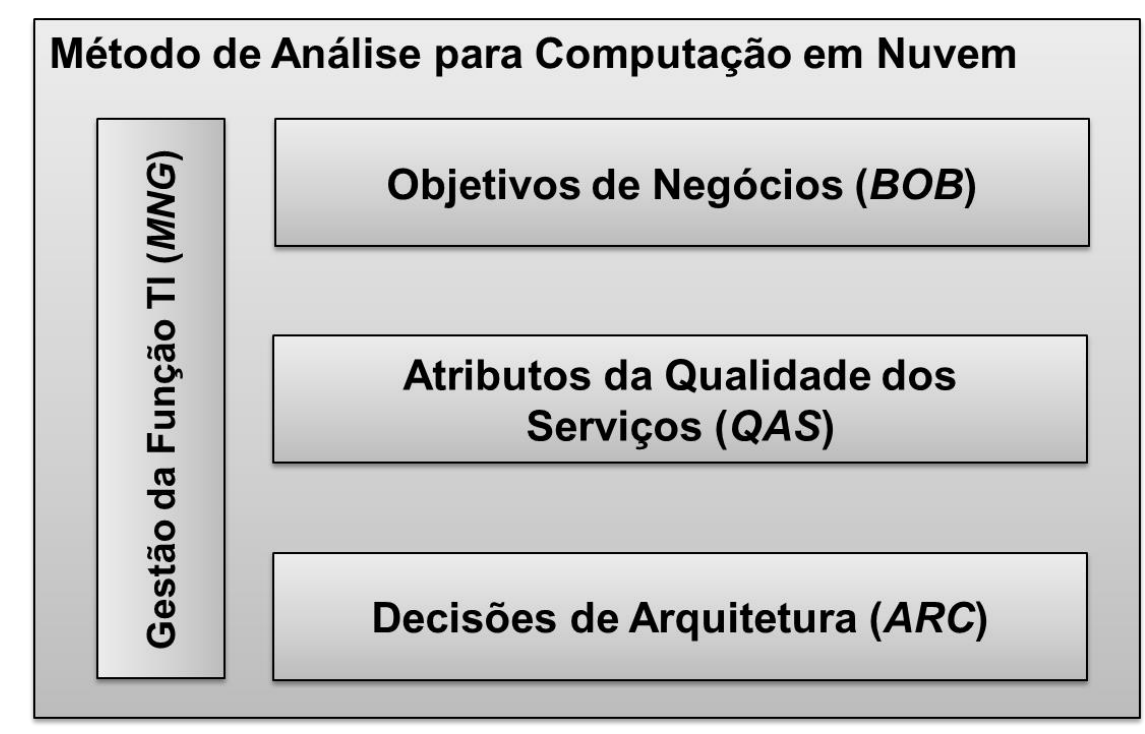

FIGURA 8 - MÉTODO DE ANÁLISE PARA COMPUTAÇÃO EM NUVEM

FONTE: ADAPTADO DE (WILLCOCKS ET AL., 2006;

KAISLER ET AL., 2012; WILLCOCKS ET AL., 2012)

A avaliação da aplicabilidade do Método de Análise para CN utilizará informações obtidas a partir de quatro questionários relacionados a cada área de 
capacidades Objetivos de Negócios (BOB), Gestão da Função TI (MNG), Atributos da Qualidade dos Serviços (QAS) e Decisões de Arquitetura (ARC), elaborados para obter informações sobre os fatores dos Quadro 8 até o Quadro 11.

O Quadro 8 lista os fatores da área de capacidades Gestão da Função TI (MNG) que podem influenciar decisões para adoção da CN.

QUADRO 8 - GESTÃo DA FUnÇÃo TI (MNG)

\begin{tabular}{|l|c|c|c|}
\hline Gestão da Função TI (MNG) & Vantagem & Desafio & Risco/Barreira \\
\hline Recursos Humanos & & D1 & \\
\hline Mudança no “ethos" & & D2 & \\
\hline Gestão de Projetos & & D3 & \\
\hline Inovação & & D4 & \\
\hline Evolução com a Nuvem & & D5 & \\
\hline Falta de capacidade técnica & & B2 & B4 \\
\hline Maturidade do fornecedor & & & B6 \\
\hline Tradição comportamental & & & \\
\hline
\end{tabular}

FONTE: ELABORADO PELO AUTOR

O Quadro 9 lista os fatores da área de capacidades Objetivos de Negócios $(B O B)$ que podem influenciar decisões para adoção da $\mathrm{CN}$.

QUADRO 9 - OBJETIVOS DE NEGÓcIOS (BOB)

\begin{tabular}{|l|c|l|l|}
\hline Objetivos de Negócios (BOB) & Vantagem & Desafio & Risco/Barreira \\
\hline Custo de capital do cliente & V1 & & \\
\hline Custo de capital do fornecedor & V2 & & \\
\hline Ciclo de implementação é reduzido & V3 & & \\
\hline Custo de entrada em novos negócios & V4 & & \\
\hline $\begin{array}{l}\text { Custo de ampliação do negócio ou } \\
\text { de entrada em novos mercados }\end{array}$ & V5 & & \\
\hline Facilidade de manutenção & V6 & & \\
\hline
\end{tabular}




\begin{tabular}{|l|c|l|c|}
\hline Objetivos de Negócios (BOB) & Vantagem & Desafio & Risco/Barreira \\
\hline Flexibilidade estratégica & V7 & & \\
\hline Foco nos negócio da organização & V8 & & \\
\hline $\begin{array}{l}\text { Viabilidade estratégica da contratação } \\
\text { externa ou oferecimento de determinados } \\
\text { serviços }\end{array}$ & & & B1 \\
\hline Deficiências do modelo de negócio & & & B3 \\
\hline
\end{tabular}

FONTE: ELABORADO PELO AUTOR

O Quadro 10 lista os fatores da área de capacidades Atributos da Qualidade dos Serviços (QAS) que podem influenciar decisões para adoção da CN.

QuAdro 10 - ATRIBUtos da Qualidade dos Serviços (QAS)

\begin{tabular}{|l|c|c|c|}
\hline $\begin{array}{l}\text { Atributos da Qualidade dos Serviços } \\
\text { (QAS) }\end{array}$ & Vantagem & Desafio & Risco/Barreira \\
\hline Facilidade de manutenção & V6 & & \\
\hline Melhoria da qualidade & V10 & D3 & \\
\hline Gestão de Projetos & & D5 & \\
\hline Evolução com a Nuvem & & B5 \\
\hline Falhas de segurança & & B7 \\
\hline Disponibilidade & & B8 \\
\hline Desempenho & & & B9 \\
\hline Confiabilidade & & & B10 \\
\hline $\begin{array}{l}\text { Acordos de nível de serviço (SLAS) e } \\
\text { qualidade }\end{array}$ & & & \\
\hline
\end{tabular}

FONTE: ELABORADO PELO AUTOR

O Quadro 11 lista os fatores da área de capacidades Decisões de Arquitetura $(\boldsymbol{A R C )}$, que podem influenciar decisões para adoção da CN. 
QuAdro 11 - DeCIsões de ARQUITETURA (ARC)

\begin{tabular}{|l|c|c|c|}
\hline Decisões de Arquitetura $(\boldsymbol{A R C})$ & Vantagem & Desafio & Risco/Barreira \\
\hline $\begin{array}{l}\text { Acesso a recursos de ponta de tecnologia de } \\
\text { TI }\end{array}$ & V9 & D4 & \\
\hline Inovação & & D5 & \\
\hline Evolução com a nuvem & & & B2 \\
\hline Falta de capacidade técnica & & & B5, B7 a B9 \\
\hline Configuração de dados arquitetura & & & B5, B7 a B9 \\
\hline Modelo de implantação de nuvem & & & \\
\hline
\end{tabular}

FONTE: ELABORADO PELO AUTOR

Os desafios, riscos e barreiras foram atribuídos pelo autor do Método às diferentes áreas de capacidades (Quadro 8 até o Quadro 11) considerando as tarefas (T1 até $\mathbf{T 4}$ ) que cada uma dessas áreas se ocupa em realizar. Eventualmente algum desafio, risco ou barreira pode estar repetido em mais de uma área de capacidades. Isto ocorre sempre que a possibilidade da associação deste aspecto com mais que uma capacidade ou tarefa enriquecer ou melhorar as oportunidades para análise desta capacidade.

A avaliação da aplicabilidade do Método de Análise para CN utilizará informações obtidas a partir de quatro questionários relacionados a cada área de capacidades, Objetivos de Negócios (BOB), Gestão da Função TI (MNG), Atributos da Qualidade dos Serviços (QAS) e Decisões de Arquitetura (ARC), elaborados para levantar informações sobre os fatores associados distribuídos nos Quadro 8 até o Quadro 11.

\subsection{Roteiro para aplicação do Método de Análise}

Uma vez definida a organização objeto da aplicação do Método de Análise, o trabalho para a sua aplicação consiste na condução das seguintes etapas:

1. Caracterização da organização e dos Sistemas de Informação ou Aplicações que serão objeto de análise com a aplicação do questionário semiestruturado do (APÊNDICE I - Protocolos para 
caracterização das organizações e descrição dos sistemas foco da aplicação do método).

2. Realização das entrevistas com a aplicação dos questionários semiestruturados do (APÊNDICE II - Questionários). Vale ressaltar que esta etapa de coleta de dados normalmente não é feita em um único contato com a organização analisada. São necessárias algumas interações através de reuniões presenciais ou comunicações (e-mail, Skype, telefone, etc.).

3. Registro estruturado das observações obtidas nas entrevistas em uma planilha com a associação dos relatos aos fatores associados à adoção da $\mathrm{CN}$, ou seja, às vantagens (de V1 até V10), aos desafios (de D1 até D5) e aos riscos e barreiras (B1 até B10). Esta etapa é feita em uma planilha Excel denominada Painel de Dados Coletados (PDC) (Miguel, 2010). Como nesta planilha constam os nomes das empresas e dos entrevistados ela não será colocada como um apêndice do trabalho. A estrutura do Painel de Dados Coletados (PDC) está descrita em 3.5 (pag. 64).

4. Preenchimento do registro de referências com as oportunidades para análise, conforme modelo (Quadro 6). Elaboração da análise dos relatos com o preenchimento das células das planilhas com cada um dos fatores associados à adoção que pode ser observado a partir das entrevistas com os executivos da organização.

5. Discussão para elaboração dos quadros com os resultados das análises para cada uma das áreas de capacidades apontadas pelo Método de Análise (Quadro 8 até Quadro 11).

6. Elaborações dos quadros resumo para cada uma das áreas de capacidades: Gestão da Função TI (MNG), Objetivos de Negócios $(B O B)$, Atributos da Qualidade dos Serviços (QAS) e Decisões de Arquitetura $(A R C)$, concluindo a discussão dos resultados para aquela 
organização estudada. As análises devem ser resumidas/codificadas conforme especificado nos códigos descritos em $6.1 .^{5}$

Uma vez completados os quadros para as áreas de capacidades é possível ter uma visão geral de quais são os fatores associados relevantes. Este quadro servirá como uma ferramenta do responsável pelo Método de Análise para a apresentação dos resultados obtidos à organização estudada.

${ }^{5}$ Para tornar o trabalho de leitura mais direto os códigos e as suas descrições utilizados nos quadros resumo das unidades estão no próprio item 6.1. (Nota do Autor). 


\section{OBSERVAÇÕES E ANÁLISES PRELIMINARES DOS CASOS}

Este capítulo traz a caracterização de cada uma das empresas e está descrito (ou transcrito de forma abreviada) o que pode ser observado no trabalho de campo para cada uma das unidades de análise. As informações obtidas, a partir do protocolo de pesquisa e dos questionários semiestruturados, serão analisadas levando-se em conta sua aplicabilidade e adequação aos fatores relacionados à adoção da $\mathrm{CN}$, conforme pode ser identificado no referencial teórico e na construção do Método de Análise (Figura 8). No texto também estão identificadas as observações que foram relacionadas aos constructos da pesquisa, ou seja, às vantagens (V1 até V10), aos desafios (D1 até D5) e às barreiras (B1 até B10) que são parte integrante do Método de Análise para adoção da CN.

\subsection{Empresa $A$}

A unidade de análise é especializada no projeto e desenvolvimento de soluções para o segmento alimentício e de produtos lácteos, cervejarias, indústrias químicas e farmacêuticas, petroquímicas e de mineração.

\subsubsection{Caracterização da Empresa A}

A Empresa A faz parte de um Grupo multinacional de origem alemã, que é um dos maiores fornecedores para a indústria de processamento de alimentos. Também fornece tecnologias de processos para uma grande variedade de outras indústrias. De acordo com o site da matriz, o Grupo atua globalmente nos seguintes segmentos:

- Tecnologias agrícolas

- Equipamentos mecânicos

- Engenharia de processos

- Tecnologias de refrigeração 
A empresa pesquisada é especializada o projeto e desenvolvimento de soluções para as indústrias de laticínios, alimentos, produtos lácteos, bebidas (cervejas, refrigerantes e sucos), química e petroquímica, farmacêutica e de cosméticos, agroindústria (açúcar, álcool, grãos e madeira), efluentes e mineração.

A Empresa $A$ oferece uma vasta gama de equipamentos, tecnologia e knowhow de processos para as indústrias de laticínios, alimentos, bebidas, produtos químicos, farmacêuticos e proteção ambiental. A maioria das empresas do Grupo são líderes mundiais em tecnologias de processamento, com muitas décadas de experiência nos vários mercados em que atuam, sendo a Empresa $\mathrm{A}$ o principal fornecedora de linhas completas e operações unitárias para a indústria mundial de lácteos.

As entrevistas foram realizadas com o gerente de TI da Empresa A, que tem a responsabilidade pela gestão da infraestrutura de todas as empresas do Grupo presentes no Brasil. As conversas ocorrem em três momentos distintos presencialmente e por e-mail. Inicialmente foram trocados e-mails com as informações sobre o contexto, motivações e objetivo da pesquisa. Na sequência em um encontro entre este pesquisador e o responsável pela $\mathrm{TI}$ foram respondidos os questionários semiestruturados.

Também foi entrevistado o gerente de uma das áreas de negócios, que além de informações adicionais sobre a politica de recursos humanos da empresa, trouxe informações sobre Sistemas de Informação (SI) que servem para o desenvolvimento de projetos de soluções de engenharia para setores industriais específicos. A área de TI manter servidores especialmente destinados a estes sistemas.

As anotações feitas durante as entrevistas foram revisadas e enviadas no mesmo dia para os entrevistados. Posteriormente foram trocados e-mails para o esclarecimento de questões onde restaram dúvidas ou que não haviam sido colocadas de forma adequada.

\subsubsection{Adoção da computação em nuvem}

\section{VANTAGENS}


A contratação da NF-e (emissão de Notas Fiscais eletrônicas) como um serviço na nuvem ocorreu por significar uma solução mais segura, mais rápida e de menor custo que o desenvolvimento interno ou da utilização direta dos serviços, como são originalmente oferecidos pela Secretaria da Fazenda (SEFAZ). Desta forma, duas das sete empresas do Grupo no Brasil utilizam uma solução de mercado para a emissão de notas fiscais eletrônicas (NF-e), que está hospedada na nuvem. (V3)

Na sua forma usual, na solução oferecida pelo SEFAZ, a empresa emite suas notas fiscais acessando, via internet, seus servidores através dos navegadores ("Browsers") padrão. Na forma adotada pelas duas empresas do Grupo, é contratado um provedor de serviços que oferece uma aplicação na nuvem que possibilita ordenar, documentar, registrar e armazenar as notas fiscais emitidas em nome das empresas usuárias. (V6)

A solução adotada atende principalmente dois objetivos:

- A comunicação com os servidores da SEFAZ para emissão da nota fiscal eletrônica, propriamente;

- A guarda em arquivos de todos os dados de todas as notas emitidas pelo sistema (em formato $X M L)$

A utilização da aplicação NF-e na nuvem resulta em um custo menor (V1), pois propiciou racionalizar a contratação dos serviços, uma vez que é utilizada por duas empresas do grupo (B3). E ainda, de acordo com o entrevistado, também representa um custo menor do que seria necessário para investir no desenvolvimento interno de solução semelhante. No entanto, o custo não foi a principal razão para adoção de aplicação na nuvem. A principal razão para a contratação foi manter os esforços da equipe da TI focados na gestão da infraestrutura específica para os negócios e na implantação do sistema do ERP $(S A P)$, que é no momento a maior prioridade da área (V8).

Não é esperado que o sistema em questão viesse a ser utilizado em um novo negócio da organização. Isto seria possível em função da generalidade do serviço 
contratado, mas há nenhum plano de entrada em novo negócio (V4). Também não é esperado que o serviço viesse a ser utilizado para a entrada em algum novo mercado. Neste caso, para que esta vantagem seria possível somente se a legislação fiscal deste novo mercado viesse a ser a mesma ou fosse também contemplada pelo serviço contratado. (V5)

Por outro lado, um benefício esperado pela adoção da aplicação na nuvem, diz respeito ao atendimento às questões da legislação fiscal, que fica por conta do prestador de serviço, permitindo manter o foco dos recursos da área de $\mathrm{TI}$ nos negócios da organização (V8).

A organização espera que o fornecedor mantenha sua infraestrutura de software e hardware atualizados para o atendimento das necessidades da organização e entende que a solução exige pouco ou quase nenhum treinamento (V9).

A organização optou pela adoção da NF-e pelo que ela agrega de serviços (armazenamento e back-up dos dados das notas fiscais emitidas) e segurança, em relação ao uso diretamente através da Internet do serviço oferecido pela secretaria da fazenda (V10).

\section{DESAFIOS}

A empresa opera com quatro níveis hierárquicos. Os empregados viajam regularmente para a Alemanha onde recebem treinamentos gerenciais e atualização tecnológica em relação aos diversos produtos que comercializa. Os treinamentos gerenciais prepararam o funcionário para que assuma um posto de nível hierárquico imediatamente superior ao que ocupam naquele momento. Este filosofia de treinamento tem por objetivo ocupar, sempre que possível, os níveis gerenciais mais altos com gestores originários da própria organização. A este processo de progressão interna nas carreiras da empresa é chamado "Leadership Pipeline Model', sendo que a mobilidade dos empregados depende do crescimento da organização (ou, eventualmente a saída de algum dos gestores atuais por aposentadoria ou por outra razão). (D1) 
Para os questionamentos específicos sobre as práticas para 0 desenvolvimento de software, foram obtidas as seguintes informações:

- Hoje as empresas do Grupo no Brasil têm pouco desenvolvimento.

- O Grupo em nível global (na matriz, em particular) tem desenvolvimento de aplicações específicas para as áreas de atuação da corporação (software para cálculos nas áreas de projetos de engenharia e manufatura).

- No Brasil o desenvolvimento é feito para as funções não suportadas pelo ERP $(S A P)$

- O desenvolvimento não é contínuo; quando são contratados fornecedores para cada projeto específico.

- O desenvolvimento em curso é feita pela própria consultoria contratada para a implantação do ERP.

- É esperada "pouca" customização no ERP (em torno de 5\%)

- O levantamento dos requisitos em geral é feito através da análise dos documentos dos processos da organização (especificação local) comparados aos processos como estão implementados pelo ERP (especificação global).

- Este trabalho foi feito durante o levantamento dos processos de negócios atuais e da elaboração dos novos processos baseados no padrão do $E R P$ escolhido (também conhecido como "business blue print"), identificando o desenvolvimento de funcionalidades específicas ("customizações") para o negócio de projetos e construção de plantas industriais.

Em função do exposto, enfatizando que as empresas do GRUPO no Brasil têm pouco desenvolvimento, o gestor considera que os projetos são tratados "ad hoc" em função do seu porte (sempre pequenos) e da sua dispersão no tempo (são raros). Ou seja, não há um processo formal para o desenvolvimento de projetos. Assim, a organização não possui certificações, como o CMMI, ou são adotadas sistematicamente melhores práticas, como as do PMBOK, para a gestão de projetos de desenvolvimento de software (D3).

\section{BARREIRAS}


$\mathrm{Na}$ avaliação do gestor da TI, no contexto do planejamento da arquitetura, novas aplicações para a nuvem irão "sempre" "conflitar" com as aplicações hoje disponíveis:

- Não há hoje necessidades especificas de utilização de aplicações ou outros serviços em nuvem, como foi o caso da NF-e. (B6)

- O pessoal de campo acessa, via dispositivos móveis, os serviços da TI disponibilizados através da WAN corporativa. (D5)

Em relação à contratação de serviços, as principais contratações para a TI são centralizadas. Os fornecedores mais importantes são: Microsoft, DELL, SAP, AutoDesk, AT\&T. Quando são necessárias contratações de serviços específicos para a TI, geralmente são feitas nos moldes daquelas feitas para a contratação da consultoria para a implantação do SAP:

- No caso da última contratação para desenvolvimento/customização foram feitas quatro consultas técnicas pelo pessoal da área de TI.

- Os orçamentos com os preços dos serviços formam enviados para a área de compras para a negociação comercial dos preços.

- Foi escolhida a consultoria que apresentou o menor orçamento atendendo às especificações técnicas.

- A análise jurídica do contrato foi feita por um profissional da área que havia trabalhado como funcionário da organização e que passou a prestar os mesmo serviços como terceiro. (O profissional é acionado sempre que há necessidade de um parecer jurídico em relação à aquisição (contratação) de serviços, pela organização). (B2)

A empresa de $\mathrm{Tl}$ do Grupo sediada na Europa responde pelo fornecimento dos serviços de $\mathrm{TI}$ das empresas sediadas naquele continente. Esta empresa também é a responsável pela elaboração da politica de gestão de riscos da TI para todas as demais empresas. A operacionalização da gestão de riscos da TI ocorre da seguinte maneira: 
- Existe um "guideline" (política) global para a gestão de risco originária desta empresa de TI do Grupo.

- Existem "guidelines" locais apoiados no "guideline" global, que são as adaptações necessárias para a implantação local da função TI (politica local para os riscos da TI). Ou seja, as necessidades da politica local são "desdobradas" da politica global da organização.

Em relação às práticas de governança de $\mathrm{TI}$ foi informada a ocorrência de reuniões mensais para o acompanhamento dos projetos da $\mathrm{Tl}$, com grande preocupação com a comunicação. Um dos principais objetivos destas reuniões é o acompanhamento das métricas para a infraestrutura de TI. Dentre estas métricas estão:

- Adesão à infraestrutura global

- Utilização dos links de comunicação

- Adesão aos testes e protótipos e testes conduzidos pela TI em nível global.

É desejo da organização a ampliação das práticas de governança da organização sobre a infraestrutura de TI:

- Hoje as práticas de governança de TI ficam restritas aos indicadores e métricas que dizem respeito à infraestrutura básica, como: comunicação, padronização das estações de trabalhos, utilização da Internet, etc. (B10)

- É desejo que o SAP venha a estabelecer padrões que possam resultar em métricas especificas para os segmentos de negócio. O objetivo final é o estabelecimento de padrões e métricas para cada empresa/aplicações específicas que possam ser acompanhadas de forma global pelas instâncias de governança apropriadas (reuniões mensais, semestrais, etc. pelos diferentes órgãos gestores). (B5) (B9)

O Grupo possui uma WAN corporativa global, cuja infraestrutura física da rede é oferecida pela $A T \& T$, que também disponibiliza servidor de e-mail e a suíte de software Microsoft Link (para serviços de mensagens e chats; similar ao SKYPE). Há 
também uma padronização global para os componentes de hardware e software conectados a este rede global. A padronização e aquisição das licenças de uso dos softwares são feitas de forma centralizada na matriz (Europa). Há também uma padronização central (em nível corporativo) para Telefonia/VoIP. (B7) (B9) (B10)

Como resultado desta padronização há uma série de limitações impostas por esta "rede corporativa global", que devem ser consideradas na gestão local das áreas de TI das diferentes empresas do Grupo.

A análise jurídica dos contratos da área de TI vem sendo feita por um profissional da área jurídica, que no passado havia trabalhado como funcionário da organização e que passou a prestar os mesmo serviços como terceiro. ( $O$ profissional é acionado pela organização sempre que há necessidade de um parecer jurídico em relação à aquisição (contratação) de serviços).

A área de TI pesquisada coordena a gestão da infraestrutura centralizada e presta serviços específicos, como a gestão da emissão de notas fiscais, para as demais empresas do Grupo no Brasil. (B2) Como regra geral:

- No Brasil cada empresa tem sua própria infraestrutura de TI para atender as suas necessidades especificas de negócios (servidores e aplicações específicas);

- As empresas do Grupo sediadas na Europa são atendidas por uma empresa, também do Grupo, que centraliza toda a prestação de serviços de TI.

No que se refere à viabilidade estratégica da contratação externa ou oferecimento de determinados serviços, a organização utiliza diversas aplicações para resolução de problemas específicos nas áreas de projeto e engenharia. Nestes casos a área de TI somente fornece a infraestrutura de servidores, ficando a responsabilidade pela gestão das aplicações diretamente com as unidades de negócios. Desta forma, as unidades de negócios tomam as principais decisões em relação aos investimentos para aquisição e manutenção destas aplicações. Ainda que, em geral, sejam aplicações de terceiros disponíveis podendo ser adquiridas por 
qualquer organização no mercado, sua utilização depende de customizações, massas de dados e conhecimentos especializados nos seus domínios de aplicação fazendo com que se transformem em ativos com valor estratégico para a organização. Portanto, estas aplicações de negócios de domínios específicos devem ficar instaladas na infraestrutura de TI propriedade da organização. (B1)

\section{PAPEL ESTRATÉGICO DA TI}

A aplicação analisada pode ser caracterizada como promotora de uma integração operacional da $\mathrm{TI}$ ao negócio. A integração da aplicação $(N F-e)$ na operação cotidiana da organização serviu como uma ligação entre a infraestrutura e processos de negócio e a infraestrutura e processos de TI. Sendo possível, assim, atender a uma necessidade legal imprescindível para a continuidade dos negócios das empresas.

A respeito da perspectiva de alinhamento estratégico da TI ao negócio, é necessário analisar a abrangência da área como um todo, isto é, além das observações feitas sobre aplicação $(N F-e)$. Neste caso é possível caracterizar a disponibilidade das aplicações de negócios, executadas na infraestrutura própria das empresas, como necessárias para a execução da estratégia de negócios da organização.

\subsubsection{Análise preliminar da Empresa A}

Como resultado das observações registradas em 5.1 .2 é apresentado o registro de referências com as oportunidades para análise (Quadro 12). É feita a seguir uma análise preliminar que procura trazer para o que contexto do trabalho 0 que foi observado em campo.

O Grupo sempre trabalha com um alto grau de padronização na infraestrutura de $\mathrm{TI}$, quando equipamentos, programas, comunicação de dados esta podem ser tratados como commodities. Estabelece processos e métricas específicas, que todas as empresas devem estar em conformidade. Por outro lado, cada empresa possui sua própria infraestrutura de servidores e aplicações relacionadas especificamente aos seus negócios (Unidades de Negócios). No Brasil, o Grupo está em processo de 
implantação do SAP, que é tratado como o objetivo de maior prioridade para a área de TI.

Em relação à adoção da $\mathrm{CN}$, o gestor da $\mathrm{TI}$ declara que esta adoção será fundamentalmente para atender necessidades pontuais específicas, como ocorreu com a NF-e. Caso outras aplicações fossem adotadas, viriam em substituição aos sistemas já implantados (D5). Em resumo, esta adoção não é uma prioridade para a área de TI.

QUADRO 12 - REGISTRO DE REFERÊNCIAS DA EMPRESA A

\begin{tabular}{|c|c|}
\hline Constructos do Método & Contexto / Observações \\
\hline Modelo de Serviço & Aplicação NF-e - Software como Serviço (SaaS). \\
\hline Modelo de Implantação & $\begin{array}{l}\text { Nuvem privada do provedor de SaaS. (A organização } \\
\text { não possui infraestrutura de nuvem). }\end{array}$ \\
\hline Alinhamento Estratégico & Integração Operacional \\
\hline $\begin{array}{l}\text { Perspectiva de Alinhamento } \\
\text { Estratégico }\end{array}$ & Execução da estratégia \\
\hline Vantagens & 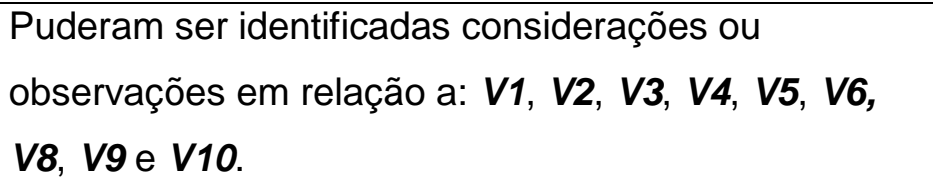 \\
\hline Desafios & $\begin{array}{l}\text { Puderam ser identificadas considerações ou } \\
\text { observações em relação a: D1, D3 e D5. }\end{array}$ \\
\hline Riscos e Barreiras & $\begin{array}{l}\text { Puderam ser identificadas considerações ou } \\
\text { observações em relação a: } \mathbf{B 1}, \mathbf{B 2}, \mathbf{B 3}, \mathbf{B 5}, \mathbf{B 6}, \mathbf{B 7} \text {, } \\
\mathbf{B 8}, \mathbf{B 9} \text { e } \boldsymbol{B 1 0} \text {. }\end{array}$ \\
\hline Capacidades essenciais & $\begin{array}{l}\text { A contratação do serviço na nuvem atendente a uma } \\
\text { necessidade específica da organização. Não há uma } \\
\text { orientação para novas contratações de serviços. }\end{array}$ \\
\hline
\end{tabular}

FONTE: ELABORADO PELO AUTOR 


\subsection{Empresa $B$}

A Empresa B atua em diversos mercados como aeroespacial, bens de consumo, construção civil, embalagens, indústria elétrica, máquinas e equipamentos, petróleo e gás, químicos e transportes.

\subsubsection{Caracterização da Empresa B}

Multinacional americana, presente em dezenas de países, atua em toda a cadeia produtiva do alumínio, desde a mineração da bauxita até a produção de transformados. É um grande produtor de alumínio primário, alumínio transformado, assim como mineradora de bauxita e refinadora de alumina.

\subsubsection{Adoção da computação em nuvem}

\section{VANTAGENS}

Como a empresa produz basicamente commodities, volumes de produção, acesso aos recursos minerais, disponibilidade e custo da energia elétrica e o desenvolvimento dos mercados consumidores são determinantes para a continuidade dos negócios. Em consequência, a organização têm estratégias claras para adicionar valor às commodities, buscando margens adequadas à remuneração dos acionistas.

Em linha com essa busca por margens que possam garantir a sustentabilidade (ambiental, econômica e de longo prazo), a migração para a utilização da CN é um direcionamento estratégico da organização, que se desdobra em ações de curto, médio e longo prazo, tendo como principal objetivo a redução de custos. (V1)

Aplicações cujo funcionamento independe de configurações ou características específicas das filiais passaram a ser utilizadas de forma centralizada, hospedadas em data centers com custos de propriedade menor que aqueles dispendido pelas unidades, quando utilizados separadamente em cada uma delas. (V2). Atualmente a unidade de análise possui os seguintes aplicativos sendo utilizados como serviços na nuvem: 
- Folha de pagamento - Gestão de RH (laaS)

- Gestão de viagens (SaaS) - Aplicação para apoiar as solicitações de viagens à serviço da corporação, os fluxos de aprovação e a posterior prestação de contas .

- Plataforma de E-learning (SaaS) - Plataforma de ensino à distância para apoiar os programas corporativos de treinamento on-line.

A partir de 2005 a empresa definiu como sendo estratégico direcionar os especialistas da TI para o negócio, com uma adoção progressiva da TI na nuvem. Como resultado desta orientação a empresa passou a contratar fornecedores externos especializados no desenvolvimento dos sistemas de gestão ERP (Oracle Applications). Este fato possibilitou o redirecionamento dos esforços internos para especificação e contratação de empresas com conhecimento especializado no desenvolvimento dos demais sistemas de informação necessários à operação, chamados internamente de "Sistemas Satélites". (V8)

Outra orientação deste direcionamento estratégico está a elaboração e execução de ações que têm por objetivo, de médio e longo prazos, a redução da base de fornecedores. (V7)

\section{DESAFIOS}

Foram obtidas as seguintes informações relacionadas aos Recursos Humanos da organização envolvidos com a CN (D1):

- Possibilita "job rotation" inclusive na área de TI. Isto é feito com a alocação de recursos das plantas dentro do site principal da TI no Brasil;

- Ocorre "job rotation" da área principal da TI no Brasil com a matriz e com áreas de TI de outros países onde a organização tem filial.

- Meritocracia: as avaliações são feitas no modelo da GE (Modelo de liderança dos 4 Es e um $P$ de Jack Welch), que impacta fortemente a remuneração do pessoal da TI. Por serem mais bem remunerados que os demais das áreas administrativas, sua bonificação também são valores mais significativos, ainda que proporcionais aos demais empregados. 
Em relação ao desenvolvimento interno de software foram obtidas as seguintes informações (D3):

- Grupo pequeno de pessoas;

- Tem um processo formal de desenvolvimento desenvolvido internamente, que é uma adaptação do PMI/Oracle adaptado para a unidade de análise;

- Os demais desenvolvimentos são feitos em plataforma MS, utilizando as ferramentas deste fornecedor;

- O desenvolvimento para o ERP/Oracle é $100 \%$ contratado de terceiros (consultorias especializadas no ERP);

- Os demais sistemas têm $70 \%$ das necessidades de desenvolvimento contratadas externamente;

- Cerca de $30 \%$ dos esforços de desenvolvimento feitos internamente são direcionados para os chamados "sistemas satélites"

- Internamente as aplicações são classificadas com aplicações $E R P$, aplicações não-ERP (onde entram os "sistemas satélites") e "pacotes de mercado".

A organização valoriza a colaboração. Para tal entende que deve disponibilizar acesso aos recursos computacionais aos seus empregados. (D4)

A empresa utiliza dispositivos móveis:

- Em sua maioria ainda são aparelhos "Black Berry";

- Os demais dispositivos são utilizados no fluxo de aprovação ("workflow") necessário aos processos de negócios;

- Controle de produção na unidade do nordeste brasileiro;

- Como aplicações analíticas do tipo "Dashboards";

- Como automação da força de vendas.

Hoje o e-mail não está na nuvem. O padrão global é o $M S$ Exchange. A utilização do MS Office 365 vem sendo avaliado na forma de um "Business Case". No entanto, o retorno ainda não justifica a sua adoção. (D5) 
A unidade de análise mantem um prêmio de inovação relacionado ao seu principal negócio, que em onze edições somou 2.262 projetos inscritos e 232 universidades participantes. O objetivo do concurso é estimular a utilização do alumínio, considerado um material infinitamente reciclável, para criar projetos com soluções inovadoras de produtos ou aplicações com esse metal. (D4)

A organização mantem uma orientação inequívoca para as suas diferentes estruturas organizacionais, ai incluída a diretoria entrevistada, para racionalização na utilização dos recursos e para redução de custos da operação. (B6) (B3)

A CN se encaixa nesta busca por redução de custos em função do ambiente altamente sensível aos preços típico do seu negócio para assegurar sua sustentabilidade. Para isso, a companhia busca constantemente parceiros e fornecedores comprometidos em atuar de acordo com seu modelo de gestão sustentável, que têm como tripé o desenvolvimento social e econômico das comunidades, cuidados com o meio ambiente e sucesso financeiro. (D2) (D5)

\section{BARREIRAS}

São três as principais "camadas" que definem uma arquitetura hierárquica dos sistemas de informação da organização:

1. Controle dos Processos de Produção - Automação da produção são os sistemas para controle de processos produtivos, implantados utilizando-se de lógica e malhas de controle presentes no "chão da fábrica". Nesta camada também estão incluídos os sistemas para a supervisão dos processos que operam nas unidades fabris.

2. IFS Applications (engenharia) - São as aplicações para 0 gerenciamento da operação das plantas e dos processos fabris. $O$ PPCP - Planejamento, Programação e Controle da Produção e o MRO - Manutenção, Reparo e Operação estão entre os principais subsistemas desta camada.

3. Gestão Corporativa - São as aplicação do ERP responsáveis pela gestão global da empresa envolvendo, além das áreas de produção, as 
áreas administrativas como: compras, contas a pagar, aprovação e acompanhamento de despesas viagens, etc.

Em relação à viabilidade estratégica da contratação externa destas camadas, os entrevistados entendem que apenas a primeira camada, isto é, a camada de controle dos processos de produção - sistemas de automação - não pode ser movida para a nuvem. Foram duas as razões apresentadas, que são consideradas como impeditivas para isto: a) aloja aplicações críticas para os processos de produção, como por exemplo, o tratamento de eventos em tempo real; e b) são aplicações que incorporam conhecimento estratégico do negócio, ou seja, a ausência deste conhecimento por competidores, ou potenciais competidores, da lógica da sua construção e da sua operação, pode funcionar como barreira de entrada para o principal negócio da empresa. (B1)

A organização possui um processo de decisão para a escolha das tecnologias que viabilizem a utilização da sua infraestrutura da TI como serviço (laaS), bem como dos fornecedores destas tecnologias. Decisões desta natureza são tomadas em conjunto com a matriz, cujo fórum de discussão são os grupos de trabalho constituídos por especialistas em arquitetura corporativa das diversas filiais, distribuídas em mais de 20 países. (B2)

A unidade de análise utiliza prioritariamente ferramentas de Microsoft, que a faz um fornecedor "natural" para o desenvolvimento para a nuvem. (B2)

Em relação aos processos para a gestão de riscos em $\mathrm{TI}$, as principais informações obtidas nas entrevistas com os responsáveis pela área de TI da unidade de análise forma:

- A gestão de riscos em TI recebe atenção total (de acordo com a responsável pela área de $\mathrm{Tl}$, sua principal atividade na gestão da $\mathrm{TI}$ é essencialmente a gestão dos riscos). (B5)

- A empresa é sempre a primeira organização a publicar seus balanços a cada ano fiscal;

- Há um comitê de ética, "compliance" e riscos. 
- Sofre auditorias de "compliance", que dizem respeito ao cumprimento das normas legais e regulamentações, das políticas e das diretrizes estabelecidas para o negócio e para as atividades da unidade de análise. Também tem por objetivo evitar, detectar e tratar desvios ou inconformidades.

- Em uma escala de um até cinco, é necessário obter pelo menos grau quatro, obrigatoriamente. Este grau tem sido atingido sistematicamente pela área entrevistada desde que as auditorias tiverem início.

- O monitoramento e controle de riscos é uma atividade prioritária da gerência da TI. Desta forma, toda a TI se mantém alinhada em relação aos riscos nas auditorias mensais.

- O monitoramento e controle de riscos compreendem os riscos: sistêmicos, desastres, atendimento legal, compromissos/cumprimento dos prazos, fornecedores, etc.

Para efeito da contratação dos serviços de $\mathrm{Tl}$, a capacitação jurídica para elaboração ou para a verificação dos contratos de serviços com seus fornecedores das aplicações e da infraestrutura têm as seguintes características:

- A maior parte dos contratos é de alcance global;

- Quando é necessária a contratação local ou regional, a TI faz a definição do escopo e especificação técnica através de RFPs/RFQs e a área de compras faz a contratação de acordo com os processos formais de aquisição ("Procurement").

- A área de compras tem uma pessoa alocada especialmente para as compras para TI. Nestes casos a análise jurídica dos contratos que são feitas por contratações pontuais de escritório de advocacia especializado.

- Em geral a contratação é feita utilizando-se minutas/contratos padronizados, abreviando o tempo dos processos e agilizando as contratações.

- Em geral contratos "fora do padrão" demandam um tempo muito maior para a sua formalização, sendo evitados sempre que possível. 
Os contratos atendem a SLAs globais com metas locais (contratantes locais) definidas no início de cada exercício fiscal. (B10)

As instalações fabris e escritórios da organização possuem conexões com a Internet através de rede de alta velocidade, utilizando canais de satélite, canais de rádio e fibras óticas, que asseguram a disponibilidade e o fluxo de dados adequado às necessidades para as diversas unidades da empresa. (B7)

Fábricas maiores têm a parte de operação rodando em servidores locais (servidores que rodam processos de automação da produção).

Outra visão dos sistemas de informação é:

1) IFS (engenharia)

2) Administrativo (vendas, $\mathrm{RH}$, demais sistemas administrativos)

3) Mobilidade (BI, aplicativos móveis)

A empresa persegue o conceito de "Smart Manufacturing", que pode ser definido com sendo a utilização intensiva de redes para comunicação de dados e Tecnologia da Informação no chão de fábricas e na cadeia de fornecimento. Seus principais componentes são os seguintes:

- Automação (operação)

- PLC (instrumentação)Comunicação de dados (redes próprias para o ambiente fabril)

O conceito de Nuvem + Mobilidade ("Manufacturing execution system"), na prática, são os operadores fazendo os apontamentos do que ocorre na produção com a utilização de dispositivos móveis. Estas informações servem de entrada para os demais sistemas de gestão e de acompanhamento da produção.

A principal executiva da organização entrevistada para o trabalho define a gestão estratégia da área de $\mathrm{TI}$ sob sua responsabilidade com os seguintes direcionadores:

- Foco em redução do custo; 
- Aumento do valor estratégico da TI para a organização como um todo focando em centralização;

- Por exemplo, a unidade brasileira desenvolveu uma solução de "single sign-on" que é utilizado globalmente;

- Outros exemplos são soluções focadas em mobilidade para acompanhamento do desempenho da produção através de um painel de controle de desempenho ("Dashboard").

A principal executiva da unidade de análise entrevistada foi a diretora de Serviços Compartilhados ("Shared Services") no Brasil. Esta diretora tem, entre outras, as seguintes responsabilidades:

- Lidera um time com 250 profissionais;

- Comanda a área de TI, que está sob responsabilidade direta da Gerente de Sistemas;

- Responsável pelo atendimento das ocorrências nas localidades ("Field Services") para a área de TI em todas as plantas na América Latina;

- Responsável pela gestão do fornecimento terceirizado da Central de Atendimento ("Call Center"), que foi trazido para a principal unidade da TI da organização;

- O ERP Oracle Application atende todas as áreas da organização e está na foi trazido para a principal unidade da TI da organização;

- O mesmo ERP atende as demais unidades de negócios operando no Brasil.

A área de TI da unidade de análise não presta serviços para outras empresas. A TI faz parte da diretoria de serviços compartilhados ("Shared Services") que fornece serviços internamente para todas as fábricas e unidades de negócios nas diversas localidades, mantendo um profissional de suporte técnico em cada uma delas. (B9)

\section{PAPEL ESTRATÉGICO DA TI}


As aplicações em nuvem analisadas indicam integração funcional da $\mathrm{Tl}$ ao negócio automatizando processos que não estão diretamente ligados aos principais negócios da organização.

Os entrevistados entendem que apenas a primeira camada da arquitetura dos sistemas que suportam a operação, isto é, a camada de controle dos processos de produção - sistemas de automação - não pode ser movida para a nuvem, sendo viável estrategicamente a contratação externa das demais camadas. Esta declaração leva a caracterização da área de TI como viabilizadora da execução da estratégica organizacional como sendo sua perspectiva de alinhamento estratégico.

\subsubsection{Análise preliminar da Empresa B}

Como resultado das observações registradas em 5.2.2 é apresentado o registro de referências com as oportunidades para análise (Quadro 13). É feita a seguir uma análise preliminar que procura trazer para o que contexto do trabalho o que foi observado em campo.

A migração para a utilização da CN é uma estratégia da organização, que se desdobra em ações de curto, médio e longo prazo, visando redução de custos dos serviços oferecidos às diferentes unidades de negócio pela Diretoria de Serviços Compartilhados ("Shared Services").

QUADRO 13 - REGISTRO DE REFERÊNCIAS DA EMPRESA B

\begin{tabular}{|l|l|}
\hline \multicolumn{1}{|c|}{ Constructos do Método } & \multicolumn{1}{|c|}{ Contexto / Observações } \\
\hline Modelo de Serviço & $\begin{array}{l}\text { Contrata Software como Serviço (SaaS) e } \\
\text { Infraestrutura como Serviço (laaS). }\end{array}$ \\
\hline Modelo de Implantação & $\begin{array}{l}\text { Nuvem privada dos provedores. (A organização não } \\
\text { possui infraestrutura de nuvem). }\end{array}$ \\
\hline Alinhamento Estratégico & Integração Operacional \\
\hline Eerspectiva de Alinhamento & Execução da estratégia \\
\hline
\end{tabular}




\begin{tabular}{|c|c|}
\hline Constructos do Método & Contexto / Observações \\
\hline Vantagens & $\begin{array}{l}\text { Puderam ser identificadas considerações ou } \\
\text { observações em relação a: } \boldsymbol{V} \mathbf{1}, \mathbf{V} \mathbf{2}, \mathbf{V 7}, \mathbf{V} 8 \text {. }\end{array}$ \\
\hline Desafios & $\begin{array}{l}\text { Puderam ser identificadas considerações ou } \\
\text { observações em relação a: D1, D2, D3, D4 e D5. }\end{array}$ \\
\hline Riscos e Barreiras & $\begin{array}{l}\text { Puderam ser identificadas considerações ou } \\
\text { observações em relação a: } \mathbf{B 1}, \mathbf{B 2}, \mathbf{B 3}, \mathbf{B 5}, \mathbf{B 6}, \mathbf{B 7} \text {, } \\
\mathbf{B 8 ,} \boldsymbol{B} \mathbf{\text { e }} \mathbf{B 1 0} \text {. }\end{array}$ \\
\hline Capacidades essenciais & $\begin{array}{l}\text { São desenvolvidas com foco na execução da } \\
\text { estratégia de evolução para a nuvem. Ou seja, os } \\
\text { profissionais da TI se preparam para aprofundar nos } \\
\text { conhecimentos e habilidades necessárias. }\end{array}$ \\
\hline
\end{tabular}

FONTE: ELABORADO PELO AUTOR

A organização valoriza a colaboração. Para tal, entende que deve disponibilizar acesso aos recursos computacionais aos seus empregados. Entende que a utilização de aplicações em nuvem é parte importante para o atingimento deste objetivo.

A partir de 2005 a empresa definiu como estratégico direcionar os especialistas da TI para o negócio como uma adoção progressiva da TI na nuvem.

\subsection{Empresa $C$}

A unidade de análise identificada como Empresa $C$ é uma universidade pública de grande porte que possui grande variedade de cursos de graduação e pósgraduação, além de desenvolver atividades de pesquisa e de extensão universitária.

\subsubsection{Caracterização da Empresa C}

Criada em meados dos anos 1930, a unidade de análise é uma das mais importantes instituições de nível superior do Brasil. A universidade vêm sendo reconhecida por diferentes rankings mundiais, criados para medir a qualidade das 
universidades a partir de diversos critérios, principalmente os relacionados à produtividade científica.

Esse desempenho, gerado ao longo de 80 anos de uma intensa busca pela excelência, permite à universidade integrar um seleto grupo de instituições de padrão mundial. Sua graduação é formada por aproximadamente 250 cursos, dedicados a todas as áreas do conhecimento, distribuídos em 42 Unidades de Ensino e Pesquisa, com mais de 58 mil alunos. A pós-graduação é composta por 239 programas, dos quais fazem parte 332 cursos de mestrado e 309 de doutorado e que têm mais de 28 mil matriculados. Atualmente, a universidade é responsável por $22 \%$ da produção científica do país.

Para desenvolver suas atividades, a universidade conta com diversos campi distribuídos pelas cidades de São Paulo, Bauru, Lorena, Piracicaba, Pirassununga, Ribeirão Preto, Santos, São Carlos, além de Unidades de Ensino, Museus e Centros de pesquisa situados fora desses espaços e em diferentes municípios.

Além do bom desempenho em rankings internacionais como Academic Ranking of World Universities (ARWU), Webometrics Ranking of World Universities, The Times of Higher Education (THE) e o QS World University Ranking, realizado pelo Quacquarelli Symonds (QS), em 2013 a universidade obteve o 1ํ lugar, pela segunda vez, no Ranking Universitário Folha (RUF), criado pelo jornal Folha de S. Paulo em 2012, para classificar 192 universidades brasileiras, de acordo com indicadores que avaliam a pesquisa, a inserção no mercado de trabalho, o ensino, a inovação e a internacionalização da instituição. A universidade também foi ganhadora do Prêmio Melhores Universidades do Ano, na categoria pública, realizado pelo Guia Abril do Estudante, da Editora Abril.

A área de TI da organização foi criada no inicio dos anos 1960 como Centro de Cálculo Numérico para atender às escolas de engenharia da instituição. Em 1963 Tornou-se um órgão autônomo da reitoria no início dos anos 1970 e uma "unidade universitária" no final dos anos 1980. Possui quase 200 funcionários, sendo cerca de 50 deles com nível universitário e aproximadamente 120 com nível médio (técnicos). 
Em 2013 possuía cerca de 110 mil contas de e-mails cadastras e atendeu a mais de 35.000 chamadas técnicas.

Hoje a infraestrutura da nuvem da universidade serve de 55 a 60 sistemas corporativos para as áreas de graduação, pós-graduação, cultura e extensão, pesquisa, administração, finanças, recursos humanos, relações internacionais, colegiados e serviços como telefonia, diploma, anuários estatísticos, entre outros.

\subsubsection{Adoção da computação em nuvem}

\section{VANTAGENS}

A redução de custos não constitui a principal justificativa para a adoção da nuvem. Como a organização não visa lucros, os benefícios do compartilhamento e da racionalização da infraestrutura de $\mathrm{TI}$, que são sempre buscados, são transferidos para as unidades/departamentos na forma de atendimento da demanda. Isto permite significativa redução no tempo necessário para a colocação de uma infraestrutura de servidores no ar, se comparado ao processo normal de licitação externa para contratação de uma infraestrutura física ou de um prestador de serviço nos moldes de um datacenter externo. (V1)

A nuvem privada da universidade também opera no modelo laaS que será, em suma, parte essencial para potencializar o desenvolvimento de novas pesquisas e projetos na instituição. De acordo com um dos entrevistados: "não há cobrança, o serviço é contínuo. Basta alocar o espaço necessário. Não é necessário fazer solicitação de orçamento com explicações complexas do direcionamento dos gastos. A bilhetagem, agora, é mais para o controle do orçamento dos projetos", detalha o entrevistado.

Especificamente em relação aos sistemas diretamente vinculados à administração e ao controle acadêmico da instituição, com a implantação da nuvem houve economia da infraestrutura e do espaço físico, pela racionalização da utilização dos servidores físicos. Foram criadas máquinas virtuais para atender as mais de 55 aplicações utilizadas na gestão e operação da instituição. (V2) 
São de 55 a 60 sistemas na nuvem, distribuídos para atender às necessidades das atividades:

- Graduação

- Pós-Graduação

- Cultura e Extensão

- Pesquisa

- Administração

- Finanças

- Recursos Humanos

- Gestão

- Relações Internacionais

- Colegiados

- Serviços

Com a implantação da nuvem houve uma maior utilização da infraestrutura de computação pelas unidades/departamentos, em função da redução do tempo e do esforço para a disponibilização de recursos computacionais para as unidades/departamentos. (V3)

Para os entrevistados, as principais vantagens da adoção da nuvem são:

- Alta disponibilidade da infraestrutura da TI

- Disponibilidade dos sistemas críticos para a organização

- Economia da infraestrutura e do espaço físico

- Redução da manutenção

- Atualização tecnológica do HW e do SW

- Acomodação da sazonalidade típica das atividades da organização $\rightarrow$ no período de matrículas agregam-se mais máquinas para os sistemas envolvidos nesta atividade ("elasticidade")

- Atendimento de uma demanda reprimida dentro da organização $\rightarrow$ hoje são mais de 4.500 máquinas virtualizadas (poderia ser entendido como 
sendo "novos mercados" para a área de TI, fazendo um paralelo com o que ocorre nas organizações privadas)

- Aplicações migradas para a nuvem $\rightarrow 120$ servidores que suportam em torno de 60 sistemas

\section{DESAFIOS}

A universidade se enquadra na figura jurídica de uma autarquia ${ }^{6}$ de regime especial, tendo autonomia administrativa para dispor sobre plano de carreira, salários, reajustes etc. De acordo com um dos entrevistados os salários pagos aos profissionais da $\mathrm{TI}$ estão no mesmo nível daqueles pagos pela iniciativa privada. Declarou também os especialistas em nuvem envolvidos no projeto não têm qualquer benefício salarial adicional ou diferenciado dos demais empregados. O plano de carreira do pessoal da TI segue os mesmos critérios das demais carreiras do pessoal técnico administrativo da instituição.

Os profissionais da TI são continuamente treinados nos produtos utilizados na área. Também fazem treinamentos sobre tecnologias emergentes, como BIG DATA, por exemplo. Além disso, existem os cursos de especialização em atividades gerenciais (como mestrado "latu sensu" e MBA) em gestão de projetos, gestão de processos e outras especialidades relacionadas às necessidades da gestão administrativa e da operação das áreas da TI. Os treinamentos acontecem em diferentes domínios do conhecimento e nas diversas faculdades, fundações ou institutos ligados à universidade. Sempre que um curso ou treinamento é solicitado, os gestores da área de $\mathrm{TI}$ se mobilizam para propiciar o treinamento desejado pelo funcionário, desde que aquele esteja alinhado com as necessidades da organização.

\footnotetext{
${ }^{6}$ Autarquias são entes com capacidade exclusivamente administrativa. Possuem a titularidade para a realização de atividades públicas e suas atividades são aquelas típicas da Administração Pública. As suas características e o grau de sua autonomia são as que a lei thes confere. São entidades que gozam de autonomia patrimonial, financeira, orçamentária e imunidade tributária; seus bens são indisponíveis; seus prazos processuais e foro são privilegiados (SANTOS, 2006).
} 
Dentro deste contexto da organização e dos seus recursos humanos, e especificamente no caso do pessoal de $\mathrm{TI}$, um bom resultado do trabalho necessita fortemente do comprometimento dos funcionários, obtidos através da motivação que se origina nos desafios técnicos e gerenciais. Particularmente daqueles envolvidos com as decisões cotidianas e para a evolução da infraestrutura para a nuvem. (D1) Investigar a posição da alta gestão da TI da instituição.

A universidade possui mais de uma centena de data centers, dos mais diferentes portes, espalhados pelas unidades/departamentos. $\mathrm{Na}$ visão do entrevistado, muitos usuários e mesmo fornecedores têm uma visão bastante conservadora da informática. Na computação cientifica é mais evidente esta tendência pela utilização daquilo que já está implantado e que é de domínio do usuário ou do fornecedor de infraestrutura de TI.

As unidades/departamentos podem ser clientes da infraestrutura centralizada ou podem adquirir sua própria infraestrutura de TI. Para o entrevistado, uma eventual resistência em adotar a infraestrutura centralizada, através da nuvem, é decorrente de uma distorção, que faz parte da cultura da organização, que confunde a autonomia de pesquisa das unidades/departamentos com a autonomia administrativa. Assim, algumas unidades/departamentos entendem que para preservar sua autonomia devem ter sua própria infraestrutura de TI. (D2)

Em relação às práticas de desenvolvimento de projetos para a nuvem pôde ser observado situações diferentes na operação e nas áreas de desenvolvimento dos sistemas acadêmicos e administrativos:

- Na área de desenvolvimento de software há processos formais para a gestão dos projetos para atualização, melhorias e manutenção dos sistemas acadêmicos e administrativos.

- Não há projetos regulares na área entrevistada para implantação da infraestrutura da TI. Desta forma, pôde ser observado que:

- Não há um processo formal de gestão de projetos; 
- Os projetos executados pela área foram feitos por consultoria externa para infraestrutura / espaço físico / software / pessoas. (D3)

A $\mathrm{Tl}$ da universidade tem a responsabilidade de manter os sistemas corporativos, a rede e o "backbone" de comunicação de dados disponíveis e atualizados tecnologicamente, não havendo uma atribuição explícita para promover inovações, que não sejam aquelas para a melhoria da prestação dos serviços. As inovações muitas vezes resultam da valorização das iniciativas do funcionário, deixando livre para prospectar as tecnologias emergentes. Existe também uma pressão da sociedade e de outras organizações de mesma natureza que impele a adoção de inovações. Exemplo da empresa Google: se a empresa disponibiliza determinados serviços / facilidades aos seus usuários, por que a infraestrutura da universidade não oferece os mesmos serviços aos membros da comunidade universitária?

De uma maneira geral, uma estratégia de inovação acontece em determinados momentos, nomeadamente quando são necessários saltos tecnológicos (bug do milênio, web, nuvem). Esta estratégia é definida via utilização de estruturas específicas, como fóruns e comitês, com a atribuição de subsidiar as decisões, que nesses casos, normalmente, ficam no nível da reitoria. (D4)

Em relação à evolução da nuvem da universidade, é desejo do gestor da área de TI a sua expansão para além das fronteiras da universidade, para que venha a atender outros órgãos da administração pública estadual. Isso elevaria os padrões de disponibilidade da infraestrutura operacional da nuvem como um todo, além de permitir economias de escala. Contudo, da mesma forma que a gestão da universidade sofre mudanças de tempos em tempos, a estrutura da $\mathrm{Tl}$, como é conduzida por gestores oriundos dos quadros de docentes e pesquisadores da instituição, também é alterada em médio prazo. Esta constatação é coerente com o que pôde ser observado em relação às inovações. (D5)

\section{BARREIRAS}


No modelo de adoção observado, ou seja, através de uma infraestrutura privada para sua nuvem, não apresenta "risco estratégico" adicional àqueles que a universidade. A segurança da informação para proteção às inovações e invenções passíveis de patentes pela universidade deve ser observada independentemente da adoção ou não da CN por uma unidade/departamento. (B1)

A eventual contratação de data centers de terceiros deve ser acompanhada dos cuidados relacionados à segurança da informação. Devem ser protegidas quanto a sua integridade, confidencialidade e disponibilidade os conhecimentos passíveis da geração de patentes, fichas médicas de pacientes tratados nos hospitais universitários, informações sensíveis para a gestão da universidade e das suas unidades/departamentos relacionadas aos processos licitatórios, etc. (B5)

A capacitação técnica das pessoas, diretamente ligadas à organização, que lidam com a infraestrutura da nuvem é feita pelos fornecedores dos produtos de software e hardware que dela fazem parte. (B2)

As barreiras relativas às possíveis deficiências do modelo de negócio $(\boldsymbol{B} 3)$ e à maturidade dos fornecedores (B4) estão fortemente associadas aos três principais fornecedores dos produtos e software para a infraestrutura da nuvem:

- Citrix (Sistema Operacional "Hypervisor XenServer", "CloudPlatform" e "Cloud Portal") - construído sobre o "Apache CloudStack" é uma solução em nuvem para orquestrar cargas de trabalho corporativas tradicionais e de aplicativos nativos em nuvem, fornecendo uma plataforma unificada de gerenciamento da nuvem. Tem a capacidade de interoperar com diferentes soluções de virtualização, dispositivos de armazenamento e redes. A implantação, suporte técnico e treinamentos são fornecidos pela Solve System, que é um parceiro tradicional do fornecedor destas tecnologias.

- Cisco (servidores "blade", roteadores, switches e painéis para conexões) servidores de perfil baixo para montagem em rack e equipamentos de redes e de comunicação de dados. 
- NetApp (sistemas de "storage") são as unidades para armazenamento de dados que oferecem escalabilidade e segurança, através de mecanismos de recuperação e de redundância.

Para o principal executivo da TI, a demanda pelos serviços disponibilizados por esta infraestrutura centralizada oferecida pela universidade é desorganizada em função da falta de disciplinamento ou orientação em relação ao seu uso pelas unidades/departamentos. Para este executivo deveria haver normas de governança corporativa, com recomendações formais em nível organizacional, determinado quando as unidades/departamentos poderiam adquirir e manter infraestrutura próprias de TI separadas da estrutura centralizada e quando seriam utilizados prioritariamente os recursos centralizados. Por questões culturais algumas das unidades/departamentos entendem que devem ter autonomia para fazer os investimentos em TI que entenderem necessários. Para o entrevistado, há uma confusão entre autonomia cientifica, altamente desejável e que deve ser mantida com determinação, e autonomia administrativa que deve pautar-se pela utilização responsável dos recursos da universidade. (B6)

Os entrevistados não identificaram um processo formal de gestão de riscos. Não há um mapeamento dos riscos da operação da infraestrutura de nuvem. A resolução dos incidentes, como queda ou indisponibilidade de links ou servidores, são restabelecidos com a mobilização das áreas envolvidas do departamento de TI, sem seguir um processo formal. (B2) (B9)

A estrutura de suporte técnico aos clientes da infraestrutura da nuvem foi descrito como sendo o que seque:

- HELPDESK - primeiro nível é prestado por área especialmente destinada à função. Atende todos os usuários da TI da organização (alunos, professores, funcionários, unidades, departamentos, etc.).

- Utiliza a biblioteca do ITIL para HELPDESK integrado, tendo o HP OPEN VIEW como ferramenta de monitoramento remoto da infraestrutura física e lógica sob responsabilidade da $\mathrm{TI}$. 
- Não suporta os usuários dos serviços diretamente oferecidos pela nuvem, que são direcionados diretamente para o suporte de "segundo nível", ou seja, a área que está sendo entrevistada (Divisão de Datacenter/Seção de Nuvem).

- A área entrevistada (Divisão de Datacenter/Seção de Nuvem) tem por objetivo da curto/médio prazo a capacitação da área de HELPDESK para que também deem suporte de "primeiro nível" para nuvem.

Há uma consultoria trabalhando com o pessoal da área de TI para a ampliação do uso do ITIL com a sua implantação nas demais áreas que compõem a estrutura da TI.

A universidade dispõe de conexões e links de comunicação com a internet, que podem ser descritos como sendo:

- Conexão com a Internet para os data centers é de 10 GB (no mínimo)

- Acesso a Internet pelas unidades/departamentos de 1 GB (tipicamente)

- O Centro de Computação Eletrônica e as unidades/departamentos possuem uma rede física de links de conexões exclusiva da universidade

- Excepcionalmente é possível acessar a infraestrutura que está na nuvem da universidade pelas conexões usuais (comerciais) de Internet

- Esta infraestrutura é definida com uma nuvem privada $\rightarrow$ composta dos links de comunicação e dos datacenters.

Em relação aos data centers os entrevistados da unidade de análise informaram que:

- Campus principal (pioneiro e o maior datacenter da instituição)

- Região metropolitana (mais recente e menor que o do campus principal)

Desta forma, as aplicações que compartilham dados através de um Sistema Gerenciador de Banco de Dados (SGBD) podem utilizar o armazenamento de dados em um mesmo data center, ainda que esteja em SGBDs diferentes ou mesmo que residam em diferentes unidade físicas de armazenamento ("Storages").

No que diz respeito à governança de TI foi possível observar que: 
- Não há um processo formal de governança de TI.

- Informações sobre serviços prestados, clientes atendidos, infraestrutura como servidores e links de comunicação, bem como os investimentos planejados são informados para as áreas usuárias ou internas da organização sempre que necessários em apresentações feitas pelos gestores dos níveis mais altos.

- Investimentos em TI, bem como outras informações sobre os serviços e a estratégia da TI são apresentados no site através de um canal de televisão próprio para divulgação de informações do interesse da universidade e da comunidade.

A universidade investe na manutenção dos seus data centers, sempre com os mais elevados padrões de qualidades do mercado. O mesmo rigor ocorre quando é necessária a contratação de data centers de terceiros para aumento da sua capacidade para entrega dos serviços. Estas ações estão voltadas para assegura a disponibilidade, confiabilidade e qualidade do fornecimento. (B7) (B8) (B9)

Até o momento das entrevistas com a unidade de análise, esta não celebra acordos formais de níveis de serviço com as unidades/departamentos. Eventuais problemas de indisponibilidade ou falta de qualidade na prestação dos serviços são tratados entre os diretores das unidades/departamentos de forma pontual e com o propósito específico de resolver o problema em questão. (B7) (B10)

\section{PAPEL ESTRATÉGICO DA TI}

A implantação da nuvem pode ser uma ferramenta de grande mudança organizacional, declarou um dos entrevistados, ao viabilizar a implantação de mecanismos de controle para utilização da infraestrutura da TI da organização, evitando, assim, o desvio no seu uso.

Além disto, uma revisão dos processos, sempre necessários quando da implantação de um novo SI, carrega um benefício independente da adoção da $\mathrm{TI}$, que consiste no trabalho de crítica aos processos existentes, gerando oportunidades de melhorias, racionalizações dos recursos, economias de escala, redução dos 
prazos, etc. Um exemplo desta situação é o Diploma Digital. Com a informatização do processo de registro e emissão dos diplomas, seria possível emitir o diploma instantaneamente; ou seja, seria já emitido no momento da colação de grau. (isto somente ainda não ocorre porque a colação de grau hoje faz parte do processo).

Estas declarações sugerem o enquadramento da TI como promotora de um "ajuste estratégico", através dos benefícios trazidos pelos aumentos de produtividade e redução de falhas e desperdícios, obtidos através do monitoramento da utilização dos recursos, e da disponibilidade de um serviço inovador à comunidade ("Diploma Digital"), que distinguiria a organização da demais. Neste caso, a TI faz a ligação entre a estratégia de negócio e a TI, evidenciando a capacidade da TI tanto de suportar como modelar estratégias de negócio.

Em relação à perspectiva de alinhamento estratégico, a $\mathrm{TI}$ pode ser considerada com suportando a execução da estratégia da organização ao disponibilizar os sistemas acadêmicos seguros, confiáveis e disponíveis nos períodos em que são necessários.

\subsubsection{Análise preliminar da Empresa $C$}

Como resultado das observações registradas em 5.3.2 é apresentado o registro de referências com as oportunidades para análise (Quadro 14). É feita a seguir uma análise preliminar que procura trazer para o que contexto do trabalho 0 que foi observado em campo.

A CN oferece vantagens amplamente conhecidas, decorrentes do compartilhamento dos recursos. No entanto, para o responsável pelo projeto de implantação da nuvem na unidade de análise, é preciso que exista um problema para ser resolvido. No caso da universidade havia um projeto no contexto científico e acadêmico para a utilização da nuvem. Contudo, o projeto que se concretizou foi adotar a nuvem para a informática administrativa.

O principal benefício para os sistemas internos e para gestão e operação e para as unidades/departamentos não está diretamente relacionado com investimento de capital. Os ganhos são no esforço e tempo anteriormente gastos 
nos processos licitatórios distribuídos pelas unidades/departamentos, o que algumas vezes acabava dificultando ou inviabilizando alguns projetos de pesquisa.

Ainda que este não tenha sido o principal objetivo alcançado pelo projeto, houve uma otimização nos recursos computacionais e, por consequência no espaço físico, representando um menor custo de operação.

Havia uma demanda reprimida pelo esforço e tempo que seriam gastos nos processos licitatórios conduzidos pelas unidades/departamentos. O oferecimento da infraestrutura como serviço (laaS) possibilitou que um maior número de unidades/departamentos passassem a utilizar recursos computacionais em seus projetos de ensino, pesquisa e extensão, que são as atividades fim da instituição.

QUADRO 14 - REGISTRO DE REFERÊNCIAS DA EMPRESA C

\begin{tabular}{|c|c|}
\hline Constructos do Método & Contexto / Observações \\
\hline Modelo de Serviço & $\begin{array}{l}\text { SaaS (para os Sistemas Acadêmicos) e laaS (para a } \\
\text { fornecimento de infraestrutura para as unidades). }\end{array}$ \\
\hline Modelo de Implantação & $\begin{array}{l}\text { Nuvem privada (construída sobre infraestrutura } \\
\text { própria e também infraestrutura contratada). }\end{array}$ \\
\hline Alinhamento Estratégico & Ajuste estratégico. \\
\hline $\begin{array}{l}\text { Perspectiva de Alinhamento } \\
\text { Estratégico }\end{array}$ & Execução da estratégia. \\
\hline Vantagens & $\begin{array}{l}\text { Puderam ser identificadas considerações ou } \\
\text { observações em relação a: } \mathbf{V} \mathbf{1}, \mathbf{V} \mathbf{2}, \mathbf{V} \mathbf{3} \text {. }\end{array}$ \\
\hline Desafios & $\begin{array}{l}\text { Puderam ser identificadas considerações ou } \\
\text { observações em relação a: D1, D2, D3, D4 e D5. }\end{array}$ \\
\hline Riscos e Barreiras & $\begin{array}{l}\text { Puderam ser identificadas considerações ou } \\
\text { observações em relação a: } \mathbf{B 1}, \mathbf{B 2}, \mathbf{B 3}, \mathbf{B 4}, \mathbf{B 5}, \mathbf{B} 6 \text {, } \\
\mathbf{B 7 ,} \mathbf{B 8 ,} \mathbf{B 9} \text { e } \mathbf{B 1 0} \text {. }\end{array}$ \\
\hline
\end{tabular}




\begin{tabular}{|l|l|}
\hline \multicolumn{1}{|c|}{ Constructos do Método } & \multicolumn{1}{|c|}{ Contexto / Observações } \\
\hline Capacidades essenciais & $\begin{array}{l}\text { Não são buscadas para atender às necessidades da } \\
\text { adoção da nuvem. Conhecimento em grande parte de } \\
\text { posse dos fornecedores. Não há uma estrutura, } \\
\text { formal ou informal, preocupada com a evolução da } \\
\text { nuvem. }\end{array}$ \\
\hline
\end{tabular}

FONTE: ELABORADO PELO AUTOR

\subsection{Empresa D}

A unidade de análise é uma empresa nacional de capital aberto, que está entre os maiores desenvolvedores de Sistema de Gestão Empresarial Integrada (sistemas $E R P$ ) do mundo. Está presente em mais de 20 países, sendo que em dois deles com unidades próprias.

\subsubsection{Caracterização da Empresa D}

As soluções da Empresa D incluem softwares de gestão empresarial integrada ("ERP"), gerenciamento de relacionamento com clientes ("CRM"), Business Intelligence ("Bl') e Supply Chain Management ("SCM'), bem como módulos industriais específicos que fornecem capacidades adicionais feitas sob medida especificamente para os ramos de negócio dos seus clientes.

A empresa acredita que o maior valor da tecnologia ocorre quando possibilita às organizações conectar, pensar e trabalhar juntas. Por isto, trabalha com e para os seus clientes. Entende também, que neste momento a oportunidade é compatibilizar o presente com futuro evoluindo suas ofertas com a implementação de três conceitos:

- A tecnologia tem que ser fácil de utilizar e implementar, simples e móvel, que promove produtividade, compartilhamento e colaboração, impactando um maior número de indivíduos e empresas

- Ofertas específicas orientadas ao negócio principal com total aderência em cada segmento. 
- Sistemas de Gestão por segmento, que passam por melhorias contínuas para ficarem sempre mais leves e focados no principal negócio das organizações. Devem estar disponíveis em "cloud computing" e "mobile" promovendo uma interface de uso natural. Este é um tema de grande preocupação para a unidade de análise.

Nos últimos 20 anos, a organização construiu um eficiente e abrangente mecanismo de distribuição. Possui um balanceado sistema de franquias e unidades próprias que possibilita a cobertura em todo o Brasil, nos principais países da América Latina e na Europa. Cada franquia é operada por empreendedores locais, para garantir rapidez e conhecimento da região. A experiência nos mercados brasileiro e latino americano permitiu desenvolver produtos já localizados, adaptáveis às alterações de legislação, flutuações econômicas e necessidades especiais, como diferenças culturais entre regiões. Para a empresa, a união da abrangência e o profundo conhecimento dos mercados constituem um elemento estratégico fundamental para a liderança que a organização exerce.

\section{Plataforma "agnóstica"}

Em um mundo dos negócios onde as empresas precisam ter controle sobre suas operações e, ao mesmo tempo, agilidade para atender aos diversos processos que acontecem simultaneamente, a organização entende que a forma de interação mudou. Assim, a comunicação e os procedimentos são determinados, mas não rígidos, e a única constância é justamente a mudança e tudo precisa estar à mão dos gestores.

Entendendo a mudança no comportamento dos indivíduos no ambiente corporativo e as demandas tecnológicas, a organização criou a plataforma (Aplicação SaaS, foco da análise) com o objetivo de centralizar em uma única tela todos os processos, documentos e sistemas, com um controle de acesso para identificação e autenticação ("login") único, em uma interface de comunicação colaborativa. 
Unificada em 2013, essa plataforma de produtividade vem evoluindo ao longo de mais de uma década - tudo começou em 2000, com o desenvolvimento de uma solução de Enterprise Content Management (ECM) com funcionalidades como Workflow (processos) e Document Management (documentos). Em 2008, incorporado um Business Process Management (BPM) e lançado um componente de Enterprise Service Bus (ESB) para integração entre sistemas.

Dois anos depois, a organização apresentou ao mercado a sua rede social corporativa e um ambiente de geração de negócio entre empresas. Já em 2012, mais dois novos componentes: um para gestão de identidades, criado por um laboratório de tecnologia no Vale do Silício e outro para construção de forma mais ágil de portais para Intranet ou Extranets.

Por último, em 2013, foi feito um grande investimento em um motor de "Analytics" (análise de dados) para a criação de painéis de controle ("Dashboards") e visões gerenciais e que, em conjunto com os outros componentes, deu origem à plataforma (Aplicação SaaS, foco da análise deste trabalho) - uma plataforma agnóstica (funciona como interface de qualquer ERP do mercado) de gestão de processos, documentos e identidades em uma interface única de comunicação colaborativa.

\subsubsection{Adoção da computação em nuvem}

\section{VANTAGENS}

Ao oferecer os seus sistemas de ERP no modelo SaaS a organização busca capturar o benefício de redução do custo de capital para os seus novos clientes. Hoje, para os clientes em carteira, a remuneração de software é feita como pagamentos mensais por quantidade de licenças utilizadas ou pagamento a vista no ato da compra, mais pagamentos anuais, a título de manutenção. Portanto, a redução do custo de capital do cliente é um objetivo para o oferecimento de serviços na nuvem para ampliação da base de clientes existentes. (V1)

A redução do custo de capital do fornecedor é um objetivo da fornecedora de sistemas ERP quando contrata infraestrutura em data centers de terceiros. Este não 
é um objetivo central para o oferecimento de serviços na nuvem, uma vez que a unidade de análise vem fazendo investimentos em data centers próprios, bem como na sua certificação para os padrões mais elevados, como Tier $5^{7}$, por exemplo. No entanto, sempre que há necessidade de aumenta da capacidade da sua infraestrutura isto é feito inicialmente com a contratação de data centers de terceiros, em geral fora do país. (V2)

A unidade de análise não tira proveito da redução do ciclo de implementação, uma vez que atua como fornecedora das soluções e também as disponibiliza para os seus clientes como serviço na nuvem. (V3)

O investimento em Data Centers para o oferecimento dos ERP na modalidade SaaS induziu ao oferecimento de laaS como uma consequência da disponibilidade e do conhecimento propiciado pela infraestrutura dos Data Centers, ou seja, houve uma redução no custo de entrada em um novos negócio. (V4)

O oferecer os sistemas de ERP no modelo SaaS reduz custo de ampliação do negócio ou de entrada em novos mercados. Ou seja, possibilita uma ampliação da base de potenciais clientes pela possibilidade de contratação dos ERP como serviço, com custos menores que o da venda pelos canais tradicionais. (V5)

A facilidade de manutenção é uma característica intrínseca do modelo de software como serviço, que deverá ser largamente aproveitada pela organização em função da quantidade de produtos ofertados e plataforma sobre as quais estes produtos operam. (V6)

A maior flexibilidade no lançamento de novas funcionalidades de negócios, produtos, correções e melhorias é uma característica intrínseca do modelo de software como serviço, que também deverá ser largamente aproveitada pelas mesmas razões que a facilidade de manutenção. (V6)

\footnotetext{
${ }^{7}$ Tier Standard: Norma TIA 942 da Associação das Indústrias de Telecomunicações ( TIA) descreve os requisitos para a infraestrutura de data centers. Fonte: (UPTIME, 2014)
} 
A flexibilidade estratégica não é uma vantagem para uma fornecedora de sistemas ERP. A organização se beneficia de características dos produtos e serviços que fidelizem seus clientes ou, eventualmente, dificultem a migração para soluções de fornecedores concorrentes. (V7)

No foco nos negócios da organização estão os sistemas ERP independentemente da forma com são oferecidos. Portanto, este não é um benefício que decorre da computação em nuvem para a organização foco da análise. (V8)

O acesso aos recursos de ponta de tecnologia de TI é um benefício que pode ser obtido pela unidade de análise e, por consequência, seus clientes. A empresa oferece aos clientes infraestrutura no "estado-da-arte", que eventualmente não estaria disponível para alguns clientes em função do porte e/ou domínio das tecnologias envolvidas. (V9)

$O$ acesso aos produtos da empresa (sistemas $E R P$ ) disponibilizados a partir dos novos "gadgets", como os smartphones, tabletes e outros dispositivos, provavelmente deverá exigir pouco ou nenhum treinamento dos usuários devido à semelhança com as demais aplicações e com o "look \& feel" destes equipamentos móveis. (V9)

Ao oferecer os sistemas de ERP no modelo SaaS, a empresa pôde propiciar aos seus cliente uma melhoria geral da qualidade por eles percebida. Na verdade, este benefício é resultado da facilidade de manutenção dos sistemas ERP e sua oferta a partir de data centers altamente confiáveis e disponíveis. (V10)

\section{DESAFIOS}

Um dos entrevistados informou que, de uma maneira geral, os treinamentos para os empregados da empresa são atendidos mediante solicitação quando estiverem de acordo com as necessidades da organização, sempre de acordo com o entendimento do gestor imediato. (D1)

Como em outras organizações do porte da unidade de análise, a remuneração variável é atrelada ao cumprimento de metas especificas da área e do resultado da organização com um todo. (D1) 
De acordo com um dos entrevistados, os desafios tecnológicos aos quais os técnicos estão expostos criam um ambiente propício à experimentação, inovação e consequentes mudanças. (D2)

De outro lado, a migração dos sistemas para uma plataforma unificada da nuvem é um enorme desafio para a alta gerência. Os produtos são oriundos de empresas adquiridas que muitas vezes mantêm sua cultura mesmo tendo sido passados anos desde a aquisição. Este é o principal desafio gerencial para o movimento estratégico para a nuvem desejado pela alta gestão da organização. (D2)

Projetos de desenvolvimento do software foco de análise utiliza metodologia "Scrum", também conhecido como "metodologia ágil para o desenvolvimento softwares ou de aplicações". (D3)

A organização possui um processo formal para o desenvolvimento de projetos. No entanto, cada uma das áreas pode fazer adaptações da metodologia para adequação as peculiaridades dos segmentos/projetos. No passado a organização foi certificada CMMI. Atualmente os processos seguem as boas práticas (PMBOK, CMMI, etc.), mas não são formalmente certificados. (D3)

Projetos de infraestrutura utilizam a metodologia proposta para pela área de qualidade para os projetos da organização. (D3)

A migração dos sistemas ERP para serem oferecidos na nuvem é uma prioridade para a organização. Os produtos e infraestrutura devem evoluir/convergir para o oferecimento na nuvem. Porém, também pode ser licenciados para instalação na infraestrutura dos clientes ("on premises"). (D4)

A organização trata inovação como sinônimo de evolução dos produtos. Para a organização a inovação é representada por um "road map" de lançamentos de novas revisões e versões dos produtos existentes. A organização historicamente faz aquisições para incorporar novas tecnologias, ou ainda, tecnologias maduras, mas que possam preencher alguma lacuna existente no seu domínio das tecnologias ou no seu portfólio de produtos. (D4) 
São chamados "evangelizadores" os funcionários que têm a missão de levar os produtos da organização para os seus clientes e, no sentido contrário, trazer as solicitação/necessidades dos clientes para que sejam incorporada nos produtos dentro do um "road map" acordado com as áreas de desenvolvimento, marketing, vendas, alta direção da organização, etc. (D4)

A organização tem tradição de aquisição de empresas que possam ampliar ou complementar seu portfolio de produtos e sua base de clientes. Em geral as empresas adquiridas continuam a operar com autonomia comercial, ou seja, continuam atendo à sua base original de clientes e vão aos poucos se integrando às praticas de desenvolvimento de sistemas e outras práticas coorporativas como, por exemplo, os processos de garantia e controle da qualidade. (D5)

Há uma determinação da alta gestão da organização para tratar iniciativas para nuvem com estratégicas. Este fato pôde ser observado pela da criação de um "produto portal" projetado nativamente para funcionar com as tecnologias da nuvem, através do qual todos os demais sistemas poderão ser acessados através da Internet, na modalidade de software como serviço. (D5)

Na mesma direção da determinação da adoção da nuvem como estratégica para a organização são feitos investimentos para aquisição de novos produtos com tecnologias relacionadas à nuvem como data centers e suas certificações e aquisição de empresas com produtos e conhecimento em mobilidade. (D5)

\section{BARREIRAS}

Existe a preocupação de preservar o conhecimento de negócios contido nos sistemas ERP. Desta forma, estes sistemas devem ser oferecidos na nuvem através de uma nuvem privada na qual a organização tenha garantias da segurança dos ativos da empresa. (B1)

A unidade de análise tem como estratégia um reposicionamento de fornecedor de produtos (ERP) para um fornecedor de serviços desses mesmos sistemas. Este reposicionamento deve ser feito com cuidado para que, no caso da redução das receitas de aquisição e de manutenção dos seus produtos tradicionais, 
estas receitas perdidas venham a ser cobertas pelas receitas provenientes dos serviços prestados, eventualmente, para uma base maior de clientes (B3)

O portfólio de produtos para ERP foi montado a partir da aquisição de uma série de empresas ao longo dos anos. Em muitos casos o antigo proprietário continua como o executivo mais importante daquela unidade de negócios, focado na evolução dos produtos sobre a sua gestão e para o atendimento, manutenção e crescimento de sua base de clientes com os produtos que controla. (B6)

A organização tem processos maduros e bem definidos para lidar com as possíveis falhas de segurança das informações, disponibilidade e desempenho dos seus sistemas para ERP, quando são fornecidos como serviços. Existem planos para "disaster recovery", bem com alternativas de contingência para eventuais falhas que possam comprometer o fornecimento dos serviços. Também há processo formal para escalar incidentes e para melhoria do Plano de Segurança da Informação (PSI).

Processos de governança corporativa, para gestão de riscos e para garantia e controle da qualidade são constantemente revistos, visando assegurar a segurança das informações, o desempenho dos sistemas, o que evidencia a maturidade do fornecedor. (B4) (B5) (B8)

A empresa, como fornecedora de sistemas ERP como serviço, investe no desenvolvimento de sistemas e nos processos de garantia e controle da qualidade deste desenvolvimento, procurando entregar seus produtos com o mínimo de erros ou problemas nos sistemas que a engenharia de software permite atualmente. (B9)

A unidade de análise também investe na construção e na manutenção dos seus data centers, sempre com os padrões de qualidades ("Padrão Tiers 3,4") mais elevados encontrados no mercado. O mesmo rigor ocorre quando é necessária a contratação de data centers de terceiros para aumento da sua capacidade para entrega dos serviços. Estas ações estão voltadas para assegura a disponibilidade, confiabilidade e o atendimento dos Acordos de Nível de Serviço (SLAs) e de qualidade do fornecimento, novamente demonstrado a maturidade do fornecedor. (B4) (B7) (B9) (B10) 


\section{PAPEL ESTRATÉGICO DA TI}

O fato da unidade de análise ser ela própria fornecedora de solução de TI evidencia o papel de ajuste estratégico da TI. O próprio direcionamento estratégico da alta gerência da organização para disponibilizar os sistemas de ERP como serviços na nuvem sinalizam claramente esta orientação.

Em relação à perspectiva de alinhamento estratégico, a Tl reflete como a tecnologia emergente da $\mathrm{CN}$ tem a capacidade, tanto de influenciar ou habilitar novas estratégias de negócio, como novas oportunidades de mercado. Assim, a perspectiva é a TI alavancar o potencial competitivo da organização, desde que tomados os cuidados para a manutenção da base de clientes, independentemente se adquirindo produtos tradicionais ou serviços da nuvem.

\subsubsection{Análise preliminar da Empresa $D$}

Como resultado das observações registradas em 5.4.2 é apresentado o registro de referências com as oportunidades para análise (Quadro 15). É feita a seguir uma análise preliminar que procura trazer para o que contexto do trabalho o que foi observado em campo.

A utilização do modelo da computação em nuvem em larga escala para os sistemas de ERP foi apontado por todos os entrevistados como sendo um objetivo estratégico e altamente prioritário para a alta gerência da empresa. Esta estratégia pressupõe a migração de todos os diferentes produtos para um produto nascido para a nuvem e que é apontado a plataforma técnica para a qual todos os demais ERP deverão migrar ou interoperar (como um "front end"). No entanto, para este objetivo seja atingido é preciso que:

- O modelo de remuneração para da $\mathrm{CN}$ não represente perda de receita dos produtos tradicionais da organização, resultando na redução global do faturamento e da margem de lucro.

- Haja o envolvimento dos gestores das diversas unidades de negócio, para que sejam dedicados os esforços para a migração dos módulos 
do ERP para nuvem, incluindo a utilização de dispositivos móveis com interfaces viáveis para a utilização destes sistemas.

- Evoluam as ferramentas da infraestrutura da nuvem, que dão suporte às aplicações como serviços, para incorporar suas características essenciais, como a contratação através da Internet e a medição dos serviços ("accounting") utilizados pelos clientes.

QUADRO 15 - REGISTRO DE REFERÊNCIAS DA EMPRESA D

\begin{tabular}{|c|c|}
\hline Constructos do Método & Contexto / Observações \\
\hline Modelo de Serviço & $\begin{array}{l}\text { Fornece Infraestrutura como Serviço (laaS) e } \\
\text { Software como Serviço (SaaS). }\end{array}$ \\
\hline Modelo de Implantação & $\begin{array}{l}\text { Nuvem privada (construída sobre infraestrutura } \\
\text { própria e também infraestrutura contratada). }\end{array}$ \\
\hline Alinhamento Estratégico & Ajuste Estratégico. \\
\hline $\begin{array}{l}\text { Perspectiva de Alinhamento } \\
\text { Estratégico }\end{array}$ & Potencial competitivo. \\
\hline Vantagens & 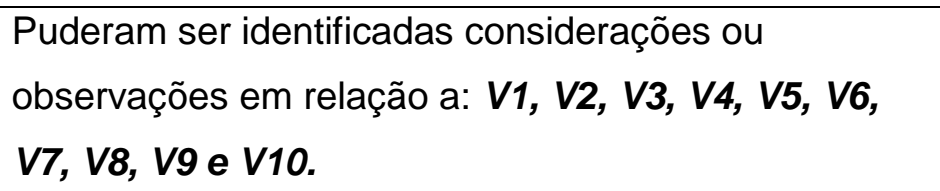 \\
\hline Desafios & $\begin{array}{l}\text { Puderam ser identificadas considerações ou } \\
\text { observações em relação a: D1, D2, D3, D4 e D5. }\end{array}$ \\
\hline Riscos e Barreiras & $\begin{array}{l}\text { Puderam ser identificadas considerações ou } \\
\text { observações em relação a: } B 1, B 3, B 4, B 5, B 6, B 7, \\
B 8, B 9 \text { e } B 10 \text {. }\end{array}$ \\
\hline Capacidades essenciais & $\begin{array}{l}\text { Em alguns casos, as capacidades para lidar com } \\
\text { desafios típicos CN já estão desenvolvidas e são } \\
\text { desempenhadas. }\end{array}$ \\
\hline
\end{tabular}

FONTE: ELABORADO PELO AUTOR 


\section{RESULTADOS OBTIDOS E DISCUSSÕES}

De acordo com Yin (2005), a análise dos casos torna-se uma atividade particularmente difícil se as estratégias e técnicas de pesquisa não tiverem sido cuidadosamente definidas. O autor elenca cinco técnicas especificas para analisar os estudos de casos: adequação ao padrão, construção da explanação, análise de séries temporais, modelos lógicos e síntese de casos cruzados. Este estudo segue a técnica da adequação ao padrão. Desta forma, as análises estão baseadas nas proposições teóricas identificadas na construção do referencial teórico, que no caso deste trabalho foram utilizadas na construção do Método de Análise.

Portanto, o processo de análise consiste na retomada da literatura de referência, utilizando-se do Método de Análise, que confrontado com as reflexões surgidas da pesquisa em campo, possam ser analisadas objetivando confirmar ou refutar o que está descrito na teoria e prescrito pelo Método.

\subsection{Discussão dos resultados}

A partir das observações e análises são apresentados neste capítulo os resultados do trabalho, fazendo uso do Método de Análise para adoção da CN proposto (4.1). Com este objetivo, foram registrados os resultados da análise em relação às áreas de capacidades essenciais, correspondendo ao Quadro 16 para Gestão da Função TI (MNG), Quadro 17 para os Objetivos de Negócios (BOB), Quadro 18 para Atributos da Qualidade dos Serviços (QAS) e Quadro 19 para Decisões de Arquitetura (ARC).

Conforme definido no Roteiro para aplicação do Método de Análise (4.2) as análises devem ser resumidas/codificadas nas seguintes legendas para formação do quadro geral em relação aos DESAFIOS relativos à capacidade Gestão da Função TI (MNG), estratificadas da seguinte forma:

- Capacidade Estruturada formalmente ( formais para execução das tarefas necessárias para o desempenho daquele desafio específico. Por exemplo: gestão de projetos, gestão de riscos, etc. 
- Capacidade Existente sem processo formal ( $\beta$ ) - os processos necessários para a execução das tarefas foram identificados, mas não foi informada a existência de um processo formal para tratar daquele desafio em específico.

- Capacidade inexistente / não identificada pelo método ( $)$ - uma determinada capacidade não foi identificada ou inexiste naquela unidade de análise para enfrentar um determinado desafio.

A notação ( $(3)$ significa que, independentemente da existência ou não dos processos formais para execução das tarefas, a organização tem preocupações especificas com as questões relacionadas com a nuvem para lidar com aquele determinado desafio.

Seguindo o mesmo princípio estabelecido para os DESAFIOS, as análises devem ser resumidas/codificadas nas seguintes legendas para formação do quadro geral em relação às VANTAGENS relativas às capacidades: Objetivos de Negócios $(B O B)$, Atributos da Qualidade dos Serviços (QAS) e Decisões de Arquitetura $(A R C)$, que são estratificadas da seguinte forma:

- Vantagem observada ( ) - a vantagem foi obtida com a adoção da CN naquela determinada unidade de análise.

- Vantagem não encontrada ( $\forall$ ) - não foi encontrada especificamente aquela vantagem na unidade de análise.

- Vantagem não observada (W) - não foi possível observar se aquela vantagem foi ou não obtida naquela unidade de análise.

As análises foram resumidas/codificadas nas seguintes legendas para formação do quadro geral em relação aos RISCOS E BARREIRAS relativas às capacidades Gestão da Função TI (MNG), Objetivos de Negócios (BOB) e Atributos da Qualidade dos Serviços (QAS) que foram estratificadas da seguinte forma: 
- Barreira encontrada ( encontrada naquela determinada unidade de análise.

- Barreira não encontrada $(V)$ ) - o risco ou barreira para a adoção da $\mathrm{CN}$ não foi identificada naquela determinada unidade de análise.

- Barreira não observada ( $)$ - o risco ou barreira para a adoção da nuvem não pôde ser observada naquela unidade de análise.

QuADRO 16 - EVIDÊnCIAS ENCONTRADAS EM GESTÃo dA FunçÃo TI (MNG)

\begin{tabular}{|c|c|c|c|c|}
\hline Gestão da Função TI (MNG) & Empresa A & Empresa B & Empresa C & Empresa D \\
\hline Recursos Humanos (D1) & & & & ر \\
\hline Mudança no "ethos" (D2) & & & & $\beta$ \\
\hline Gestão de Projetos (D3) & & & & \\
\hline Inovação (D4) & & & & \\
\hline $\begin{array}{l}\text { Evolução com a } \\
\text { Nuvem (D5) }\end{array}$ & & & & \\
\hline $\begin{array}{l}\text { Falta de capacidade } \\
\text { técnica (B2) }\end{array}$ & & & $\checkmark$ & \\
\hline $\begin{array}{l}\text { Maturidade do } \\
\text { fornecedor (B4) }\end{array}$ & & & & \\
\hline $\begin{array}{l}\text { Tradição } \\
\text { comportamental (B6) }\end{array}$ & i & & in & \\
\hline
\end{tabular}

FONTE: ELABORADO PELO AUTOR 
Notas relacionadas às evidências encontradas em Gestão da Função TI (MNG) (Quadro 16):

* A unidade A tem apenas três pessoas na equipe de TI. Quando necessários os projetos são contratados junto a empresas especializadas e executados de acordo com as práticas da contratada.

** A capacitação técnica mencionada pela literatura pesquisada refere-se aos quadros internos da organização ("in house"), como mencionado anteriormente a unidade de análise $\mathbf{A}$ tem poucos profissionais atuando na $\mathrm{Tl}$ em tarefas de gestão da infraestrutura de $\mathrm{Tl}$ e suporte técnico aos usuários. No caso da unidade de análise $\mathbf{B}$, a capacitação técnica para a $\mathrm{CN}$ é dos fornecedores dos equipamentos $\mathrm{e}$ softwares utilizados para viabilizar a infraestrutura da nuvem.

QuAdRo 17 - EVIDÊnCIAS EnCONTRADAS Em OBJetivos de Negócios (BOB)

\begin{tabular}{|l|l|l|l|l|}
\hline $\begin{array}{l}\text { Objetivos de Negócios } \\
\text { (BOB) }\end{array}$ & Empresa A & Empresa B & Empresa C & Empresa D \\
\hline Custo de capital do cliente (V1) & & & & \\
\hline $\begin{array}{l}\text { Custo de capital do } \\
\text { fornecedor (V2) }\end{array}$ & & & & \\
\hline $\begin{array}{l}\text { Ciclo de implementação é } \\
\text { reduzido (V3) }\end{array}$ & & & & \\
\hline $\begin{array}{l}\text { Custo de entrada em novos } \\
\text { negócios (V4) }\end{array}$ & & & & \\
\hline $\begin{array}{l}\text { Custo de ampliação do negócio } \\
\text { ou de entrada em novos } \\
\text { mercados (V5) }\end{array}$ & & & & \\
\hline \begin{tabular}{l} 
Facilidade de manutenção (V6) \\
\hline
\end{tabular} & & & & \\
\hline
\end{tabular}




\begin{tabular}{|l|l|l|l|l|}
\hline $\begin{array}{l}\text { Objetivos de Negócios } \\
\text { (BOB) }\end{array}$ & Empresa A & Empresa B & Empresa C & Empresa D \\
\hline $\begin{array}{l}\text { Flexibilidade estratégica (V7) } \\
\text { Foco nos negócio da } \\
\text { organização (V8) }\end{array}$ & & & & \\
\hline $\begin{array}{l}\text { Viabilidade estratégica da } \\
\text { contratação externa ou } \\
\text { oferecimento de determinados } \\
\text { serviços (B1) }\end{array}$ & & & & \\
\hline $\begin{array}{l}\text { Deficiências do modelo de } \\
\text { negócio (B3) }\end{array}$ & & & & \\
\hline
\end{tabular}

FONTE: ELABORADO PELO AUTOR

Notas relacionadas às evidências encontradas em Objetivos de Negócios (BOB) (Quadro 17):

* A unidade C é uma autarquia e não tem fins lucrativos. Desta forma, esta vantagem V8 deve ser encarada como sendo o foco nas atividades fins da organização, que são o ensino, pesquisa, extensão, etc.

** Outra particularidade da unidade $\mathbf{C}$ acontece em relação à barreira $\mathbf{B 1}, \mathbf{a}$ inexistência da barreira "viabilidade estratégica da contratação externa ou oferecimento de determinados serviços" não significa que a organização não tenha conhecimentos que devam ser protegidos. No entanto, a maneira de proteger este conhecimento é através de mecanismos de registros de patentes e outros típicos para proteção de ativos das organizações de pesquisa técnico-científicas.

*** A unidade de análise tem como estratégia um reposicionamento de fornecedor de produtos (sistemas ERP) para um fornecedor de serviços desses mesmos sistemas. Este reposicionamento deve ser feito com cuidado para que, no caso da redução das receitas de aquisição e de manutenção dos seus produtos 
tradicionais, estas receitas perdidas venham a ser cobertas pelas receitas provenientes dos serviços prestados, eventualmente, para uma base maior de clientes. Desta forma, caberá direcionar os benefícios da nuvem adequadamente para os clientes, sem que haja perda significativa da receita da modalidade de fornecimento tradicional.

QUADRO 18 - EVIDÊNCIAS ENCONTRADAS EM QUALIDADE DOS SERVIÇOS (QAS)

\begin{tabular}{|l|l|l|l|l|}
\hline $\begin{array}{l}\text { Atributos da Qualidade dos } \\
\text { Serviços (QAS) }\end{array}$ & Empresa A & Empresa B & Empresa C & Empresa D \\
\hline Facilidade de manutenção (V6) & & & & \\
\hline Melhoria da qualidade (V10) & & & & \\
\hline Gestão de Projetos (D3) & & & & \\
\hline Evolução com a Nuvem (D5) & & & & \\
\hline Falhas de segurança (B5) & & & & \\
\hline Disponibilidade (B7) & & & & \\
\hline Acordos de nível de serviço & & & & \\
\hline (SLAs) e qualidade (B10) & & & & \\
\hline Fesempenho (B8) & & & & \\
\hline
\end{tabular}

FONTE: ELABORADO PELO AUTOR

Nota relacionada às evidências encontradas em Qualidade dos Serviços (QAS) (Quadro 18): 
* Na unidade $\mathbf{C}$ as decisões em relação aos investimentos em inovações para a área de TI são tomadas em no nível mais elevado da gestão. Como efeito desta situação é necessário que a área de $\mathrm{TI}$, ou mesmo as unidades/departamentos da universidade, tomem a iniciativa de propor inovações. Esta situação é bastante diversa de organizações do mercado com fins lucrativos que sofrem a pressão do mercado, quer seja dos clientes, quer seja da concorrência para que se mantenham atualizadas. A dinâmica em uma instituição pública de ensino da inovação da TI tem peculiaridades que a distinguem de uma organização empresarial do segmento privado.

QUADRO 19 - EVIDÊNCIAS ENCONTRADAS NAS DECISÕES de ARQUITETURA (ARC)

\begin{tabular}{|c|c|c|c|c|}
\hline $\begin{array}{l}\text { Decisões de Arquitetura } \\
(A R C)\end{array}$ & Empresa A & Empresa B & Empresa C & Empresa D \\
\hline $\begin{array}{l}\text { Acesso a recursos de ponta } \\
\text { de tecnologia de } \mathrm{TI}(\mathbf{V} \mathbf{9})\end{array}$ & & & & \\
\hline Inovação (D4) & & & & \\
\hline Evolução com a nuvem (D5) & & & & \\
\hline $\begin{array}{l}\text { Falta de capacidade } \\
\text { técnica (B2) }\end{array}$ & & & & \\
\hline $\begin{array}{l}\text { Configuração de dados } \\
\text { arquitetura (B5, B7 a B9) }\end{array}$ & & & & \\
\hline $\begin{array}{l}\text { Modelo de Implantação (B5, } \\
\text { B7 a B9) }\end{array}$ & & & & \\
\hline
\end{tabular}

FONTE: ELABORADO PELO AUTOR

Nota relacionada às evidências encontradas em Decisões de Arquitetura (ARC) (Quadro 19): 
* $\mathrm{Na}$ unidade $\mathrm{C}$ o compromisso de evolução com a nuvem tem similaridade muito grande com a questão da inovação, anteriormente mencionada em Qualidade dos Serviços (QAS). Existem peculiaridades na dinâmica para a apresentação de projetos e tomada de decisão em função da organização ser uma universidade que pertencente ao setor público.

A seguir são apresentados os resultados sobre a aplicação do Método de análise onde é verificada a viabilidade da sua aplicação, sua utilidade e as habilidades necessárias para a sua aplicação.

Seguem-se as análises sobre os constructos do Método de Análise e por fim o resultado do trabalho em relação às suas proposições.

\subsection{Resultados sobre a aplicação do Método de Análise}

As observações sobre a aplicação do Método de Análise trouxe para este trabalho os seguintes resultados:

- Viabilidade - o Método de Análise utilizado mostrou-se adequado para capturar as peculiaridades (e também os desejos) das organizações pesquisadas. Esta afirmação decorre da observação de que fatores associados à adoção foram previamente abordados pelo método, capturados apropriadamente pelos questionários e analisados de acordo com aquilo que havia sido inicialmente proposto. Não foi observado outro aspecto relacionado à adoção da $\mathrm{CN}$ que não estivesse contemplado no Método de Análise.

- Utilidade para a tomada da decisão pela adoção - traz a tona de forma organizada e sistematizada os fatores associados (vantagens, desafios, riscos e barreiras) que auxiliam os executivos quando tomam decisões para aquisição, contratação e a operação dos serviços na nuvem.

- Utilidade para a melhor condução da adoção - uma vez tomada a decisão pela adoção ou para o aprofundamento da adoção dos serviços em nuvem, as organizações podem mapear suas capacidades existentes, vis-à-vis as capacidades necessárias para que possam superar eventuais lacunas identificadas. 
- Entrevistados e as habilidades necessárias - o levantamento das informações necessárias ao Método de Análise deve ser conduzido por um pesquisador, com experiência e com conhecimento das questões relacionadas à gestão da TI, através de entrevistas e consultas com executivos da organização que são diretamente responsáveis pela área de $\mathrm{TI}$ e que tenham, preferencialmente, conhecimento da estratégia organizacional. Entrevistas com gestores de nível médio ou operacional podem ser valiosas para o cruzamento das informações e para uma observação do cotidiano do oferecimento dos serviços de TI de uma maneira geral, e em particular, dos serviços da nuvem.

- Clientes dos serviços oferecidos na nuvem - não foram percebidas diferenças na aplicação do Método em organizações que fornecem internamente serviços de TI na nuvem daquela organização que tem como atividade fim o fornecimento de soluções e serviços de TI.

- Aparentemente a organização onde menos benefícios seriam obtidos na utilização do Método é a instituição pública de ensino. Isto decorre da forma como são tomadas as decisões e, principalmente, pela desorganização da demanda pelos serviços da $\mathrm{TI}$, resultante da autonomia das unidades/departamentos que seriam os potenciais usuários da TI na nuvem.

- Oportunidade para análise - as organizações pesquisadas ofereceram a possibilidade de análise da maior parte dos fatores associados (vantagens, desafios, riscos e barreiras) em função da complexidade das suas áreas de TI, pois estão estruturadas para atender ao grande porte das organizações.

\subsection{Resultados sobre os constructos do Método de Análise}

Em relação aos elementos constituintes (constructos) do Método de Análise as conclusões do trabalho foram as seguintes:

Respondendo à (Q1), "como organizações que adotaram ou pretender adotar a computação em nuvem procuram identificar os fatores associados, envolvidos na avaliação para esta adoção?" o trabalho trouxe o seguinte resultado: 
Desafios - as unidades de análise procuram se preparar para os desafios impostos pela adoção da $\mathrm{CN}$ preocupados com a novidade trazida pelo paradigma. Quando maior a importância estratégica da CN maior se manifesta a preocupação com os desafios identificados pelo Método de Análise.

Todas as organizações pesquisadas possuem processos muito bem estruturados para a gestão de recursos humanos e gestão de projetos. Assim, ainda que a adoção da nuvem, no que diz respeito às tecnologias envolvidas exijam habilidades específicas dos recursos humanos ou alterações nos processos usuais de desenvolvimento de projetos, as adaptações necessárias nestes processos são feitas como evoluções necessárias e naturais na gestão destas áreas específicas.

No entanto, os desafios tipicamente impostos pelas mudanças culturais como, por exemplo, a estruturação da demanda de serviços da TI pela universidade ou o processo da adoção do paradigma da nuvem como uma inovação imperativa e irreversível para a fornecedora de ERP precisam de cuidado adicional, diferenciado e permanente dos níveis organizacionais mais altos.

Riscos e Barreiras - A maior parte dos riscos e barreiras que poderiam ser identificados através do Método de Análise é enfrentada na gestão cotidiana da área de TI. Ações que levam em conta as peculiaridades da adoção da CN poderiam reduzir ou mesmo eliminar barreiras impostas para sua adoção.

A barreira "viabilidade estratégica da contratação externa ou oferecimento de determinados serviços" (B1), associada à área de capacidades Objetivos de Negócios $(B O B)$, sempre está presente quando analisado o conjunto de $\mathrm{SI}$ da organização como um todo. A exceção da universidade (unidade de análise $\mathbf{C}$ ), as demais unidades de análise possuem sistemas de informação que não se tornariam serviços, quer seja por razões estratégicas (unidades de análise $\mathbf{A}, \mathbf{B}$ e $\mathbf{D}$ ), quer por razões operacionais (unidade de análise $\mathbf{B}$ ).

Em resposta à (Q2), "como organizações que adotaram ou pretender adotar a computação em nuvem identificam as vantagens desta adoção?", a aplicação do Método de Análise permitiu a identificação das vantagens da adoção da nuvem em 
todos os casos analisados. Em cada um deles uma vantagem ou um conjunto específico de vantagens se apresentava para a organização. Esta conclusão enseja a possibilidade da aplicação do Método para a identificação de vantagens eventualmente ainda não identificadas pelos gestores, o que viria a facilitar a aprovações de iniciativas de adoção da nuvem quando estas são levadas para análise nos níveis hierárquicos superiores nas organizações.

Respondendo à (Q3), "como as organizações que adotaram ou pretender adotar a computação em nuvem analisam suas capacidades essenciais, relacionadas com a adoção da computação em nuvem?", nos resultados foram encontradas capacidades estruturadas formalmente incorporando especificidades da nuvem. Como nos casos abaixo:

- Gestão da Função TI (MNG) - encontradas menções da necessidade de capacidades específicas para lidar como os desafios impostos pela nuvem (D2, D4 e D5) nas unidades de análise B e D.

- Qualidade dos Serviços (QAS) - encontrada menção de capacidades específica para tratar do desafio (D5) nas unidades de análise D.

- Decisões de Arquitetura $(A R C)$ - encontradas menções da necessidade de capacidades específicas para lidar como os desafios (D4 e D5) nas unidades de análise B e D.

O trabalho de campo, conduzido através da aplicação do Método, encontrou evidências de preocupações prévias específicas com o desenvolvimento de capacidades essenciais, conforme definidas neste trabalho, como um fator necessário para a adoção da $\mathrm{CN}$, nas unidades de análise em que está presente uma orientação estratégica clara para a contratação ou o fornecimento de serviços na nuvem.

A oportunidade de análise nas organizações de grande porte escolhidas se mostrou adequada para a observação da maioria significativa dos elementos constituintes do Método de Análise. Houve certamente limitações relacionadas às observações dos riscos e barreiras, em especial aqueles do cotidiano da operação 
da TI, como disponibilidade dos meios de comunicação e das aplicações, por exemplo.

\subsection{Alinhamento Estratégico da TI ao negócio}

Em resposta à questão (Q4), "a adoção da computação em nuvem pode contribuir para o alinhamento estratégico da TI com o negócio?", o resultado do trabalho evidenciou que a adoção ou não da computação em nuvem decorre de necessidades da estratégia ou de necessidades específicas do negócio. É possível concluir que em todas as unidades de análise as decisões relacionadas à adoção da nuvem produziram impactos no alinhamento estratégico da TI ao negócio, independentemente da perspectiva deste alinhamento. Isto é, tanto para as organizações cuja $\mathrm{TI}$ tem a finalidade de suportar o negócio, quanto para aquela na qual a TI tem potencial competitivo, ou seja, de transformar o negócio, foram identificados impactos no alinhamento estratégico.

Observou-se também que a adoção da nuvem em organizações, cuja TI tem primordialmente a função de suportar o negócio, serviu como oportunidade de integração operacional dos processos e da infraestrutura da TI para atender necessidades do negócio, enquanto que na organização com potencial de transformação, a adoção da nuvem trouxe a oportunidade de um "ajuste estratégico" com a abertura de um novo negócio para a empresa.

\subsection{Resultados sobre as proposições do estudo}

O Quadro 20 os resultados obtidos em relação às proposições. 
QUADRO 20 - RESULTADOS SOBRE AS PROPOSIÇõES

\begin{tabular}{|c|c|c|}
\hline Proposição & Resultado & Justificativa \\
\hline P1 & Verificada & $\begin{array}{l}\text { Ficou evidenciado nos casos A e C. No caso A, a adoção da } \\
\text { nuvem foi para atender uma necessidade específica da } \\
\text { organização. No caso C, ainda que a houvesse intenção da } \\
\text { adoção estratégica, o projeto somente ganhou escala } \\
\text { quando veio a atender uma necessidade específica (garantia } \\
\text { da continuidade "do negócio") dos sistemas para gestão } \\
\text { administrativa e acadêmica. }\end{array}$ \\
\hline $\mathrm{P} 2$ & $\begin{array}{l}\text { Verificada } \\
\text { parcialmente }\end{array}$ & $\begin{array}{l}\text { As organizações pesquisadas possuem processos muito } \\
\text { bem estruturados para a gestão de recursos humanos e } \\
\text { gestão de projetos como compromissos já consolidados e de } \\
\text { longo prazo. Por outro lado, mudanças culturais e o incentivo } \\
\text { às inovações dependem do esforço contínuo e pontual dos } \\
\text { gestores. }\end{array}$ \\
\hline P3 & Refutada & $\begin{array}{l}\text { As organizações estudadas possuem as estruturas } \\
\text { necessárias para lidar com as barreiras impostas para } \\
\text { adoção nuvem. Contudo, as ações são tomadas sem que as } \\
\text { peculiaridades da nuvem sejam levadas em conta; ou seja, } \\
\text { são tratados como as barreiras "usuais" da gestão da } \\
\text { Tecnologia da Informação. Os riscos e barreiras são } \\
\text { enfrentados na gestão cotidiana da área de Tecnologia da } \\
\text { Informação. }\end{array}$ \\
\hline P4 & $\begin{array}{l}\text { Verificada } \\
\text { parcialmente }\end{array}$ & $\begin{array}{l}\text { O trabalho de campo, conduzido através da aplicação do } \\
\text { Método, encontrou evidências nas unidades de análise B e } \\
\text { D de preocupações prévias específicas com o } \\
\text { desenvolvimento de capacidades essenciais, como um fator } \\
\text { necessário para a adoção da CN, nos casos em que está } \\
\text { presente uma orientação estratégica clara nesta direção. }\end{array}$ \\
\hline
\end{tabular}




\begin{tabular}{|c|l|l|}
\hline Proposição & Resultado & \multicolumn{1}{|c|}{ Justificativa } \\
\hline P5 & Verificada & $\begin{array}{l}\text { Em todas as unidades de análise as decisões de adoção da } \\
\text { nuvem produziram impactos no alinhamento estratégico da } \\
\text { TI ao negócio, independentemente da perspectiva deste } \\
\text { alinhamento. Isto é, tanto para as organizações cuja TI tem a } \\
\text { finalidade de suportar o negócio, quanto para aquela na qual } \\
\text { a Tl tem potencial competitivo, ou seja, de transformar o } \\
\text { negócio, foram identificados impactos no alinhamento } \\
\text { estratégico da TI ao negócio. }\end{array}$ \\
\hline
\end{tabular}

FONTE: ELABORADO PELO AUTOR 


\section{CONCLUSÕES}

Esta pesquisa estabeleceu um método para compreender como as organizações tomam decisões relacionadas à contratação e ao gerenciamento de serviços da CN. Partindo do Método de Análise elaborado dentro do seu escopo, e utilizando a metodologia de estudos de casos múltiplos, procurou-se responder às questões de pesquisa a partir do resultado do trabalho de campo realizado em quatro organizações de grande porte.

O trabalho de campo foi conduzido de acordo com o proposto pelo Método de Análise, que por sua vez foi construído a partir constructos extraídos do referencial teórico. As proposições da pesquisa foram utilizadas como orientadoras na análise dos resultados obtidos. A verificação ou refutação, total ou parcial, destas proposições conduziram aos principais resultados deste trabalho.

As observações sobre o Método de Análise possibilitaram evidenciar sua aplicação como viável e útil quando utilizado no processo para a tomada da decisão pela adoção da CN nos casos pesquisados. Uma vez tomada decisão pela adoção ou para o aprofundamento da adoção dos serviços em nuvem, os subsídios identificados pelo Método também têm utilidade para uma melhor condução da sua implementação, pois a organização pode mapear suas capacidades existentes, visà-vis as capacidades essenciais necessárias, para que possam superar eventuais lacunas identificadas.

A aplicação do Método de Análise mostrou também que o levantamento das informações necessárias deve ser conduzido por um profissional com experiência e com conhecimento das questões relacionadas à gestão da TI, através de entrevistas e consultas com executivos da organização que são diretamente responsáveis pela área de $\mathrm{TI}$. Além do papel estratégico da $\mathrm{TI}$, é desejável que estes executivos tenham conhecimento da estratégia competitiva global da organização. Entrevistas com a média gerência ou em nível operacional podem ser valiosas para o cruzamento das informações e para uma observação do cotidiano do oferecimento dos serviços de TI de uma maneira geral, e em particular, dos serviços da nuvem. 
Em relação aos constructos constituintes do Método de Análise, a sua aplicação permitiu a identificação das vantagens da adoção da nuvem em todos os casos analisados. Em cada um deles uma vantagem ou um conjunto específico de vantagens se apresentava para a organização. Esta conclusão enseja a possibilidade da aplicação do Método para a identificação de vantagens eventualmente ainda não identificadas pelos gestores, o que viria a facilitar a aprovações de iniciativas de adoção da nuvem quando estas são levadas para análise nos níveis hierárquicos superiores nas organizações.

Nos resultados do trabalho foram encontradas evidências que as unidades de análise procuram se preparar para os desafios impostos pela adoção da CN preocupados com a novidade trazida pelo paradigma. Quando maior a importância estratégica da CN, maior se manifesta a preocupação com os desafios identificados pelo Método de Análise.

Todas as organizações pesquisadas possuem processos muito bem estruturados para a gestão de recursos humanos e gestão de projetos. Assim, ainda que a adoção da nuvem, no que diz respeito às tecnologias envolvidas exijam habilidades específicas das pessoas ou alterações nos processos usuais de desenvolvimento de projetos, as adaptações necessárias nestes processos são feitas como evoluções necessárias e naturais na gestão destas áreas específicas, independentemente da racionalização utilizada para adoção da CN.

No entanto, os desafios tipicamente impostos pelas mudanças culturais como, por exemplo, a estruturação da demanda de serviços da TI pela universidade ou o processo da adoção do paradigma da nuvem como uma inovação imperativa e irreversível para a fornecedora de ERP precisam de cuidado adicional, diferenciado e permanente dos níveis organizacionais mais altos.

A maior parte dos riscos e barreiras que poderiam ser identificados através do Método de Análise é enfrentada na gestão cotidiana da área de TI. Ações que levam em conta as peculiaridades da adoção da $\mathrm{CN}$ poderiam reduzir ou mesmo eliminar barreiras impostas para sua adoção. 
O trabalho de campo, conduzido através da aplicação do Método, encontrou evidências de preocupações prévias específicas com o desenvolvimento de capacidades essenciais, conforme definidas neste trabalho, como um fator necessário para a adoção da $\mathrm{CN}$ nas unidades de análise em que está presente uma orientação estratégica clara pela adoção de serviços na nuvem.

O Método pôde ser aplicado em organizações onde a TI é uma atividade meio, ou seja, a área de TI é uma prestadora de serviços para as áreas internas à organização ou na organização onde a Tl é uma atividade fim. Este resultado era esperado em função da CN ser consumida como serviço em algum dos Modelos de Serviço que a caracterizam. Assim, um fornecedor de serviços no Modelo SaaS, pode ser ele próprio um cliente no Modelo laaS.

A adoção ou não da $\mathrm{CN}$ decorre de necessidades da estratégia ou de necessidades específicas do negócio. É possível concluir que em todas as unidades de análise as decisões relacionadas à adoção da nuvem produziram impactos no alinhamento estratégico da $\mathrm{Tl}$, independentemente da perspectiva deste alinhamento. Isto é, tanto para as organizações cuja TI tem a finalidade de apoiar o negócio, quanto para aquela na qual a TI tem potencial competitivo, ou seja, de transformar o negócio, foram identificados impactos no alinhamento estratégico da $\mathrm{TI}$ ao negócio.

Como esperado, o Método de Análise elaborado mostrou-se robusto o suficiente para capturar, através do trabalho de campo, as peculiaridades (e também os desejos) da organização e, ao confrontá-las com a literatura, mostram-se capazes para auxiliar quando na tomada de decisões para aquisição, contratação e a operação dos serviços, no que diz respeito aos seus Objetivos de Negócios $(B O B)$, à Gestão da Função TI (MNG), aos Atributos da Qualidade dos Serviços (QAS) e às Decisões de Arquitetura $(A R C)$ considerando influências de fatores como vantagens, desafios, riscos e barreiras associados à $\mathrm{CN}$.

Ainda que a $\mathrm{CN}$ seja uma modelo relativamente recente para o oferecimento de soluções de TI, pôde-se observar que as principais questões tratadas são as mesmas que cercam a TI na forma tradicionalmente encontrada nas organizações. 
Questões como estratégia organizacional, governança, capacitação técnica e jurídica, segurança da informação, gestão de pessoas, gestão de projetos, gestão de contratos estão presentes e são as mesmas do modelo majoritário de $\mathrm{TI}$, ainda que aqui vistas sob a ótica da $\mathrm{CN}$.

Espera-se que o Método de Análise para adoção da CN possa ser utilizado pelas áreas de $\mathrm{TI}$ das empresas, no planejamento da sua estrutura gerencial e operacional, nos modelos do fornecimento dos serviços e também na sua infraestrutura. Também é esperado que o Método venha a ser aprimorado, através do seu uso e de novos trabalhos científicos.

Entre as melhorias possíveis estão um refinamento do Roteiro para aplicação do Método de Análise através do uso de questionários estruturados que buscassem classificar as respostas obtidas em algumas poucas categorias previamente definidas. Isso permitiria que o Método de Análise pudesse ser aplicado sem que fosse necessário ao pesquisador de campo um profundo conhecimento da gestão e da operação da $\mathrm{Tl}$ em organizações de grande porte.

Tendo por objetivo maior generalização da aplicabilidade do Método de Análise, podem ser feitos novos estudos em organização de médio ou pequeno porte ou em empresas que tenham a TI fortemente terceirizada. Ou seja, para as quais o "Nível de Serviço" seja a perspectiva de Alinhamento Estratégico da TI (condição não identificada em nenhuma das unidades de análise desta pesquisa).

Também podem ser feitos novos trabalhos de pesquisa diretamente relacionados à adoção da $\mathrm{CN}$ para identificar fatores que representem impacto para a TI e, consequentemente, para organização ou para a TI. Um trabalho de natureza quantitativa poderia ser conduzido em empresas atuando no país para medir o impacto da adoção da nuvem em relação aos custos da operação da $\mathrm{TI}$, às eventuais mudanças de perfis e quantidade dos recursos humanos e à capacidade de entrega dos serviços de TI destas organizações. 


\section{REFERÊNCIAS}

ALTMAN, E.; NAGLE, F.; TUSHMAN, M. Innovating without Information Constraints: Organizations, Communities, and Innovation When Information Costs Approach Zero. Harvard Business School Organizational Behavior Unit, Working Paper 14043, November 16, 2013.2 Disponível em: http://www.hbs.edu/faculty/Publication\%20Files/14-043 f5b89cf8-ad89-4cfd-bd26d296a8eb67f6.pdf Acesso em: 12 mar. 2014.

ARMBRUST, M. et al. A view of cloud computing. Communications of the ACM, v. 53, n. 4, p. 50-58, 2010.

BENLIAN, A.; HESS, T. Opportunities and risks of software-as-a-service: Findings from a survey of IT executives. Decision Support Systems, v. 52, n. 1, p. 232-246, 2011.

BERTO, R. M. V. S.; NAKANO, D. N. A PRODUÇÃO CIENTÍFICA NOS ANAIS DO ENCONTRO nacional de engenharia de produção: um levantamento de métodos e tipos de pesquisa. Encontro Nacional de Engenharia de Produção (ENEGEP), v. $19,2000$.

BERTRAND, J. W. M.; FRANSOO, J. C. Operations management research methodologies using quantitative modeling. International Journal of Operations \& Production Management, v. 22, n. 2, p. 241-264, 2002.

BETTMAN, J.R. Perceived risk and its components: a model and empirical test, Journal of Marketing Research, 10 (2), p.184-190, 1973.

BOILLAT, T.; LEGNER, C. From on premise software to cloud services: the impact of cloud computing on enterprise software vendors' business models. Journal of theoretical and applied electronic commerce research, v. 8, n. 3, p. 39-58, 2013. BRYNJOLFSSON, E.; HOFMANN, P.; JORDAN, J. Cloud computing and electricity. Communications of the ACM, v. 53, n. 5, p. 32, 2010. 
BUYYA, R.; YEO, C. S.; VENUGOPAL, S. Market-Oriented Cloud Computing: Vision, Hype, and Reality for Delivering IT Services as Computing Utilities. 10th IEEE International Conference on High Performance Computing and Communications, p. 5-13, 2008.

BUYYA, R.; YEO, C. S.; VENUGOPAL, S.; BROBERG, J.; BRANDIC, I.; Cloud computing and emerging IT platforms: Vision, hype, and reality for delivering computing as the 5th utility. Future Generation Computer Systems, v. 25, n. 6, p. 599-616, 2009.

CAPPUCIO, D.; KEYWORTH, B.; KIRWIN, W. Total Cost of Ownership: The Impact of System Management Tools. Gartner Group, Stamford, CT, 1996.

CHAN, Y. E. Why haven't we mastered alignment? The importance of the informal organization structure. MIS Quarterly executive, v. 1, n. 2, p. 97-112, 2002.

CHAVES, S.; SOUZA, C. Barreiras à Adoção da Computação em Nuvem: Um Estudo Delphi Conduzido com Profissionais e Acadêmicos Brasileiros. CONF-IRM 2012 Proceedings. Paper 62, $2012 . \quad$ Disponível em: http://aisel.aisnet.org/confirm2012/62. Acesso em: 15 mar. 2013.

CHEN, D.; ZHAO, H. Data Security and Privacy Protection Issues in Cloud Computing. 2012 International Conference on Computer Science and Electronics Engineering, n. 973, p. 647-651, 2012.

CHOUDHARY, V. Comparison of software quality under perpetual licensing and software as a service, Journal of Management Information Systems 24 (2) p. 141-165, 2007.

CHOW, R. et al. Controlling data in the cloud: outsourcing computation without outsourcing control. In: Proceedings of the 2009 ACM workshop on Cloud computing security. ACM, p. 85-90, 2009.

CHUDNOV, D. A view from the clouds. Computers in Libraries, 30(3), 33-35, 2010. 
CIBORRA, C. De profundis? Deconstructing the concept of strategic alignment. Scandinavian Journal of Information Systems, v. 9, n. 1, p. 67-82, 1997.

CRAIGHEAD, C. W.; MEREDITH, J. M. Operations management research: evolution and alternative future paths, International Journal of Operations \& Production Management, $\quad$ v. $28, \quad$ n. 8 , p. 710-726, 2008. Disponível em: http://dx.doi.org/10.1108/01443570810888625. Acesso em: 20 jun. 2014.

CROOM, S. Topic issues and methodological concerns for operations management research. Eden Doctoral Seminar on Research Methodology in Operations Management, Brussels, Belgium, 31st Jan.-4th Feb., 2005.

CROSS, J. IT outsourcing: British Petroleum's competitive approach. Harvard Business Review, vol. 73, no 3, p. 94-102, 1995.

CURRIE, W. L.; SELTSIKAS P.; Exploring the supply-side of IT outsourcing: evaluating the emerging role of application service providers, European Journal of Information Systems, v. 10, n. 3, p. 123-134, 2001.

DHAR, S. From outsourcing to Cloud computing: evolution of IT services. Management Research Review, v. 35, n. 8, p. 664-675, 2012.

DiROMAULDO, Anthony; GURBAXANI, Viijay. Strategic Intent for IT Outsourcing. Sloan Management Review, Vol. 39 N. 4, pp. 67-80, 1998. Disponível em: http://escholarship.org/uc/item/7kc4d3p1 Acesso em: 20 maio 2014.

DOSTAL, E.; CLOETE, Anacreon; JÁROS, György. Biomatrix: a systems approach to organisational and societal change. BiomatrixWeb, 2005.

FEENY, D. F.; WILLCOCKS, L. P. Core IS capabilities for exploiting information technology. Sloan management review, v. 39, n. 3, p. 9-21, 1998.

FILIPPINI, R; VOSS, C. Editorial. International Journal of Operations and Production Management, v. 17, n. 7, p. 653-654, 1997. 
FILIPPINI, R. Operations Management Research: Some Reflections on Evolution, Models and Empirical Studies in OM. International Journal of Operations \& Production Management, vol. 17, number 7, p. 655-670, 1997.

FORZA, C. Survey research in operations management: A process based perspective. International Journal of Operations \& Production Management, vol. 22, number. 2, p. 152-194, 2002.

FOSTER, I. et al. Cloud computing and grid computing 360-degree compared. In: Grid Computing Environments Workshop, 2008. GCE'08. IEEE, p. 1-10.2008.

PRING, B Cloud computing: The next generation of outsourcing. Gartner Group, p. 117, 2010.

GARTNER Gartner Group: Top 10 Key Technology Trends for 2013. Cloud Times. [Online]. Disponível em: http://cloudtimes.org/2012/11/06/gartner-top-10-keytechnology-trends-for-2013/. Acesso em: 30 mar. 2014.

GEWALD, H.; DIBBERN, J., Risks and benefits of business process outsourcing: a study of transaction services in the German banking industry, Information and Management 46 (4) pp. 249-257, 2009.

GIL, A. C. Como Elaborar Projetos de Pesquisa. São Paulo: Atlas, 1996.

GONZALEZ, R.; GASCO, J.; LLOPIS, J. Information systems outsourcing reasons and risks: an empirical study, International Journal of Social Sciences 4 (3) 180191 (2009).

HENDERSON, J. C.; VENKATRAMAN, N. Strategic alignment: leveraging information technology for transforming organizations, IBM Systems Journal, vol. 32, issue 1, pp. 4-16, 1993. http://dx.doi.org/10.1590/S0103-65132007000100015

IYER, B.; HENDERSON, J. Preparing for the Future: Understanding the Seven Capabilities of Cloud Computing, MIS Quarterly Executive (9:2), pp 117-131, 2010. 
JOHA, A.; JANSSEN, M. Design Choices Underlying the Software as a Service (SaaS) Business Model from the User Perspective: Exploring the Fourth Wave of Outsourcing, Journal of Universal Computer Science, v.18, n. 11, p. 1501-1522, 2012.

KAISLER, S.; MONEY, W. H.; COHEN, S. J. A Decision Framework for Cloud Computing. 2012 45th Hawaii International Conference on System Sciences, p. 1553-1562, jan.Jan. 2012.

KAUFFMAN, R.J.; SOUGSTAD, R. Risk management of contract portfolios in IT services: the profit-at-risk approach, Journal of Management Information Systems 25 (1) p. 17-48, 2008.

KERN, T.; WILLCOCKS, L. P.; LACITY, M. C. Application service provision: risk assessment and mitigation, MIS Quarterly Executive, 1 (2) p. 113-126, 2002.

KONDO, D. et al. Cost-benefit analysis of cloud computing versus desktop grids. In: Parallel \& Distributed Processing, 2009. IPDPS 2009. IEEE International Symposium on. IEEE p. 1-12, 2009.

LACERDA, D. P.; DRESCH, A.; PROENÇA, A.; ANTUNES JÚNIOR, J.A.V. Design Science Research: método de pesquisa para a engenharia de produção. Gestão \& Produção, 20, p. 741-761, 2013.

LACITY, M. C., WILLCOCKS, L. P., FEENY D.F.: The value of selective IT outsourcing, Sloan Management Review, 37, 3, p. 13-25, 1996.

LACITY, M. C.; KHAN, S. A.; WILLCOCKS, L. P. A review of the IT outsourcing literature: insights for practice, The Journal of Strategic Information Systems, 18 (3) 130-146, 2009.

LACITY, M.C.; WILLCOCKS, L. P. An empirical investigation of Information Technology sourcing practices: lessons from experience, MIS Quarterly, 22 (3) 363408, 1998. 
LAKATOS, E. M.; MARCONI, M. A. Metodologia científica. 5a. ed. São Paulo: Atlas, 2009.

LAURINDO, F. J. B. Tecnologia da Informação: Planejamento e Gestão de Estratégias. $1^{a}$ ed. São Paulo: Editora Atlas, 382 p., 2008.

LEVINA, N.; ROSS, J.W. From the vendor's perspective: exploring the value proposition in information technology outsourcing, MIS Quarterly, 27 (3) 331-364, 2003.

LINTHICUM, D. S. Cloud Computing Andand SOA Convergence Inin Your Enterprise: A Step-by-step Guide. 1를. Edtados Unidos: Addison Wesley, 2009a.

LINTHICUM, D. S. Defining the Cloud Computing Framework: Refining the Concept, Cloud Computing Journal, 2009b. Disponível em: http://cloudcomputing.syscon.com/node/811519. Acessado em: 20 maio 2013.

LINTHICUM, D. S. The cloud won't save you money - and that's OK junJun, 2011 Disponível em: http://www.infoworld.com/d/cloud-computing/the-cloud-wont-saveyou-money-and-thats-ok-923. Acesso em: 10 mar. 2013.

LUFTMAN, J.; PAPP, R.; BRIER, T. Enablers and inhibitors of business-IT alignment. Communications of the AIS, v. 1, n. 3es, p. 1, 1999.

LUFTMAN, J. N.; LEWIS, P. R.; OLDACH, S. H. Transforming the enterprise: the alignment of business and information technology strategies. IBM System Journal, v. 32, n. 1, p. 198-220, 1993.

LUFTMAN, J.N. Applying the strategic model. In: LUFTMAN, J.N. (ed.) Competing in the Information Age: Strategic Alignment in Practice, New York: Oxford University Press, p. 43-69, 1996.

MARCHAND, D.A.; KETTINGER, W.J.; ROLLINS, J.D. Information orientation: the link to business performance. New York: Oxford University Press, 2001.

MARCONI, M. A.; LAKATOS, E. M. Fundamentos de metodologia científica. 5ª ed. São Paulo: Atlas, 2003. 
MARKS, E. A.; LOZANO R. R. Executive's guide to cloud computing. Hoboken, NJ: John Wiley. 2010

MARSTON, S.; LI, ZHI; BANDYOPADHYAY, S.; ZHANG, J.; GHALSASI, A. Cloud computing -The business perspective. Decision Support Systems, vol. 51, oㅜ 1, p. 176-189, 2011.

MARTENS, B.; TEUTEBERG, F. Decision-making in cloud computing environments: A cost and risk based approach. Information Systems Frontiers, v. 14, n. 4, p. 871893, 26 jul.Jul. 2011.

MATHER, T.; KUMARASWAMY, S.; LATIF, S. Cloud security and privacy. Beijing; Cambridge [Mass.]: O'Reilly. 2009.

MATTAR, F. N. Pesquisa de Marketing: Metodologia e Planejamento. São Paulo: Atlas, 1996.

McAFEE, A. What Every CEO Needs to Know About the Cloud, Harvard Business Review, vol. 89, no 11, pp. 124-132, 124, 2011.

McFARLAN, F. W. Information technology changes the way you compete, Harvard Business Review vol. 63, no 3, pp. 98-105, 1984.

MELL, P.; GRANCE, T. The NIST Definition of Cloud Computing - Recommendations of the National Institute of Standards and Technology, 2011. Disponível em: http://csrc.nist.gov/publications/nistpubs/800-145/SP800-145.pdf. Acesso em: 15 mar. 2013.

MIGUEL, P. A. C. Adoção do estudo de caso na engenharia de produção. Metodologia de pesquisa em engenharia de produção e gestão de operações. Rio de Janeiro: Elsevier, p. 129-143, 2010.

MIGUEL, P. A. C. Estudo de caso na engenharia de produção: estruturação e recomendações para sua condução. Revista Produção, v. 17, n. 1, p. 216-229, abr. 2007. 
MIGUEL, P. A. C. Metodologia de pesquisa em engenharia de produção e gestão de operações. Elsevier, 2012.

MILLER, M. Cloud computing: Web-based Applications That Change the Way You Work and Collaborate Online. Indianapolis, IN (US): Que Publishing, 2008.

NAKANO, D. Métodos de Pesquisa Adotados na Engenharia de Produção e Gestão de Operações. In: MIGUEL, P. A. C. et al., Metodologia de Pesquisa em Engenharia de Produção e Gestão de Operações. cap. 4, p. 63-72. Rio de Janeiro: Campus, 2010.

NORONHA, D. P.; FERREIRA, S. M. S. P. Revisões da Literatura. In: Campello, B.S., Cendón, B.v. e Kremer, J.M. Fontes de Informação para Pesquisadores e Profissionais. Belo Horizonte: Ed. UFMG, p. 191-198, 2000.

O'REILLY, T. What is Web 2.0: Design patterns and business models for the next generation of software, 2005. Disponível em: http://www.oreillynet.com/lpt/a/6228. Acesso em: 20 jun. 2014.

PAQUETTE, Scott; JAEGER, Paul T.; WILSON, Susan C. Identifying the security risks associated with governmental use of cloud computing.Government Information Quarterly, v. 27, n. 3, p. 245-253, 2010.

PETER, J.P.; RYAN, M.J. An investigation of perceived risk at the brand level, Journal of Marketing Research, 13(2) 184-188. 1976.

RICHARDSON, R. J. Pesquisa social: métodos e técnicas. 3ํe․ São Paulo: Atlas, 1999.

RIED, S. et al. Sizing the Cloud, Understanding And Quantifying The Future Of Cloud Computing. Forrester Research, Inc, v. 21, 2011.

SAMBAMURTHY, V.; ZMUD, R. W. Arrangements for Information Technology Governance: A Theory of Multiple Contingencies, MIS Quarterly, 23 (2) 261-290, 1999, 1999. 
SANTOS, L. Figuras Jurídicas da Administração Pública. In: Debates GV Saúde Vol. 1 - 1ํㅗㄴ semestre, 2006. Disponível em:

http://gvsaude.fgv.br/sites/gvsaude.fgv.br/files/2.pdf. Acesso em: 03 jun. 2014.

SCHRAMM, W. Notes on Case Studies of Instructional Media Projects. 1971.

SEBRAE-SP. SERVIÇO BRASILEIRO DE APOIO A MICRO E PEQUENA EMPRESA. Critérios de classificação de empresas: EI - ME - EPP, 2013. Disponível em: http://www.sebrae-sc.com.br/leis/default.asp?vcdtexto=4154. Acesso em: 03 mar. 2014.

SOMMERVILLE, lan. Engenharia de software. Addison Wesley, 2003.

SOUZA, R. Case research in operations management. Eden Doctoral Seminar on Research Methodology in Operations Management, Brussels, Belgium, 31st Jan.4th Feb., 2005.

SOUZA, R.; VOSS, C. Quality Management: Universal or Context Dependent? Production and Operations Management, v. 10, n. 4, p. 383-404, 2001.

SPÍNOLA, M.M; PESSÔA, M.S.P. Tecnologia da Informação. In: CONTADOR, J.C. (coord.) Gestão de Operações - a Engenharia de Produção a serviço da modernização da empresa. São Paulo. p.97-105. Editora Edgard Blücher. 1997.

SUBASHINI, S.; KAVITHA, V. A survey on security issues in service delivery models of cloud computing. Journal of Network and Computer Applications, v. 34, n. 1, p. 1-11, 2011.

SVANTESSON, D.; CLARKE, R. Privacy and consumer risks in cloud computing. Computer Law \& Security Review, v. 26, n. 4, p. 391-397, 2010.

TAURION, C. Cloud Computing: Computação em Nuvem: Transformando o Mundo da Tecnologia da Informação. 1를. Ed. Rio de Janeiro: Brasport, 2009.

THIOLLENT, M. Metodologia da Pesquisa-Ação. São Paulo: Atlas, 1997. 
UPTIME The Uptime Institute, 2014. Disponível em: http://uptimeinstitute.com/. Acesso em: 17 jul. 2014.

VAQUERO, L.; RODERO-MERINO, L.; CACERES, J.; LINDNER, M. A break in the clouds: towards a cloud definition. ACM SIGCOMM computer communications review, 2009.

VENTERS, W.; WHITLEY, E. A. A critical review of cloud computing: researching desires and realities. Journal of Information Technology, v. 27, n. 3, p. 179-197, 14 ago. 2012.

VERAS, M. Datacenter: Datacenter: Componente Central da Infraestrutura de TI. $1^{\underline{a}}$ Ed. Rio de Janeiro: Brasport, 2009.

VIANNA, W. B.; ENSSLIN, L. O design na pesquisa quali-quantitativa em engenharia de produção - questões epistemológicas. Revista Produção Online, 2008.

VOSS, C; TSIKRIKTSIS, N; FROHLICH, M. Case research in operations management. International journal of operations \& production management, v. 22, n. 2, p. 195-219, 2002.

WEILL, P.; ROSS, J. W. A matrixed approach to designing IT governance, MIT Sloan Management Review, 46 (2) 26-34, 2005.

WEISS, A. Computing in the clouds. Networker, v. 11, n. 4, 2007.

WHITTEN, D.; CHAKRABARTY, S.; WAKEFIELD, R. The strategic choice to continue outsourcing, switch vendors, or back source: do switching costs matter? Information and Management, 47 (3) 167-175, 2010.

WILLCOCKS, L. P.; FEENY, D.; OLSON, N. Implementing Core IS Capabilities, European Management Journal, v. 24, n. 1, p. 28-37, 2006.

WILLCOCKS, L. P.; FITZGERALD, G. Market as opportunity? Case studies in outsourcing information technology and services, The Journal of Strategic Information Systems v. 2, n. 3, p. 223-242, 1993. 
WILLCOCKS, L. P.; KERN, T. IT Outsourcing as Strategic Partnering: The case of the UK Inland Revenue, European Journal of Information Systems, v. 7, n. 1, p. 29-45, 1998.

WILLCOCKS, L. P.; VENTERS, W.; WHITLEY, E. Cloud Sourcing: Implications for Managing the IT Function. Springer Berlin Heidelberg, p. 142-163, 2012.

XIN, M.; LEVINA N. Software-as-a-Service Model: Elaborating Client-side Adoption Factors, Proceedings of the 29th International Conference on Information Systems, Paris, France, December, p. 14-17, 2008.

YIN, R. K. (Ed.). The case study anthology. Sage, 2004.

YIN, R. K. Estudo de Caso: Planejamento e Métodos. $2^{2}$ ed., Porto Alegre: Bookman, 2001.

YIN, R.K. Estudo de Caso: Planejamento e Métodos, $3^{a}$ ed., Porto Alegre: Bookman, 2005.

ZHANG, Q.; CHENG, L.; BOUTABA, R. Cloud computing: state-of-the-art and research challenges. Journal of internet services and applications, v. 1, n. 1, p. 718, 2010. 


\section{APÊNDICES}

\subsection{APÊNDICE I- Protocolos para caracterização das}

organizações e descrição dos sistemas foco da aplicação do método

\section{Caracterização da organização-alvo (Unidade de Análise A, B, C...) \\ Descrição dos sistemas-alvo para aplicação do método}

a) Descrição da operação e da Gestão da Infraestrutura de TI - detalhes da operação da função TI: será preciso detalhar, como feito com os itens b) e c), abaixo.

b) Descrição do processo de desenvolvimento - como acontece 0 desenvolvimento (processo, gestão de projetos):

- Levantamento e elicitação dos Requisitos

- Estimativa de Esforço e Prazo

- Matriz de Rastreabilidade

- Análise de riscos

- Testes

- Gestão da Configuração

- Documentação Técnica

- Documentação Usuário

- Contratações Específicas para o desenvolvimento

- Equipe de projeto (tamanho, formação e vínculo)

- Gestão do Projeto - Padrões, boas práticas e profissionais certificados.

- Definição dos processos de desenvolvimento 
- Certificações da organização

- Outros pontos relevantes

c) Descrição dos sistemas candidatos ou que já estão baseados e/ou implantados na nuvem:

- Nome do sistema

- Principais funcionalidades

- Arquitetura do SI (módulos e tecnologias)

- Interoperabilidade do sistema - outros sistemas, interfaces e/ou tecnologias.

- Base de Dados (independente de bases de dados ou utiliza SGBD específico) 


\subsection{APÊNDICE II-Questionários}

Este apêndice traz os três questionários utilizados na pesquisa de campo e elaborados de acordo com os elementos constituintes do Método de Análise.

\subsubsection{Questionário 1 - Vantagens da adoção da computação}

\section{em nuvem}

1) V1 - É esperada redução de custos ao mover as aplicações para a nuvem? Justificar.

2) V3 e V4 - O sistema em questão será utilizado em algum novo negócio da organização? Neste caso, existe a expectativa de que a sua utilização na nuvem reduza o tempo e/ou o custo para entrada neste novo negócio?

3) V5 - O sistema em questão será utilizado para que a organização atue em novos mercados? Neste caso, existe a expectativa de que a sua utilização na nuvem reduza o tempo e/ou o custo para entrada neste novo mercado?

4) V6 - E esperado maior facilidade de manutenção das aplicações em questão? Em caso positivo, entende que esta facilidade de manutenção pode dar maior flexibilidade para os negócios da organização?

5) V7 - E esperada maior facilidade para substituir os fornecedores dos sistemas atuais para novos fornecedores na nuvem? A organização acredita serem necessários fornecedores alternativos para os sistemas em questão? Em caso positivo, entende que este fornecimento seria facilitado pela utilização do modelo da computação em nuvem?

6) V8 - A manutenção dos atuais sistemas "in house" pode estar exigindo uma dedicação que poderia ser mais bem utilizada em funções diretamente ligadas às aplicações focadas nos principais negócios da organização?

7) V9 - E esperado menor necessidade de treinamento para suportar aplicações em questão? É esperado que o fornecedor da nuvem mantivesse os recursos e as tecnologias utilizadas pelas aplicações atualizadas? 
8) V10 - É esperado um aumento da eficiência e eficácia dos processos relacionados às aplicações movidas para a nuvem? É esperado um aumento na segurança das informações dessas aplicações? É esperado que problemas com "back-ups" de dados sejam resolvidos com a contratação das aplicações como serviços da nuvem?

\subsubsection{Questionário 2 - Desafios para adoção da computação em nuvem}

1) D1 - Há um plano de carreiras para as pessoas que trabalham na área de TI?

2) D1 e D2 - Há um plano de atualização tecnológica para aqueles que trabalham na área de TI?

3) D1 - A organização tem uma política de remuneração variável, atrelada ao cumprimento de metas?

4) D1 - A organização tem uma política de "job rotation", dando oportunidade para o desenvolvimento de diferentes habilidades e conhecimentos da sua operação e ambiente de negócios?

5) D2 - O clima organizacional é adequado às mudanças?

6) D3 - Como são gerenciados os projetos de desenvolvimento de software?

7) D3 - Há um processo formal de gestão de projetos de software?

8) D3 - Os projetos de desenvolvimento de software adotam melhores práticas como as do PMBOK?

9) D3 - A organização possui alguma certificação como CMMI?

10) D4 - Identificar as oportunidades da adoção da $C N$ para o alinhamento estratégico da $\mathrm{TI}$ ao negócio. Considerar as possiblidades de "ajuste estratégico" e de "oportunidades de novos negócios" pela adoção da CN.

11)D4 - Como são discutidas as oportunidades de novos negócios dentro da organização? 
12)D4 - Há uma instância de discussão para projetos inovadores e para racionalização de processos?

13)D4 - A organização tem mecanismo para escutar propostas dos seus colaboradores de melhorias de processos, de racionalização das tarefas cotidianas e melhorias do ambiente de trabalho?

14)D4 - A organização patrocina práticas colaborativas como fóruns ou outros mecanismos de troca de informações em relação às oportunidades para melhorias dos processos ou para o aproveitamento de oportunidades de negócio?

15)D4 - A organização tem mecanismo para escutar de forma sistemática e consequente seus fornecedores, em especial os de TI?

16) $D 5$ - A alta direção da organização acompanha a movimentação das iniciativas na direção das oportunidades relacionadas com a computação em nuvem?

17) $D 5$ - A alta direção da organização está comprometida com iniciativas na direção das oportunidades relacionadas com a computação em nuvem?

D5 - As iniciativas na direção das oportunidades relacionadas com a computação em nuvem sugerem alguma alteração na estrutura organizacional objetivando dar maior autonomia para a gestão dos negócios relacionados à nuvem?

\subsubsection{Questionário 3 - Barreiras para utilização da nuvem}

B1 - Para a direção da organização existem Sistemas de Informações (SIs) por ela desenvolvidas e/ou customizadas e/ou mantidas que constituem um conhecimento de negócio estratégico, capaz de representar uma barreira de entrada para novos competidores no seu mercado ou negócio?

1) B1 - A direção da organização aceita compartilhar com a competição o conhecimento do seu negócio representado pelas regras implementadas nestas Sistemas de Informações (SIs)

2) B1 - Qual é a maior barreira de entrada para o negócio da organização? 
3) B1 - Qual é a maior barreira de entrada para o negócio atual da organização?

4) B2 - A organização possui um processo de decisão para a escolha das tecnologias infraestrutura como serviço (laaS)?

5) B2 - A organização possui um processo de decisão para a escolha do (s) fornecedor (es) da infraestrutura como serviço (laaS)?

6) B2 - A capacitação técnica envolve o desenvolvimento do sistema para a nuvem. Pode ser do interesse da organização trabalhar desde o início do desenvolvimento com um paradigma de independência (ou menor dependência possível) da plataforma tecnologia do fornecedor da infraestrutura como serviço (laaS).

7) B2 - A capacitação jurídica para verificação e/ou elaboração dos contratos de serviços com seus fornecedores da computação em nuvem e para "elaboração dos contratos de serviços" com os clientes dos "sistemas foco da análise" (quando esses "sistemas foco da análise" tiverem impacto no atendimento às necessidades específicas dos clientes da organização).

8) B3 - A organização faz parte de um grupo empresarial? Em caso afirmativo, de que porte?

9) B3 - A adoção da CN pode alterar a forma de remuneração de produtos e/ou serviços da organização, que possa significar perdas temporárias ou definitivas de receitas?

10)B3 - A organização planeja obter investimentos no setor de "private equity", "venture capital" ou "seed capital" em instituições financeiras ou agências oficiais de fomento e desenvolvimento com o BNDES?

11)B4 - Há disposição para a implantação de uma gestão de riscos de Tl?

12)B4 - A alta gestão da organização se envolve diretamente nas questões operacionais que envolvam riscos? 
13)B4 - A alta gestão, uma vez envolvida diretamente nas questões operacionais relacionadas aos riscos, está disposta a fazer os investimentos necessários para respondê-los?

14)B6 - Qual a disponibilidade das conexões de internet na organização. Considera que disponíveis e confiáveis para atender às necessidades da utilização remota dos "sistemas foco da análise"?

15)B6 - Dentro de um plano de negócio para comercialização dos "sistemas foco da análise", os mercado-alvo possuem uma infraestrutura que ofereça conexões de internet disponíveis e confiáveis para atender às necessidades da utilização dos "sistemas foco da análise" como um serviço (SaaS)

16)B7 - Os "sistemas foco da análise" utilizam dados de outras aplicações durante a sua operação normal? Ou seja, na maior parte do seu tempo execução e/ou nas interações constantes com os seus usuários?

17)B7 - Os "sistemas foco da análise" enviam dados de outras aplicações críticas durante a sua operação normal? Ou seja, para aplicações críticas que dependam destes dados na maior parte do tempo e/ou com nas interações constantes com os seus usuários?

18)B8 - Há comprometimento da alta gerência com a contratação dos serviços e com novos modelos para sua aquisição?

19)B8 - A organização se dispõe a correr riscos ao fazer investimentos em projetos cujo retorno possa ocorrer em longo prazo (cinco ou mais anos)?

20)B8 - Há uma estrutura formal de governança TI?

21)B8 - Há métricas específicas para o cumprimento de objetivos relacionados à governança TI?

22)B9 - A organização tem hoje fornecedores de serviços de TI? Quais são e de que natureza?

23)B9 - As eventuais contratações de serviços envolvem SLAs? Há problemas no cumprimento desses SLAs? 
24)B9 - Os advogados da organização verificam dos eventuais contratos de fornecimento de serviço?

25)B9 - A organização fornece hoje serviços de TI?

26)B9 - Os eventuais contratos de fornecimento de serviços envolvem SLAs?

Observação: Não foram elaboradas questões para investigar diretamente como organização tratará da barreira confiabilidade (B10) no contexto do fornecimento do serviço para computação em nuvem. Este ponto foi investigado indiretamente através das outras questões, como as que tratam de SLAs, por exemplo. 


\subsection{APÊNDICE III - Estudo de caso piloto}

\section{Computação em Nuvem}

\section{Trabalho: Avaliação para Adoção de Computação em Nuvem}

Grupos de Trabalho: deverão ter pelo menos dois e no máximo cinco integrantes. Os alunos também podem se organizar em grupos já estruturados para trabalhos de outras disciplinas deste período.

\section{Descrição do Trabalho}

- Consiste em um levantamento na empresa relativo à adoção da computação em nuvem. Para tanto, devem ser coletadas as seguintes informações:

- Características Gerais

- Características da área de TI

- Aplicações / SI / Serviços foco da Análise

- Utilização da Computação em Nuvem

\section{Características Gerais}

- Tipo da atividade econômica da empresa: Setor, Comércio, Agropecuária, Governo, Serviços ou Serviços financeiros

- Principais atividades/Negócios

- Número de empregados

- Faturamento anual

- Origem do Capital (nacional ou transnacional)

\section{Características da área de TI}

- Número de empregados na área de TI

- Cargo do principal responsável pela TI

- Subordinação do principal responsável pela TI 
- Infraestrutura:

- Conexões de Internet

- Nível de automação da força de venda - uso de dispositivos móveis (notebooks, tabletes, smartphones, etc.)

\section{Sistemas / Serviços}

- Descrever a Aplicação, Sistema de Informação ou Serviço que será objeto de análise para adoção da CN:

- Nome do sistema

- Principais funcionalidades

- Arquitetura do SI (módulos e tecnologias)

- Interoperabilidade do sistema - outros sistemas, interfaces e/ou tecnologias.

- Base de Dados (independente de bases de dados ou se utiliza um SGBD específico)

\section{Questionário sobre a CN - Vantagens}

Investigar as vantagens da adoção e/ou do uso da CN, levando-se em conta, pelo menos, os seguintes fatores:

- Custos (redução/economia)

- Facilidade de uso e manutenção

- Confiabilidade

- Compartilhamento e Colaboração

- Segurança e privacidade 


\section{Questionário sobre a CN - Desafios}

Investigar os possíveis desafios para empresa no caso da adoção e/ou do uso da $\mathrm{CN}$, considerando fatores como:

- Recursos Humanos

- Mudança na cultura, valores, princípios orientadores, crenças

- Gestão de Projetos

- Inovação

- Evolução com a Nuvem

\section{Questionário sobre a CN - Barreiras}

Investigar as barreiras para a adoção e/ou para o uso da CN, levando-se em conta, pelo menos, os seguintes fatores:

- Viabilidade estratégica da contratação dos serviços

- Tradição comportamental - abandono do modelo tradicional de TI

- Governança

- Deficiências do modelo de negócio

- Falta de capacidade técnica

- Acordos de nível de serviço (SLAs)

- Segurança

- Confiabilidade

- Disponibilidade

- Desempenho 


\section{Questionário sobre a CN-Modelos de Remuneração dos Serviços}

Investigar os modelos de serviços, implantação e remuneração dos serviços no caso da adoção e/ou no uso da CN, considerando fatores como:

- Modelos de serviços utilizados/possíveis: laaS, PaaS, SaaS, combinação dos anteriores;

- Modelos de implantação: Nuvem Pública, Privada, Comunitária ou Híbrida;

- Modalidade de pagamento: licenciamento por usuários, por transação, valor fixo por período, etc.

\section{Entregas do Trabalho}

Data da Entrega: 03/12/2013 (quando aplicado para a primeira turma).

Entregas:

- Apresentação (.ppt ou .pptx) de 15 minutos, seguindo o roteiro solicitado no trabalho.

- Documento (.doc ou .docx) com as informações (respostas das questões) recolhidas na empresa. 


\section{ANEXOS}

\subsection{ANEXO I-Condução do estudo de caso}

Miguel (2012) faz a seguinte proposta de conteúdo e sequência para a condução de um estudo de caso, com base nos trabalhos de Forza (2002), Croom (2005) e Souza (2005):

\section{- Definição da estrutura conceitual/teórica}

- Mapeamento da literatura:

- Localiza o tópico de pesquisa no contexto da literatura sobre 0 assunto.

- Indica a abrangência da literatura demonstrando como o tópico em estudo é influenciado pelas fontes bibliográficas existentes.

- A partir da busca e organização bibliográfica é possível identificar lacunas onde a pesquisa pode ser justificada, bem como extrair os constructos.

- Delineamento das proposições. As proposições podem ser estabelecidas a partir dos constructos extraídos durante o mapeamento da literatura.

- Delimitação das fronteiras e grau de evolução. O referencial teórico tem as seguintes finalidades:

- Delimitar as fronteiras do que será investigado, fornecendo um suporte teórico para a pesquisa (fundamentação)

- Explicitar o grau de evolução (estado-da-arte) sobre o tema estudado. 
- Servir como um indicativo da familiaridade e conhecimento do pesquisador sobre o tema.

- Planejamento dos casos

- Seleção das unidades de análise e contatos

- Escolha dos meios para coleta e análise dos dados

- Desenvolvimento do protocolo para coleta dos dados

- Definição dos meios de controle da pesquisa

- Condução do teste piloto

- Teste dos procedimentos de aplicação

- Verificação qualidade dos dados

- Execução dos ajustes necessários

- Coleta dos dados

- Contato com as unidades de análise

- Registro dos dados

- Limitar os efeitos do pesquisador

- Análise os dados

- Produção de uma narrativa

- Redução dos dados

- Construção do painel

- Identificação de causalidades

- Geração do relatório

- Desenho das implicações teóricas

- Prover estrutura para replicação 